\title{
MASTER
}

\section{Low-Temperature Thermal Energy Storage Program Annual Operating Plan FY 1978}
H. W. Hoffman
D. M. Eissenberg

OAK RIDGE NATIONAL LABORATORY OPERATED BY UNION CARBIDE CORPORATION - FOR THE DEPARTMENT OF ENERGY 


\section{DISCLAIMER}

This report was prepared as an account of work sponsored by an agency of the United States Government. Neither the United States Government nor any agency Thereof, nor any of their employees, makes any warranty, express or implied, or assumes any legal liability or responsibility for the accuracy, completeness, or usefulness of any information, apparatus, product, or process disclosed, or represents that its use would not infringe privately owned rights. Reference herein to any specific commercial product, process, or service by trade name, trademark, manufacturer, or otherwise does not necessarily constitute or imply its endorsement, recommendation, or favoring by the United States Government or any agency thereof. The views and opinions of authors expressed herein do not necessarily state or reflect those of the United States Government or any agency thereof. 


\section{DISCLAIMER}

Portions of this document may be illegible in electronic image products. Images are produced from the best available original document. 


\section{Printed in the United States of America. Available from National Technical Information Service \\ U.S. Department of Commerce \\ 5285 Port Royal Road, Springfield, Virginia 22161 \\ Price: Printed Copy $\$ 7.25$; Microfiche $\$ 3.00$}

This report was prepared as an account of work sponsored by an agency of the United States Government. Neither the United States Government nor any agency thereof, nor any of their employees, contractors, subcontractors, or their employees, makes any warranty, express or implied, nor assumes any legal liability or responsibility for any third party's use or the results of such use of any information, apparatus, product or process disclosed in this report, nor represents that its use by such third party would not infringe privately owned rights. 
Contract No. W-7405-eng-26

Engineering Technology Division

LOW-TEMPERATURE THERMAL ENERGY STORAGE

PROGRAM ANNUAL OPERATING PLAN

FY 1978

H. W. Hoffman

D. M. Eissenberg

Date Published - JANUARY, 1979

Prepared by the OAK RIDGE NATIONAL LABORATORY Oak Ridge, Tennessee 37830 operated by UNION CARBIDE CORPORATION for the DEPARTMENT OF ENERGY

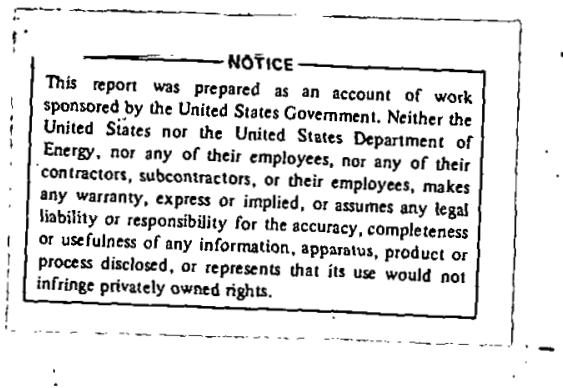




\section{THIS PAGE}

\section{WAS INTENTIONALLY LEFT BLANK}


CONTENTS

$\underline{\text { Page }}$

LIST OF TABLES $\ldots \ldots \ldots \ldots \ldots \ldots \ldots \ldots \ldots \ldots \ldots \ldots \ldots \ldots \ldots \ldots \ldots \ldots \ldots$

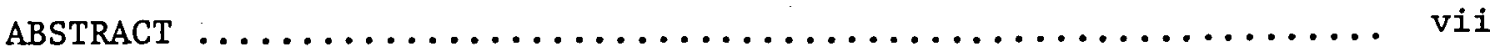

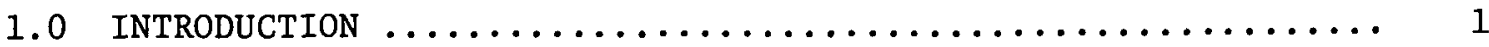

1.1 Scope of Program $\ldots \ldots \ldots \ldots \ldots \ldots \ldots \ldots \ldots \ldots \ldots \ldots \ldots \ldots$

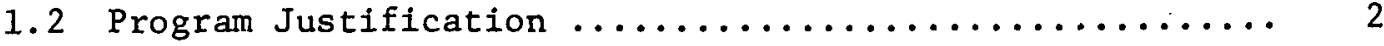

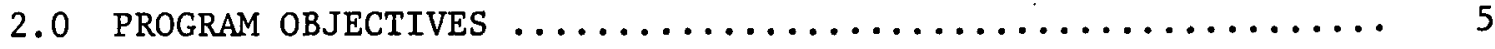

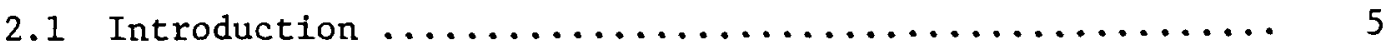

2.2 LTTES Technology Considerations ............... 5

2.2.1 Sensible Heat Storage Technology ........... 5

2.2.2 Latent Heat Storage Technology ............. 7

3.0 PROGRAM IMPLEMENTATION: PROCEDURES AND SCHEDULES ......... 9

3.1 Implementation Procedures $\ldots \ldots \ldots \ldots \ldots \ldots \ldots \ldots \ldots \ldots$

3.2 Implementation Schedules $\ldots \ldots \ldots \ldots \ldots \ldots \ldots \ldots \ldots \ldots \ldots$

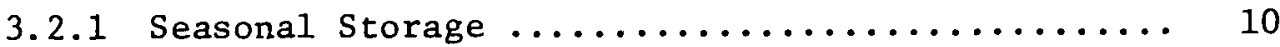

3.2.2 Daily/Short-Term Storage ................... 11

3.2.3 Waste Energy Recovery and Reuse ............ 13

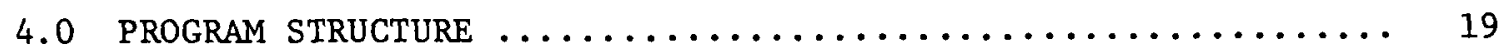

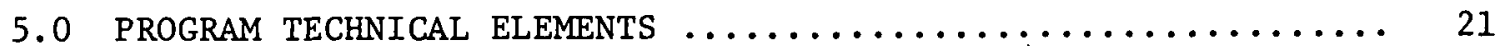

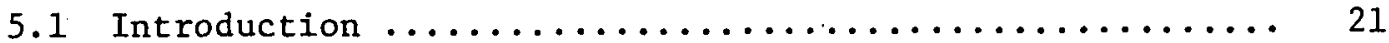

5.2. Seasonal Storage Projects .................... 21

5.2 .1 Aquifer TES Projects .................. 21

5.2 .2 Earth TES Projects .................... 46

5.2 .3 Pond TES Projects .................... 46

5.3 Daily/Short-Term Storage Projects ............... 50

5.3.1 PCM's in Building Materials TES Projects ....... 50

5.3.2 PCM's in Modular Units TES Projects .......... 57

5.4 Waste Energy Recovery and Reuse Projects ........... 76

5.4.1 Tndustrial Waste Heat TES Projects .......... 76

5.4.2 Agricultural Waste Heat TES Projects ......... 84

5.4.3 Commercial Waste Heat TES Projects .......... 84

5.4.4 Utility Cogenerated Heat TES Projects ......... 84

5.5 Support R\&T and Systems Studies Projects .......... 85

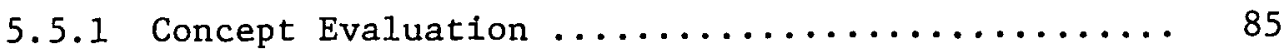

5.5.2 Materials Characterization ............... 85

5.5.3 Component Performance ................ 86 


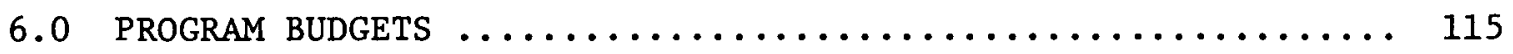

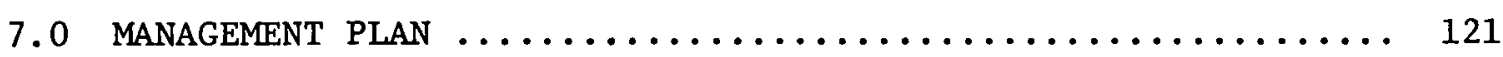

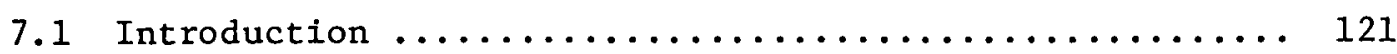

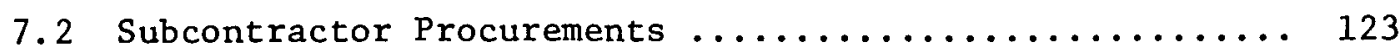

7.3 Planning, Controlling, and Reporting ............ 123 
2.1.1 National TES program goals supported by the Low-

3.2.1 Seasonal storage for building heating and cooling: consolidated development schedule

3.2.2 Daily/short-term storage for building heating and

3.2.3 Waste energy recovery and reuse through thermal

4.1.1 Work breakdown structure (WBS) for LTTES program; details shown only for aquifer storage effort

Projects supporting aquifer TES technology development

Projects supporting daily/short-term TES technology

5.4.1 Projects supporting waste heat recovery and reuse

5.5.1 Systems studies and research in support of TES technology development 
THIS PAGE

\section{WAS INTENTIONALLY LEFT BLANK}


vii

\begin{abstract}
The LTTES program operating plans for FY 1978 are described in terms of general program objectives and the technical activities being implemented to achieve these objectives. The program structure provides emphasis on several principal thrusts; namely, seasonal thermal storage, daily/short-term thermal storage, and waste heat recovery and reuse. A work breakdown structure (WBS) organizes the efforts being carried out in-house or through subcontract within each thrust area. Fiscal data are summarized in respect to thrust area, individual efforts, and funding source.
\end{abstract}




\subsection{INTRODUCTION}

This Annual Operating Plan (AOP) proposes activities to be carried out by the Low-Temperature Thermal Energy Storage (LTTES) Program during FY 1978. The effort is being managed by the Oak Ridge National Laboratory (ORNL) in support of the Department of Energy (DOE) Program on thermal energy storagc as implemented through the DOE-Division of Energy Storage Systems (STOR). Responsibility for managing the LTTES program was delegated to ORNL in FY 1976; the work is carried out in consultation with and with the concurrence of DOE-STOR.

The LTTES program objectives and plans are detailed in the succeeding chapters of this document. Overall (long-range) objectives and schedules are described in Chapters 2.0 and 3.0 , respectively; these are now organized in accord with the revised thrusts (principal emphases) established early in FY 1978. The implementation plan (Chapter 3.0) is developed further in terms of a work breakdown structure (WBS, Chapter 4.0), whose elements are consistent with those of the other two areas of the national program (High-T'emperature Thermal Energy Storage managed by NASA-Lewis Research Center, and Thermochemical Thermal Energy Storage and Transport managed by Sandia Laboratories-Livermore. This WBS coincides with the established thrusts. A description of each specific work element in progress to fulfill the stated objectives and achieve the desired milestones is given in Chapter 5.0. Budget (Chapter 6.0) and management plans (Chapter 7.0) complete this presentation.

The AOP amplifles the information provided in the Budget Proposal Activity C8 010102 1, 189 No. 00001, for FY 1978.

\subsection{Scope of Program-}

The LTTES prngram includes research, development, and demonstration efforts appropriate to achieving technologies for sensible and latent heat storage at temperatures to $250^{\circ} \mathrm{C}\left(482^{\circ} \mathrm{F}\right)$. The program is directed to the development of advanced Thermal Energy Storage (TES) systems and excludes the refinement of existing systems. Emphasis is on the development of TES technologies supporting energy conservation in building heating and 
cooling applications; corollary interests include the generation of potable and process hot water, low-temperature manufacturing and processing (e.g., food, drugs, and lumber), and such agricultural activities as crop and grain drying.

Heat sources exploited by LTTES applications are:

1. Waste energy discharged to the environment from utility or industrial operations, principally as discarded cooling water or exhaust stack gases (waste heat);

2. Energy held within a system. for subsequent reuse, such as heat regenerated by off-peak electricity or heat Lransferred (via storage) from one step in a manufacturing process to a later step (energy management);

3. Energy derived from the solar heat source through various collection devices (solar thermal); and

4. Energy originating naturally in consequence of climatic or geographic conditions, e.g., winter-chill or other "energies of opportunity" (environmental).

\subsection{Program Justifiration}

The need for energy storage is related to the need for increased energy conservation and the national imperative to shift fuel use from the scarce petrolpum and natural gas fuels to alternatives that are more abundant (see above). In achieving these goals, thermal energy storage serves primarily as a "buffer" between energy availability and ellergy demand.

Applications relevant to the LTTES program fa11 within the llouseluuld and Commercial (H/C) and Industrial and Agricultural (I/A) use sections. Approximately, 18.4 quads of energy from petroleum and natural gas were uucd in 1976 by or in support of the household and commercial energy use sector. Historically, building heating and cooling and water heating energy requirements account for over $70 \%$ of the total consumption in this sector. In the same year, the Industrial and agricultural sector consumed 217.2 quads of energy derived from natural gas and petroleum. The potential for significant savings is large. 
Shifting fuel use can be accomplished by using thermal energy storage to accommodate peak electrical demand, thus increasing the utilization of base load plants burning coal or nuclear fuel and reducing the amount of oil and natural gas consumed in peaking plants. Further, there are significant potentials for energy conservation and fuel shifting through the incorporation of LTTES into heating and cooling systems to enable these systems to operate more efficiently. For instance, the cooling requirements for a building could be met by operating a heat pump at night (when ambient temperatures are lower) to cool a TES system that, in turn, would be used to satisfy the daytime cooling requirements. A system operating under these conditions would not only be more efficient but could also take advantage of off-peak electricity pricing. 


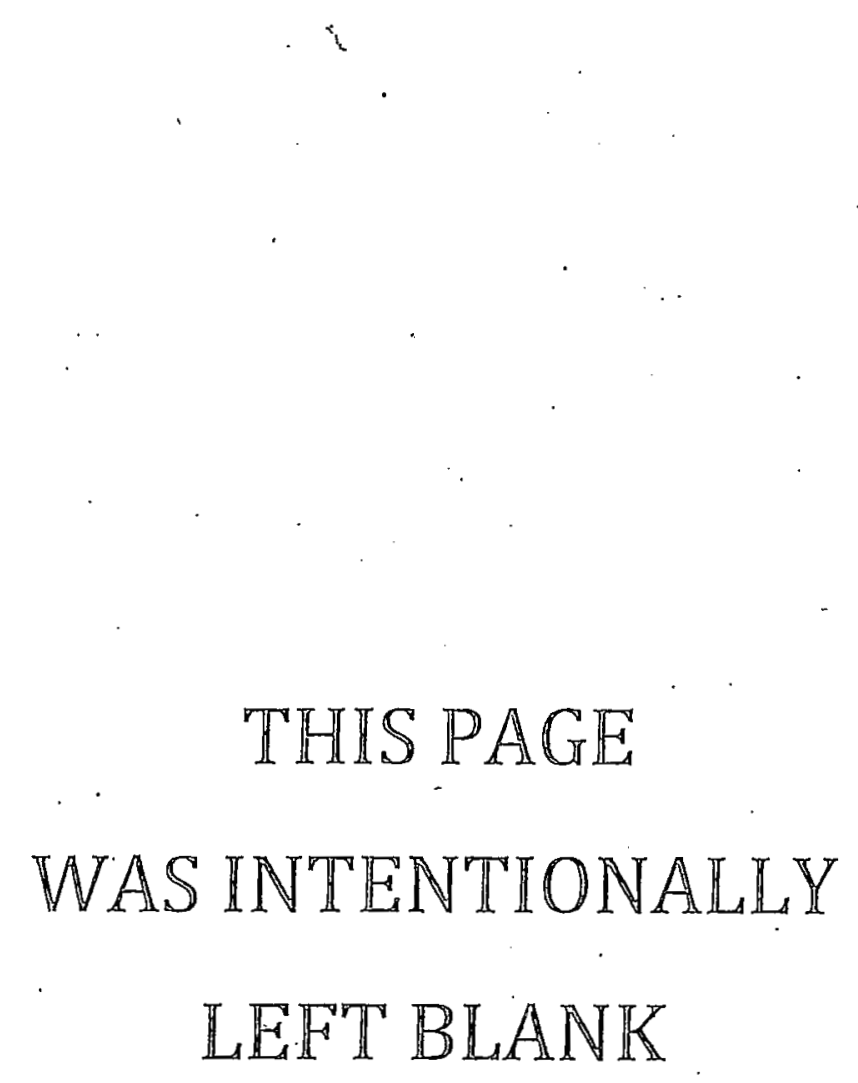




\subsection{PROGRAM OBJECTIVES}

\subsection{Introduction}

The objectives of the Low-Temperature Thermal Energy Storage (LTTES) Program are:

(1) to develop sensible and latent heat storage technologies capable of effectively accepting, storing, and discharging thermal energy supplied at temperatures up to $250^{\circ} \mathrm{C}$, and

(2) to define the potential of these technologies in the conservation of energy and natural resources.

Technologies will be proven in the LTTES program up through the prototype system development stage. Both the economic and technical feasibilities of the concepts under development will be established sufficiently to recommend their viability for demónstration and ultimate commercialization. These technologies will be considered in the context of both new and retrofit applications for centralized systems or decentralized systems. The objectives of the LTTES program are consistent with those of the National TES Program and are to be accomplished within the framework of the DOE National Plan. Specific National TES Goals supported by the LTTES program are indicated in Table 2.1.1. This table, organized into four general application sectors, relates the National TES Program Goals with the application areas. As shown, the LTTES program provides support to the TES program in two of these application sectors: (1) household and commercial [H/C], and (2) industrial and agricultural [I/A].

\subsection{LTTES Technology Considerations}

The thermal energy storage technologies being explored under the LTTES program Include both sensible and latent heat modes; each is discussed separately below:

\subsubsection{Sensible Heat Storage Technology}

The involvement of the LTTES program in sensible heat storage systems is directed at advanced systems and advanced applications. These include 
Table 2.1.1. National TES program goals supported by the Low-Temperature Thermal Energy Storage program

\begin{tabular}{|c|c|c|c|}
\hline $\begin{array}{l}\text { Application } \\
\text { area }\end{array}$ & & TES program goals & $\begin{array}{l}\text { LTTES primary } \\
\text { support }\end{array}$ \\
\hline \multirow{3}{*}{$\begin{array}{l}\text { Household and } \\
\text { commercial }\end{array}$} & 1) & Improve energy management & Yes \\
\hline & 2) & Improve economics of solar systems & Yes \\
\hline & 3) & $\begin{array}{l}\text { Use of waste heat from industry } \\
\text { and utilities }\end{array}$ & Yes \\
\hline \multirow[t]{2}{*}{ Utilities } & 4) & $\begin{array}{l}\text { Use of base load generating system } \\
\text { for peak load following }\end{array}$ & Nò \\
\hline & 5) & $\begin{array}{l}\text { Improve economics of solar electric } \\
\text { power generation }\end{array}$ & No \\
\hline \multirow{3}{*}{$\begin{array}{l}\text { Industrial } \\
\text { and } \\
\text { agricultural }\end{array}$} & 6) & $\begin{array}{l}\text { Improve process efficiency and waste } \\
\text { heat utilization }\end{array}$ & Yes \\
\hline & 7) & $\begin{array}{l}\text { Improve economics of solar generated } \\
\text { process heat }\end{array}$ & Yes \\
\hline & 8) & Improve energy management & Yes \\
\hline Transportation & 9) & $\begin{array}{l}\text { Use of vehicle heat storage for } \\
\text { propulsion system }\end{array}$ & No \\
\hline
\end{tabular}


primarily thermal energy storage in natural geological structures (i.e., aquifers, caverns, and the earth) for commerctal and industrial applications where significant quantities of thermal energy are consumed for thermal conditioning of buildings, for process steam applications, and for drying operations. The storage of the sensible heat of water and oils in atmospheric or pressurized tanks and of liquids and gases in rock, sand, or gravel beds is considered existing practice requiring only optimization with respect to specific designs, containment materials, and costs. Thus, such sensible heat storage technologies are examined within the LTTES program context only where feasibility has not yet been demonstrated and where the ability to predict performance and costs is limited. These applications are described in Section 2.2.3.

A primary objective of the sensible heat storage portion of the LTTES program is performance of the research and development necessary to develop natural geological systems as effective thermal storage systems, with aquifers being the prime candidate for this purpose. The United States Geological Survey is cooperating with DOE in this activity both as a cosponsor and by supplying experts in the field of underground hydrology. The activities to be accomplished in developing aquifers and other similar natural geological systems involve: (1) categorizing and selecting suitable sites, (2) establishing thermal cycle effects, (3) establishing charge and discharge characteristics, (4) determining environmental impact potential, and (5) performing system analyses. Earth storage systems are also being evaluated, this concept is attractive if undisturbed or relatively undisturbed earth can be used as the thermal energy storage medium, because of availability and low costs.

\subsubsection{Latent Heat Storage Technology}

With few exceptions, latent heat energy storage devices are not commercially available. Although development of this concept received attention in past years (e.g., work on Glauber's salt for residential use since the forties and thermal capacitors for space vehicles and aircraft in the sixties); this heat storage mode is still in an embryonic stage of development when compared to the sensible heat mode. 
The primary advantages which can be obtained with latent energy storage devices are compactness resulting from the higher energy storage density and a more uniform temperature supply caused by the narrow temperature ranges over which the storage materials melt/solidify. The primary disadvantage is that latent systems may be more expensive than the sensible systems primarily due to higher storage medium costs, containment costs, and/or heat exchanger costs.

The LTTES program will concentrate on defining viable latent heat storage concepts, proving their feasibility for specific applications and developing each viable concept to a state ready for integration into field demonstration. Latent heat storage concepts involve combinations of such design elements as bulk, macroencapsulated, or dispersed PCM containment, active and passive TES, application (heating, cooling, peak shaving, etc.), TES structure (separate unit or integral part of the building), storage term, etc. 


\subsection{PROGRAM IMPLEMENTATION: PROCEDURES AND SCHEDULES}

\subsection{Implementation Procedures}

The LTTES program is organized to achieve both near-term (by 1985) and mid-term (1985 to 2000) implementation goals with emphasis directed to concepts displaying early technical and economic viability. Thus, as noted, principal attention will be glven to certain implementation thrusts; namely,

(1) seasonal storage for building heating and cooling,

(2) daily/short-term storage for building heating and cooling, and

(3) waste energy recovery and reuse through TES.

A sufficient corollary effort will be maintained to accommodate studies generic to low-temperature TES and to assure a reasonable "hearing" for novel storage concepts as such may be proposed.

For each thrust development to the demonstration phase will normally involve establishing feasibility, measuring fundamental characteristics at the laboratory scale, carrying out necessary $R \& D$ and demonstration at the engineering scale, and defining unit and system costs. Demonstration, under this program, implies a prototype unit that is of sufficient size to establish satisfactory performance in regard to both function and cost. In some cases, an actual system installation will be involved. The elements under which program control will be exercised are those of the work breakdown structure described in Chapter 4.0.

The program will be constituted such that, in the main, national laboratuiles, unfiversities, and research institutes will carry out feasibility evaluations and perform fundamental laboratory studies; while industrial organizations and private-sector research institutes will establish engineering and economic feasibility and conduct technology (system) demonstrations. This structure provides for application of individual talents and organizational strengths in contexts appropriate to the problems and, lience, should expedite the progression from concept to utilization. Finally, industry in concert with the DOE "end-use" divisions will usually carry the burden of commercialization of the most attractive technologies; in most instances, the LTTES program will support technical monitoring 
efforts to Insure effective technology transfer and to acquire data for predictive model validation.

Implementation will be principally by means of Requests for Proposals (RFPs), so as to maintain control over technology development directions and to assure responsiveness to needs. In more mature efforts, the RFP will be supplemented with sole-source contracts where specific and unique talents are needed or where it is in the program's best interests to continue subsequent phases of a project with the original contractor. In addition, unsolicited proposals will be accepted as a means for surfacing new and novel ideas; some unsulicited problems of a scoping nature may be funded.

\subsection{Implementation Schedules}

Overal1 schedules for LTTES technologies are described in the following sections treating the key areas (thrusts) where successful implementation will effect significant energy conservation:

\subsubsection{Seasonal Storage for Building Heating and Cooling}

Seasonal collection and storage of thermal energy on a large scale can 1mpact building heating and cooling practices such as to reduce substantially or eliminate totally prlmasy dependence on conventional electrical or fossil fuel energy sources. Storage at this scale would of economic necessity involve geo-containment: aquifers, surface water bodics, earth. Ilse of each of these storage vchicles is suspected to be technically feasible and econumically vlable but the correctness nf this surmise has thus far not been demuristrated. This program area focuses on the development of a technology sufficiently mature to encuurage privntc investment. Achipving this state is to be accomplished by a sequence of studies involving for each concept (1) technical definition and preliminary economic evaluation, (2) small field-scale tests to identify problems, obtrain solutions, and indicate performance, and (3) larger [though generally less than full scale] demonstrations to develop final economics and display operational reliability. Attention will concentrate initially on aquifers; subsequent efforts will evaluate earth as a storage medium (with 
the solar heat source) and ponds for situations where appropriate aquifers are unavailable.

A summary schedule is given in Table 3.2.1.

\subsubsection{Daily/Short-Term Storage for Building Heating and Cooling}

Solar Source. Utilization of solar energy for home heating and cooling offers the enticlng prospect of major savings in oil and natural gas consumption. To accomplish this effectively requires a thermal storage element capable of accepting sufficient energy in a single 8- to 10-hr day to supply thermal demand for a period of as much as three days. Further, current technology requires that the heat stored for cooling (absorption air conditioning) be at a substantially higher temperature than that for heating. Options for satisfying these requirements are multiple; rock/ gravel beds, atmospheric and pressurized water in tanks, solar ponds, tanks containing phase-change materials (PCMs) with and without convective heat exchange capability, and building materials with or without thermal capacity augmentation are numbered among the possibilities. Some of these can be considered current practice (e.g., rocks and atmospheric water), while others are unproven and require substantial development. Satisfying fully the requirements of daily or short-term storage could involve combinations of several of these techniques.

This program will concentrate on developing the advanced (or unproven) technologies. Emphasis will be given to the system involving enhancement of the thermal capacity of building materials through incorporation of PCMs into the building matrix. This system can perform effectively in either the passive (radiation) or active (convection) heat exchange modes. Further advantages include the creation of constant temperature room surfaces effecting "comfort zone" temperature control and the elimination of the need for additional space to "house" the storage system. Development will be pursued through the stages of establishing the capability of competing procedures for containing PCMs of appropriate phase-change temperature and sufficient latent heat capacity in building materials (concrete blocks, ceiling tiles, wall panels) and demonstrating ability to manufacture such building elements at competitive costs and in forms that impact traditional construction techniques minimally. Earth and pond storage of solar energy. 
Table 3.2.1 Seasonal storage for building heating and cooling: consolidated development schedule

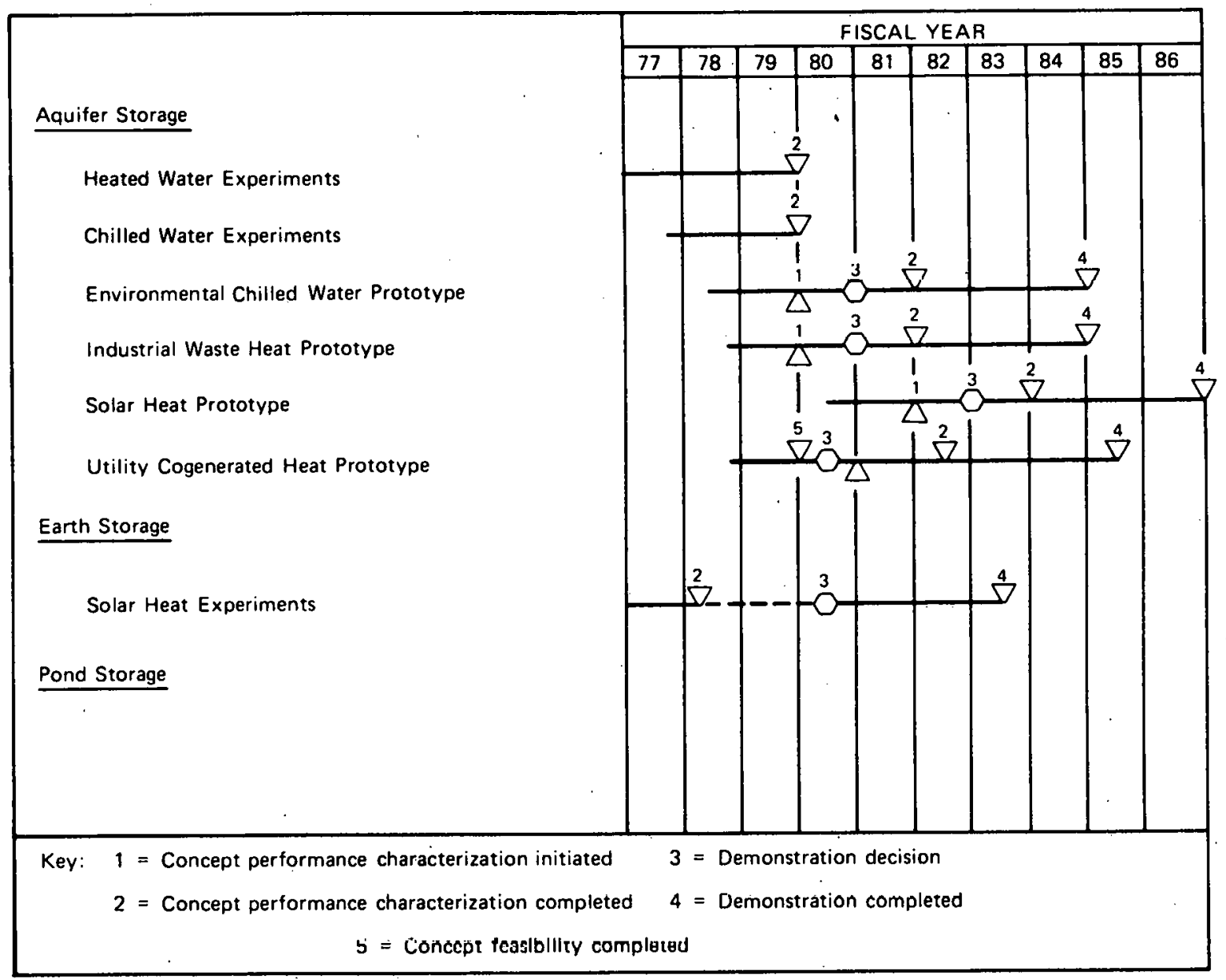


will be accorded secondary consideration in this aspect of the LTTES program.

Off-Peak Electricity Source. Uniform (base) loading of electrical power-generating stations is a concept of significant cost-saving and energy-conservation potential. Thermal energy storage can be used to achieve this ideal situation. In one configuration, storage units located in a building can tap electrical production in such fashion as to smooth the system demand. This off-peak source is presently accomplished commercially through resistive heating of ceramic bricks arranged within a "furnace-sized" unit. Latent heat storage offers the prospect of higher energy densities (important in retrofit applications because of smaller packaging) and of a constant temperature source-sink (important for solar collector and heat pump applications). Systems involving either PCM incorporated in building materials or PCM (bulk or encapsulated) in modular units can satisfy the storage requirements. While initial emphasis (enforced by. program budget constraints) will be on PCMs in building materials, higher temperature needs - as for absorption air conditioning - are better accomplished with PCMs in modular units. A variety of schemes for accomplishing such storage were incorporated into the LTTES program at its inception; these efforts were in the main supported by National Science Foundation (NSF) funding with, in some cases, limited extension to reach a logical conclusion under LTTES funding. In the hiatus until sufficient LTTES funds become available to support an intensive development, the program effort will be carried by two additional DOE-SOLAR funded programs. Summary development schedules for daily/short-term storage in PCMs are given in Table 3.2.2.

\subsubsection{Waste Energy Recovery and Reuse}

Energy conservation through the recovery, storage, and later reuse of low-temperature heat wasted (rejected) from industrial processes is one goal within the L'I'l'S program. Ot the total U.S. energy use in recent years, $\sim 45 \%$ was consumed in the industrial sector. Various surveys have identified industries of appropriate nature (in respect to energy consumption, quantity and temperature of the waste heat, energy cost relative to product price, and geographical distribution) to warrant serious examination as to potential for significant energy recovery. Efficient 
Table 3.2.2. Daily/short-term storage for building heating and cooling: consolidated development schedule

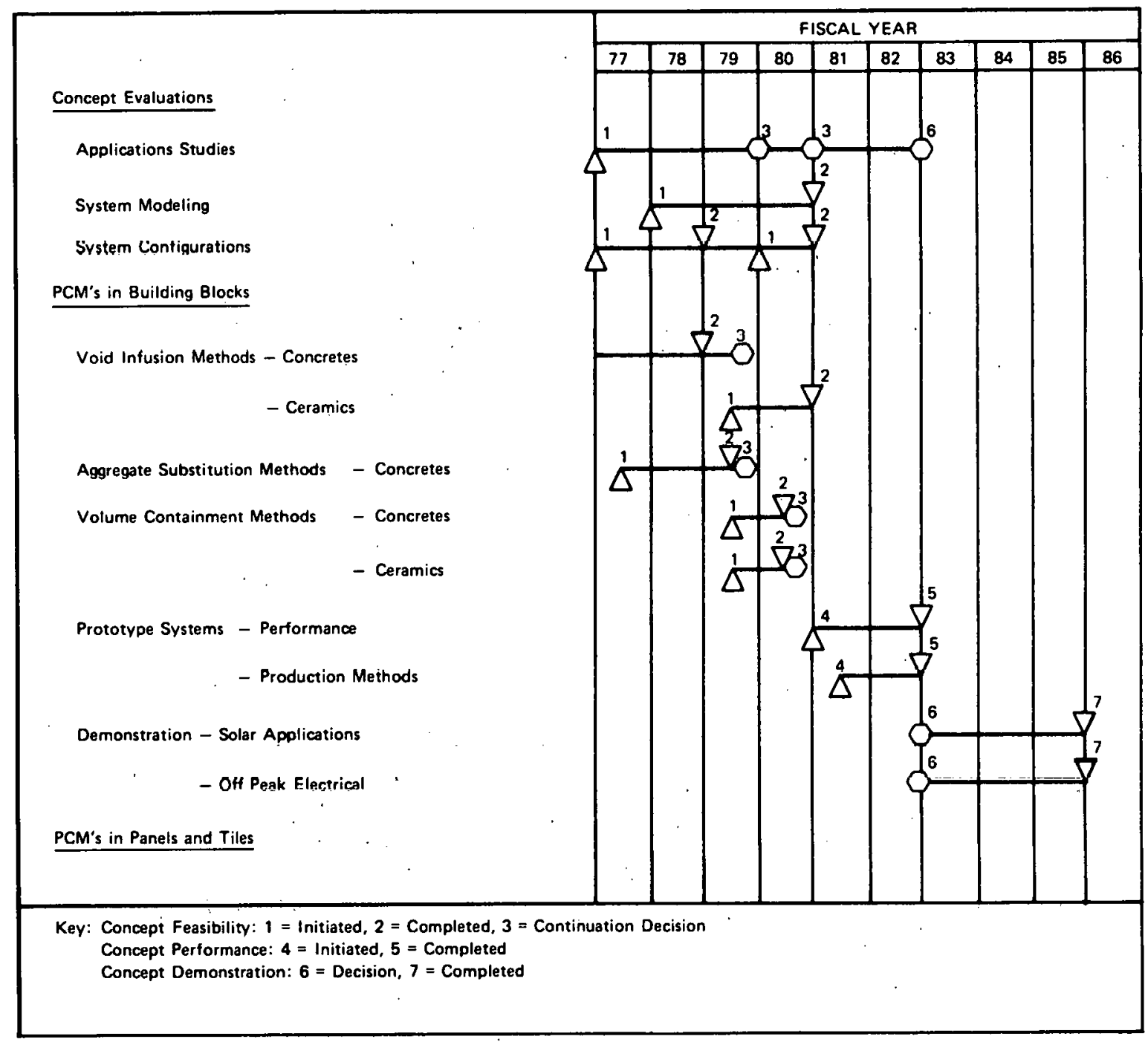


Table 3.2.2. (continued)

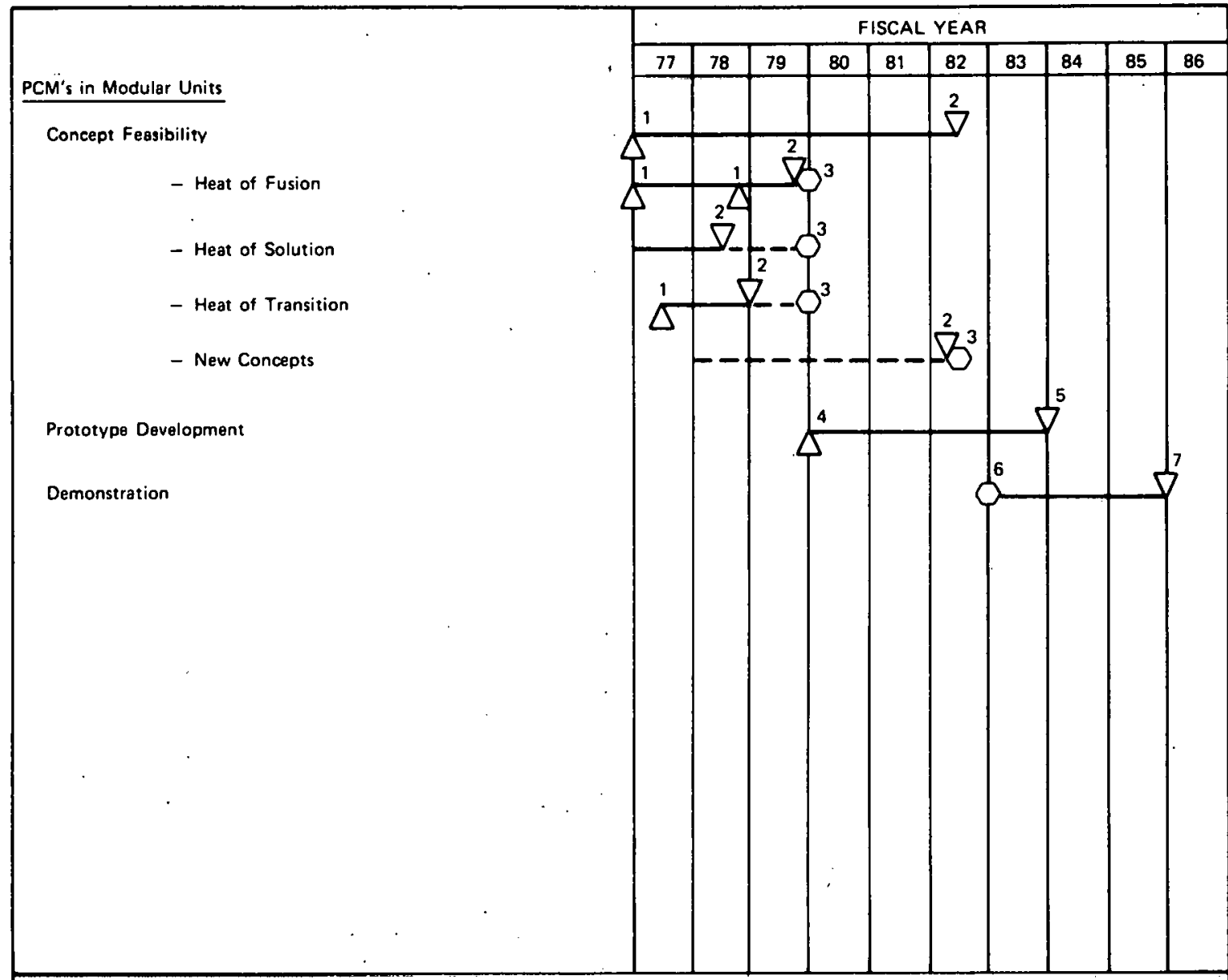

Key: Concept Feasibility: 1 - Initiated, 2 = Completed, $3=$ Continuation Decision

Concept Performance: $\mathbf{4}=$ Initiated, $5=$ Completed

Concept Demonstration: $6=$ Decision, $7=$ Completed 
Table 3.2.3. Waste energy recovery and reuse through thermal storage: consolidated development schedule

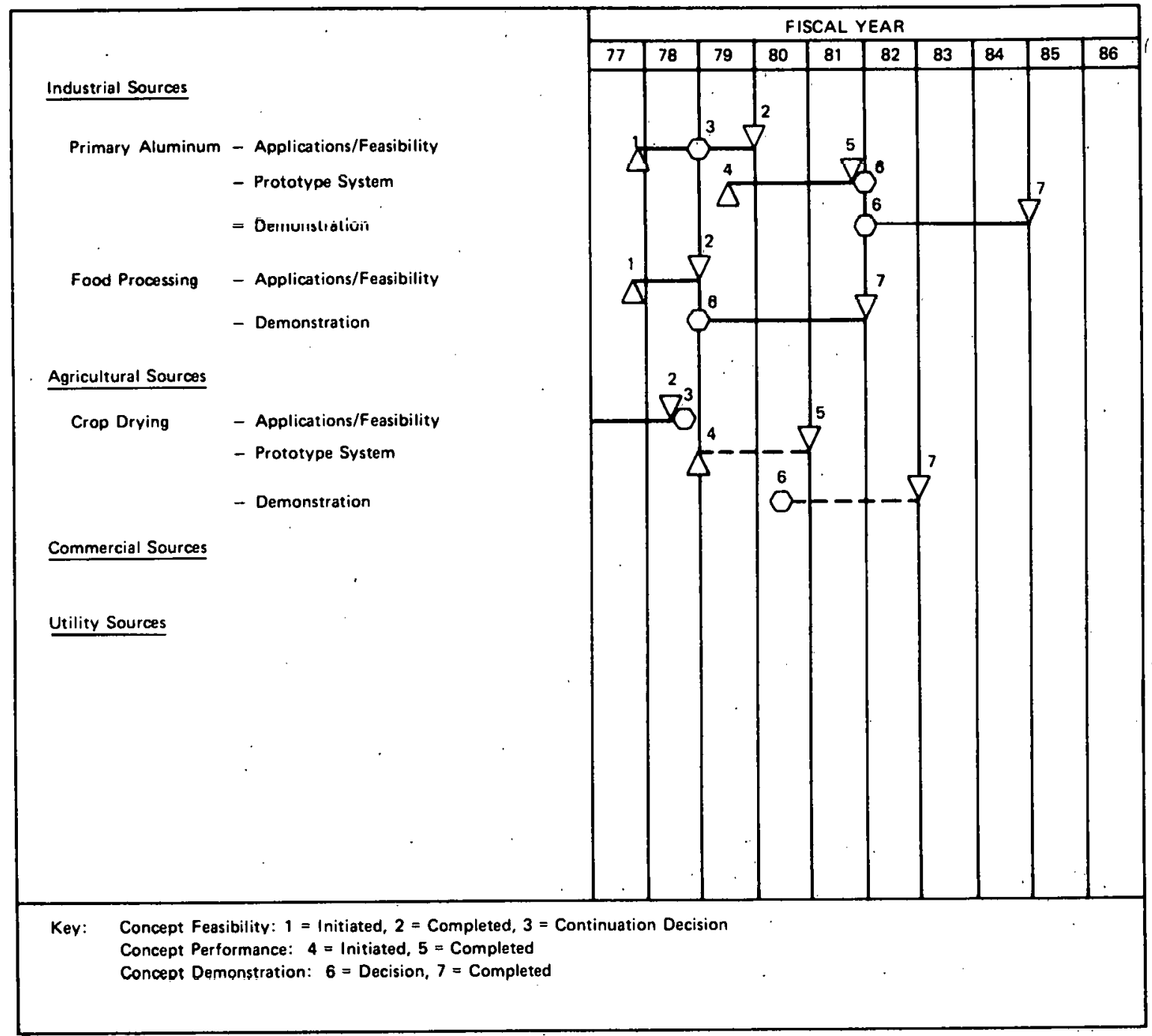


ut1lization of this rejected heat, whether for on-site purposes (electricity generation or heating) or for off-site consumption (principally, district heating), requires a storage element to bridge the gap between time of availability and time of use and to accommodate the unbalance between the quantity of rejected heat and the use demand. Accordingly, an effort has been mounted to delineate the energy conservation potential in a number of selected industries and to define the thermal energy storage (TES) element.

A summary schedule is given in Table 3.2.3. 
THIS PAGE

\section{WAS INTENTIONALLY LEFT BLANK}




\subsection{PROGRAM STRUCTURE}

The "work breakdown structure" (WBS) has been adopted as the means for organizing the numerous individual projects of the national thermal energy storage program. The WBS system assigns responsibility for work elements, aids in developing plans and schedules, supports allocation of resources, enables assessment of work status, and provides for evaluation of work performance.

The LTTES program WBS is defined at the primary level in terms of the principal thrusts previously described (Chapter 3.0); program management and support R\&T elements are also included. The latter element provides for these studies and experiments of a more general nature where results are of common value to several or all activities. A skeletal WBS description for the LTTES program is given in Table 4.1.1, substantively for the upper two levels and lllustratively for the lower levels; thus, only the aquifer storage effort is depicted in full detall. Each program element description of Chapter 5.0 is coded according to the WBS.

This system is further structured to indicate the state of the individual project in the course from conception to commercialization of an idea. Within the LTTES program, these stages are currently confined in order of increasing maturity - to concept definition, concept development and system definition, system prototype development, and prototype demonstration. These steps are not isolated, and it is recognized that performance in a stage and decision-making between stages sometimes overlap. However, in the main, review and evaluation will take place at the end of each performance phase to: 1) determine whether concept development should move on to the next phase, 2) determine whether concept development is sufficiently advanced as to warrant skipping a phase, 3) determine whether concept development should be redirected with new objectives, and 4) determine whether concept development should be terminated. 
Table 4.1.1. Work treakdcwn structure (WBS) for LTTIS program; details shown only for aquifer storage effort

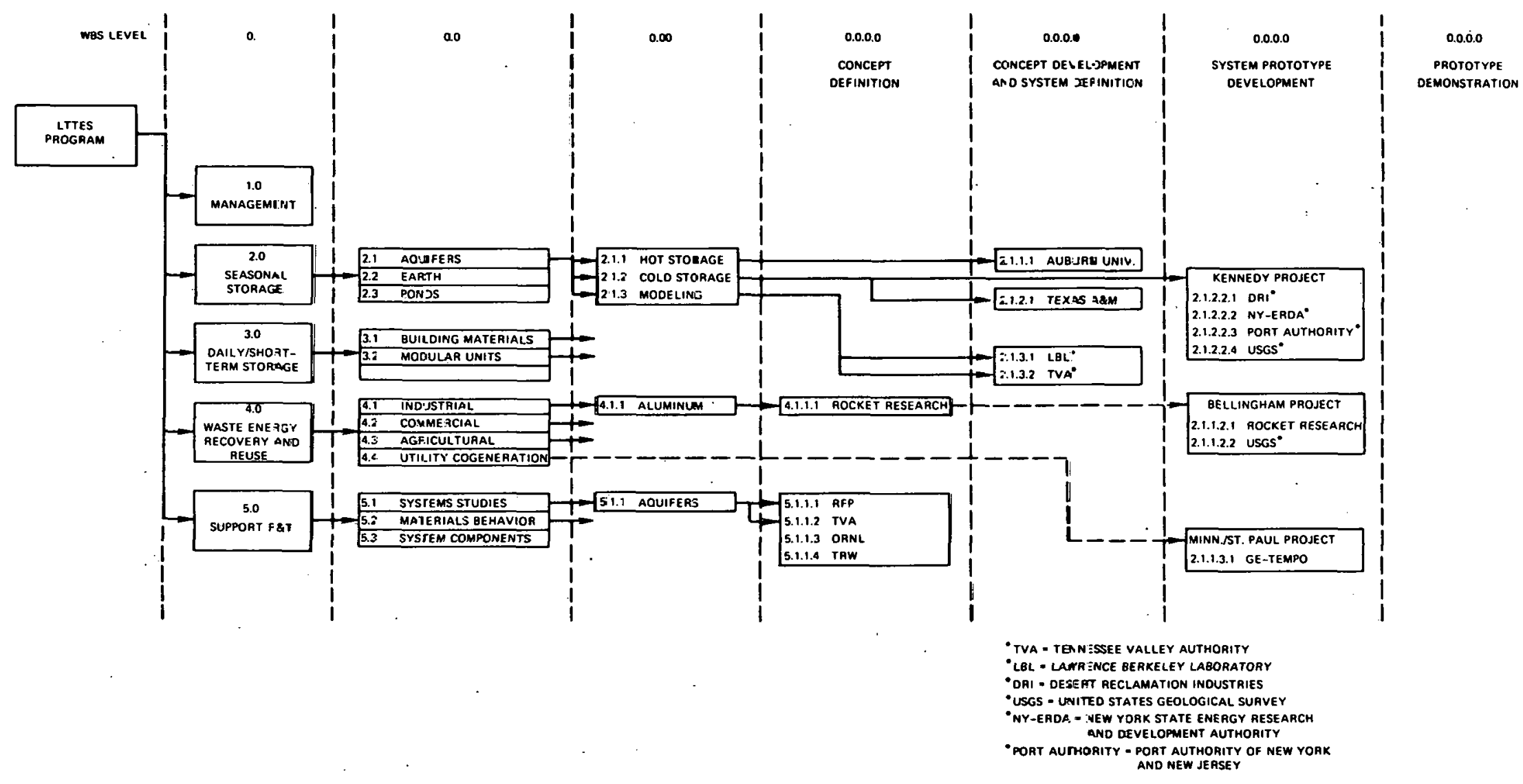




\subsection{PROGRAM TECHNICAL ELEMENTS}

\subsection{Introduction}

The Low-Temperature Thermal Energy Storage (LTTES) Program is directed to developing advanced technology concepts for sensible and latent heat storage. Concepts whose technical and economic viability are believed demonstrable in the near-term (by 1985) are being emphasized. However, the program also encompasses concept development in the intermediate-term (1985-2000, where conservation impact could be significant) and, to a more limited extent, in the far-term (beyond 1985, where the need is not immediate, reduction to practice appears difficult, and/or current poor economics can be projected to improve with time). Room exists for projects establishing the merits of novel concepts.

The program descriptions following are organized in accord with the principal LTTES thrusts; the WBS identification is indicated for each project.

\subsection{Seasonal Storage Projects (WBS 2.0)}

LTTES program activity in this area is directed to the long-term (seasonal) storage of waste heat, solar thermal, utility cogenerated heat, and environmental energles for the heating and cooling of single buildings and building complexes. Aquifers storing hot or cold waters have been identified as the primary mode for storage; earth or water in surface ponds are considered as alternatives.

\subsubsection{Aquifer TES Projects (WBS 2.1)}

Studies to explore and demonstrate the feasibility of aquifer storage will be continued in FY 1978; this activity is currently accorded the highest priority within the multiple thermal storage technology development programs supported by DOE-STOR.

The exploration phase of this effort includes field studies to determine aquifer storage potential, to identify problems and develop solutions, and to validate predictive computer models, as well as computational support on charge-diecharge etrategico, numbero and locationo of wello, 
aquifer dynamics, and geochemistry. Specific projects supporting this activity in FY 1978 (active or planned) are identified in Table 5.2.1 by WBS element; detalled descriptions follow this discussion.

Demonstration of aquifer storage through prototype installations utilizing different energy sources is to be accelerated in FY 1978; active or planned projects are shown also in Table 5:2.1. Each demonstration project is to begin with a techno-economic evaluation to determine merit for further development; since these are site specific, negative results from any such study does not necessarily eliminate application possihilities at other locations. 
Table 5.2.1. Projects supporting aquifer TES technology development

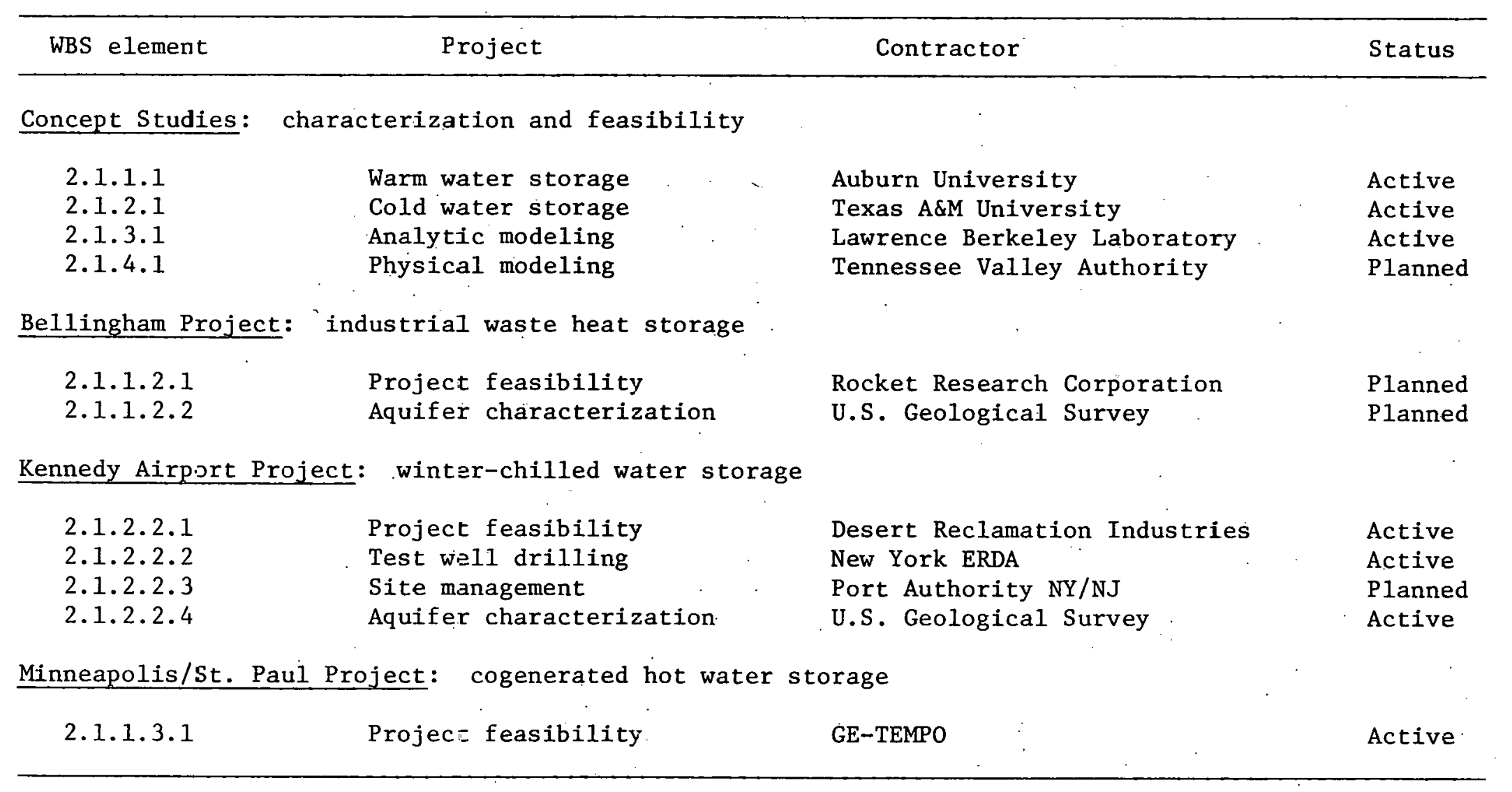


WBS Element: 2.1.1.1

Contract Title: Experimental Study of Warm Water Storage In a Confined Aquifer

Contractor: Auburn University, Water Resources Research Institute

Principal Investigator: F. J. Molz

Contract Amount: $\$ 306,263$

Contract Term: July 1, 1977 to May 31, 1979.

Objective: Determine Technical feasibility for storing warm water in a confined aquifer for extended times; obtain thermal hydraulic data for verifying existing analytical descriptions of aquifer performance.

Project Description: In a field test, warm water will be injected Into a confined aquifer, stored for some time, and then withdrawn. Appropriate instrumentation in 14 observation wells disposed around the Injection well will provide data on water temperature and level throughout the experiment. Injection water will be taken from an overlying aquifer and heated in a portable boiler to the desired injection temperature of $120^{\circ} \mathrm{F}$; the withdrawn water will be discarded. Surface subsidence and rebound will be measured during the injection/ storage/withdrawal cycles. The experiment will determine recovery thermal efficiency and identify physical or chemical problems pertinent to the furtherance of this storage concept.

Prior Accomplishments: In an earlier test, injection of $\sim_{10} \times 10^{6}$ gal of . $100^{\circ} \mathrm{F}$ water was attempted. The experiment was aborted by a "blowout" along the injection well casing into the upper aquffer after introduction of only about $2 \times 10^{6} \mathrm{gal}$; this failure was attributed to a pressure increase due to aquifer field plugging by fines (silt). 
FY 1978 Program: The experimental injection procedure will be modified to eliminate the plugging problem; the following tests will then be carried out:

1. Inject $18 \times 10^{6}$ gal of $120^{\circ} \mathrm{F}$ water on a 6-month cycle (2-man injection/2-man storage/2-man withdrawa1); report temperature profile within storage field as a function of time and position; determine recovery efficiency.

2. Inject $9 \times 10^{6}$ gal of $120^{\circ} \mathrm{F}$ water on a shorter 3 -month cycle.

3. Install network to measure surface subsidence and rebound during injection/storage/withdrawal cycles.

Beyond FY 1978: Carryout injection/withdrawal cycle with ambient temperature water containing a chemical tracer to determine mass dispersion coefficients.

\section{Schedule:}

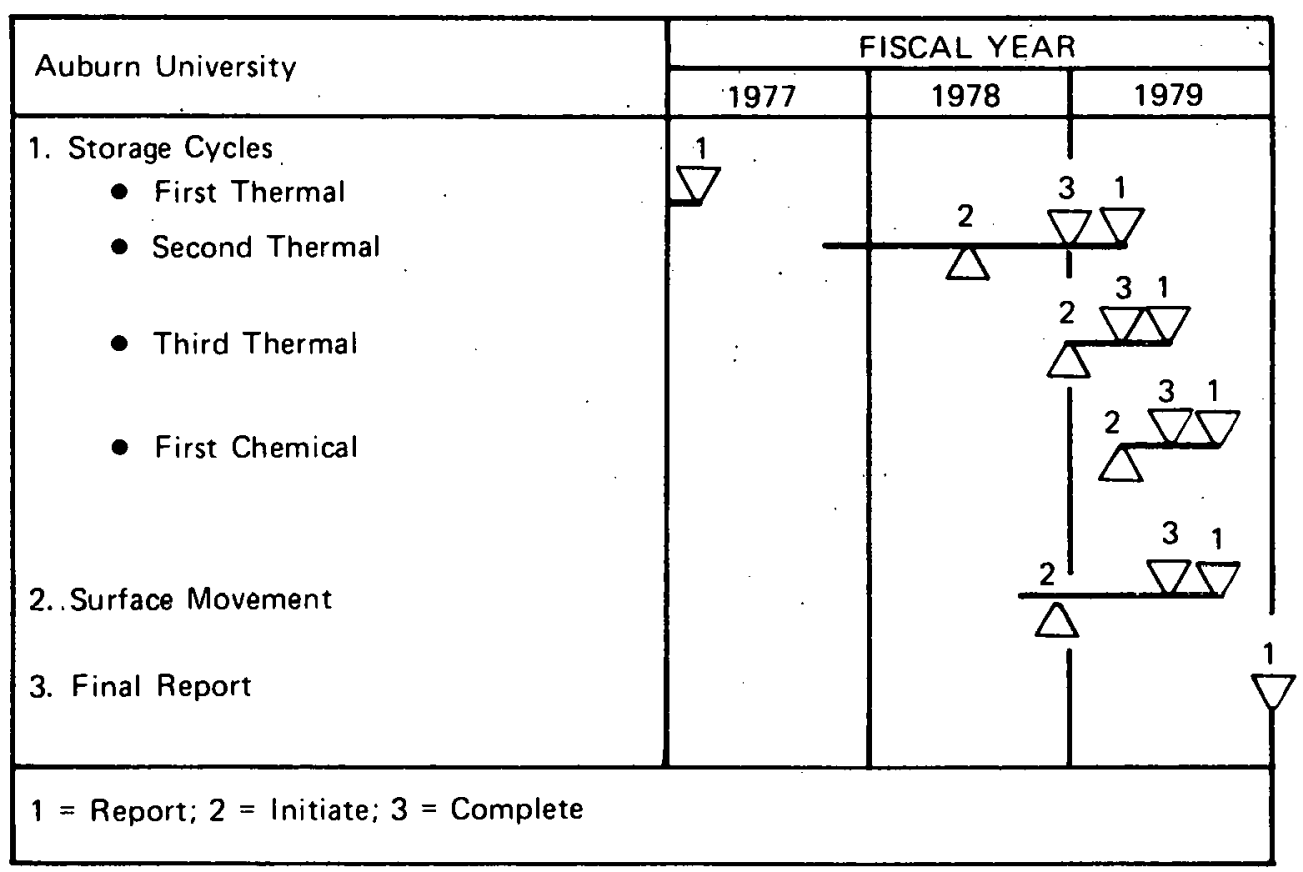


WBS Element: 2.1.1.2.1

Contract Title: Aluminum Industry Reject Heat Capture, Storage, and Utilization: Evaluation of Aquifer TES

Contractor: Rocket Research Corporation

Principal Investigator: L. B. Katter

Contract Amount: TBD*

Contract Term: TBD

Objective: Determine the role and economic feasibility of utilizing aquifer TES in association with the proposed Intalco waste heat recovery and ut111zation project (see WBS 4.1.1.1).

Project Description: Rocket Research will drill up to 10 small-diameter (6 to 8-in.) wells of $1000-\mathrm{ft}$ maximum depth to discover aquifer appropriate for use as storage vehicles and to determine the flow characteristics. For the latter purpose, the wells will be cased and instrumentation for monitoring and sampling installed. If geological characteristics are found sultable, two of these wells.will be enlarged and converted for carrying out production tests; these wells would be linked so that water withdrawn from one would be returned at ambient temperature to the other. If this doublet test indicates satisfactory flow performance, a heat exchanger will be added to the circuit between the two wells; and heated water injection and withdrawal tests will be carried out.

Prior Accomplishments: New project in FY 1978.

*To be developed. 
FY 1978 Program: Develop work scope and costs for performing drilling operations.

Beyond FY 1978: Complete exploratory drilling. Identify doublet, install piping, and carry out flow pumping tests. Procure heat exchanger and install for heated water experiments; perform tests and complete feasibility evaluations.

Schedule:

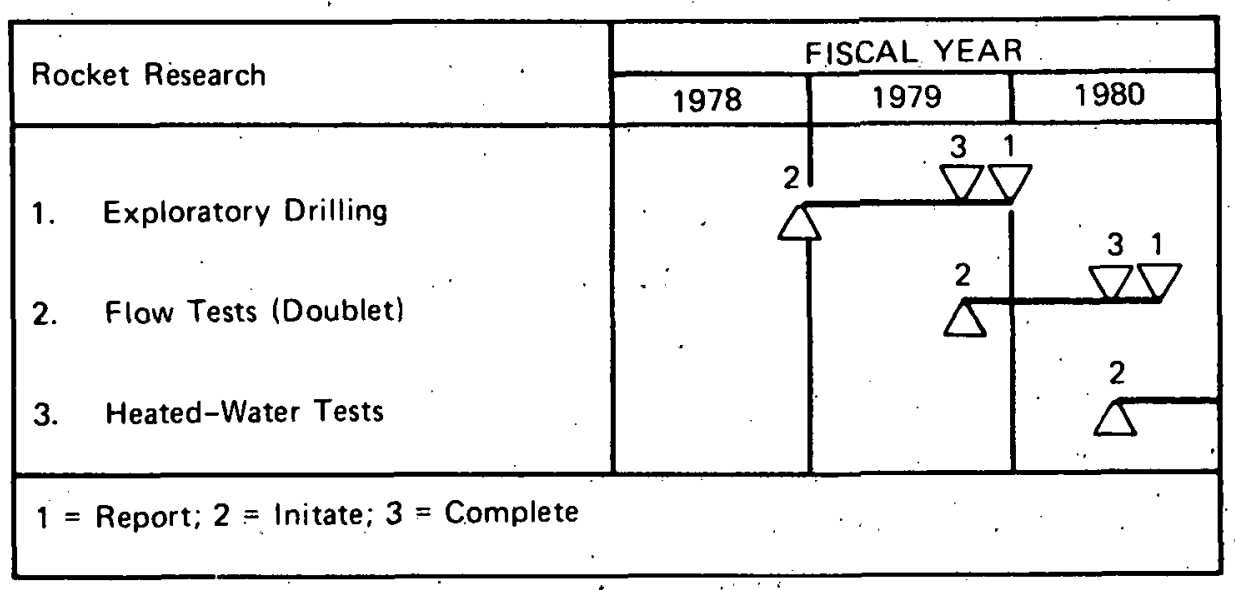


WBS Element: 2.1.1.2.2

Contract Title: Bellingham Aquifer Storage Project: Local Aquifer Characteristics

Contractor: U. S. Geological Survey

Principal Investigator: C. Collier

Contract Amount: $\$ 36,000$

Contract Term: Interagency Agreement (initiated 1978 and reviewed annually)

Objective: Provide consultation and revlew services to the LTTES

program relative to the geological and hydrological characteristics of the Bellingham, WA, region.

Project Description: USGS will interpret the geological and hydrological features of the Bellingham, WA, area aquifer structures to the prime contractor (WBS 2.1.1.2.1), and will provide the LTTES program project manager with critical comment on the aquifer storage aspect of the Bellingham heat recovery, storage, and district heating project. USGS will also monitor any test drillings to assure proper execution and will carry out the interpretative evaluations of the data obtained.

Prior Accomplishments: Effort to be initiated in final quarter of FY 1978. 
FY 1978 Program: Review proposals to develop aquifer storage of the Bellingham site in respect to implied aquifer performance.

Participate in aquifer characterization in Bellingham region; this will include review of drillers' spectfications, logging of holes, description and analysis of samples, and preparation of geological reports describing the test results.

Beyond FY 1978: Continue to provide support as requested by LTTES program.

Schedule:

\begin{tabular}{|c|c|c|c|}
\hline \multirow{2}{*}{ USGS-WA } & \multicolumn{3}{|c|}{ FISCAL YEAR } \\
\hline & 1978 & 1979 & 1980 \\
\hline & & & \\
\hline 2. Aquifer Characterization & & & \\
\hline
\end{tabular}

$1=$ Report $; 2$ = Initiate; $3=$ Complete 
WBS Element: 2.1.1.3.1

Contract Title: Evaluation of Thermal Energy Storage for the Proposed Twin Cities District Heating System

Contractor: General Electric Company - Center for Advanced Studies (TEMPO)

Principal Investigator: C. F. Meyer

Contract Amount: $\$ 132,141$

Contract Period: August 1978 through September 1979

Objective: Determine the technical and economic feasibility and the systems and costs advantages of including aquifer storage in the proposed Minneapolis-St. Paul district heating system.

Project Description: The Department of Energy, Minnesota Energy Agency, Northern States Power Company, and other local governmental and private organizations are cooperatively performing an in-depth study to determine the feasibility of district heating in the Minneapolis-St. Paul area using cogenerated hot water from power plants. GE-TEMPO will examine the impact of incorporating seasonal storage of hot water on this concept. Specifically, technical requirements, potential problems, preliminary costs (capital, operating, and return on investment), and environmental factors will be identified.

Prior Accomplishments: None; new project in FY 1978. GE-TEMPO has done significant generic work on the aquifer storage of cogenerated heat and finds strong economic and conservation incentive for applying this concept widely. 
FY 1978 Program: The following tasks will be initiated:

1. Review the proposed Twin Cities district heating system; define the possible role of aquifer TES.

2. Evaluate the potential benefits of incorporating aquifer storage.

Beyond FY 1978: Complete technical and economic feasibility studies.

Further activity will depend on the results of this initial feasibility study.

Schedule:

\begin{tabular}{|l|r|r|r|}
\hline \multirow{2}{*}{ GE-TEMPO } & \multicolumn{3}{|c|}{ FISCAL YEAR } \\
\cline { 2 - 4 } & 1977 & 1978 & 1979 \\
\hline 1. Feasibility Study & & 2 & \multicolumn{1}{c|}{$\frac{1}{7}$} \\
\hline $1=$ Report; 2 = Initiate; 3 = Complete & & & \\
\hline
\end{tabular}


WBS Element: 2.1.2.1

Contract Title: Aquifer Storage Experiment for Cold Water in an Unconfined Aquifer

Contractor: Texas A\&M University

Principal Investigator: D. L. Reddel1

Contract Amount: $\$ 360,450$

Contract Term: September 1, 1977 to September 30, 1981

Objective: Evaluate the technical feasibility of generating winterchilled water by means of a spray pond and of storing this water on a seasonal scale in an unconfined aquifer; gather thermalmydraulic data for validating existing analytic models.

Project Description: In a field test, large volumes of winter-chilled water will be injected into an unconfined aquifer. This water will be stored through the spring quarter and then withdrawn during the summer months. The field will be instrumented through observation wells, whose locations will be appropriate to the aquisition of thermal-hydraulic data through the injection/storage/withdrawal cycle. Water taken from the same aquifer at a distance sufficient to avoid interference will be cooled in a spray pond when weather conditions are suitable. Surface subsidence and rebound will be measured during the test cycles.

Prior Accomplishments: Project initiated in final month of FY 1977. 
FY 1978 Program: The experimental facility (spray pond, water source, injection/withdrawal well, and observation wells) will be completed by early summer 1978. Tests during the remainder of the warm months of FY 1978 will:

1. Establish the magnitude of ground water movement at the test site.

2. Identify potential chemical and biological problems through the injection of warm aerated water.

Beyond FY 1978: With the onset of cold weather in the winter season of 1978-1979, water will be chilled and injected into the test field; this will continue as temperatures permit throughout the cold period. The cold water stored through spring will then be withdrawn in the summer of 1979 . This cycle will be repeated through the two succeeding winters.

Schedule:

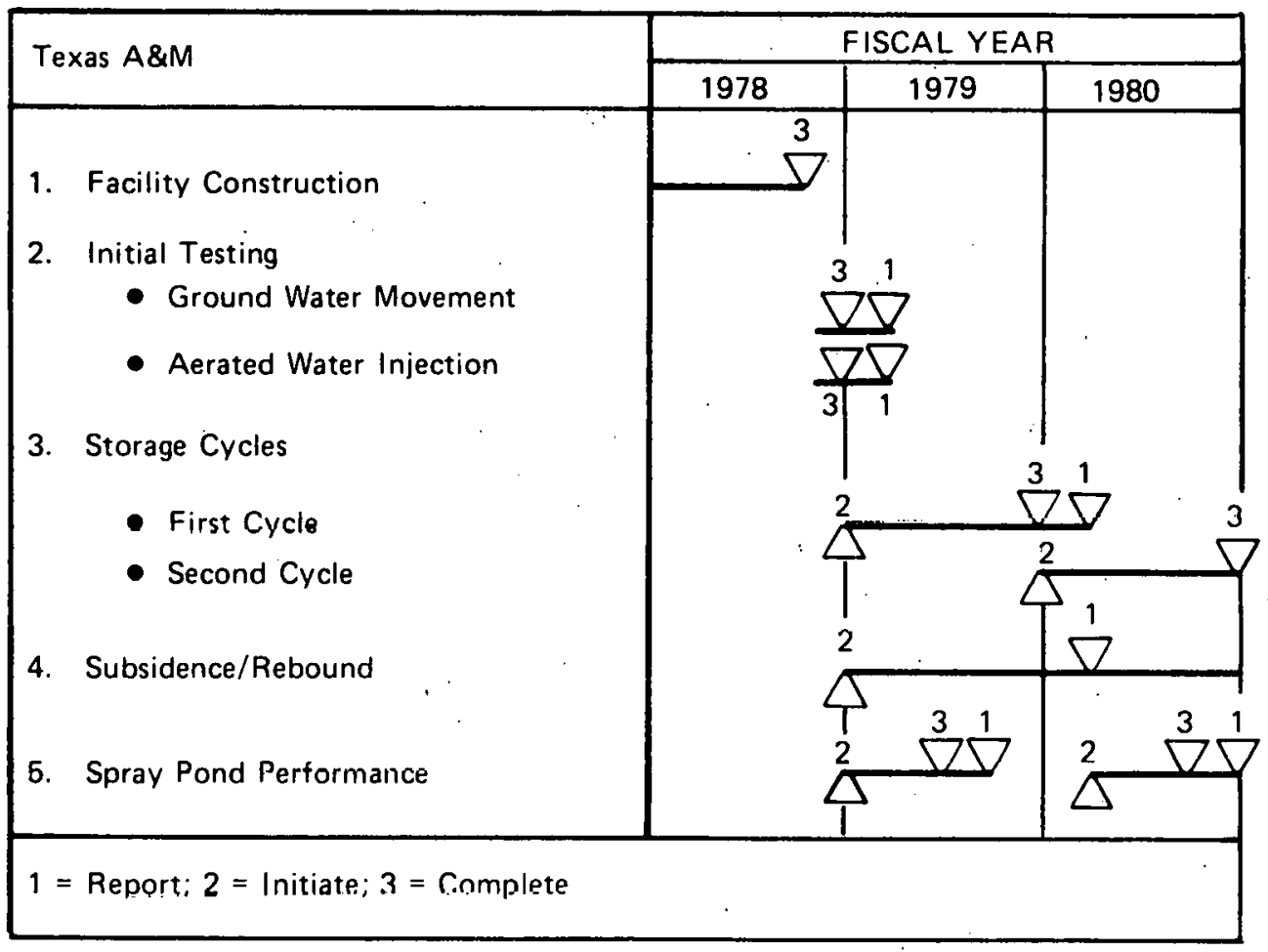


WBS Element: 2:1.2.2.1

Contract Title: Aquifer Storage of Winter Cold for Summer Air Conditioning

Contractor: Desert Reclamation Industries

Principal Investigator: H. J. Hibshman

Contract Amount: $\$ 102,180$ (awarded under DOE-STOR PRDA)

Contract Term: October 4, 1977 to September 30, 1978

Objective: Establish the technical and economic.feasibility of winterchilling water, changing to this water to an aquifer beneath the JF Kennedy Airport (long Island, NY), and subsequently recovering this water for summer air condittoning of terminal buildings.

Project Description: This activity is the first phase of a projected four-phase program to acquire, store, recover, and use winter-chilled water for summer air conditioning. The specific application is to utilization in the terminal buildings of the JF Kennedy International Airport. Phase $I$ is an economic, geohydrologic, and engineering feasibility study based on available information. Engineering design and optimization studies, aquifer chracteristics used in modeling, and analysis of investment and operating costs will be carried out and synthesized into an overall perspective for deciding whether to proceed with the next phase.

Prior Accomplishments: This is a new effort funded at the beginning of FY 1978. 
FY 1978 Program: Phase I tasks to be undertaken in this effort are as follows:

1. Develop preliminary designs and cost estimates for alternate winter-cold capture systems; this will include determination of the availability of cold and estimate investment and operating costs for the winter-cold capture subsystems.

2. Develop a preliminary design and cost estimate for the storage systems; this will include selection of probable parameters for the aquifer storage subsystem and development of a preliminary model, selection of probable parameters for the aquifer itself and incorporation into a model, and develop preliminary subsystem designs.

3. Develop a preliminary design and cost estimate for the cold-well water use system.

4. Use above design and cost estimate information to update the cost effectiveness evaluation of the project.

5. Develop basis for detailed aquifer characterization.

6. Evaluate environmental effects of operating a pilot project at the site.

Beyond FY 1978: Further work rests on potential identified.

\section{Schedule:}

\begin{tabular}{|c|c|c|c|}
\hline \multirow{2}{*}{ Desert Reclamation } & \multicolumn{3}{|c|}{ FISCAL YEAR } \\
\hline & 1977 & 1978 & 1979 \\
\hline $\begin{array}{l}\text { 1. Prèliminary Designs and Costs } \\
\text { - Cold Capture } \\
\text { Storage Subsystem } \\
\text { Cold Well } \\
\text { 2. Cost-Effectiveness Update } \\
\text { 3. Aquifer Characterization Plans } \\
\text { 4. Environmental Effect Estimates } \\
\text { 5. Summary Evaluation }\end{array}$ & & $\overbrace{\Delta}^{2}$ & \\
\hline $1=$ Report $; 2=$ Initiate $3=\mathrm{Co}$ & & & \\
\hline
\end{tabular}


WBS Element: 2.1.2.2.2

Contract Title: JFK Airport Aquifer Storage Project: Test Well Drilling Program

Contractor: New York Energy Research and Development Authority

Principal Investigator: M. E. Singer

Contract Amount: $\$ 65,000$

Contract Term: August 15, 1978 to January 15, 1979

Objective: Determine the thicknesses, lateral extent, depths, and stratigraphy of the aquifers underlying the JFK Airport, Long Island, NY.

Projest lescripc1on: The stratigraphy and preliminary hydrology of the Jameco aquifer under the JFK Airport will be investigated by drilling, sampling, logging, and casing four small-diameter boreholes of about 500-ft length. This work, providing Information for the better design and development of a cold-water aquifer storage system at JFK, is designated as Phase $1 \mathrm{~A}$ of the overall project (see WBS 2.1.2.2.1).

Prior Accomplishments: New effort in. FY 1978. 
FY 1978 Program: Dri11, sample, and log four, 6- to 8-in.-diam boreholes of about 500-ft length; issue report documenting geological data obtained.

Beyond FY 1978: This effort will be completed by mid-FY 1979 .

Schedule:

\begin{tabular}{|l|r|r|r|}
\hline \multirow{2}{*}{ NY-ERDA } & \multicolumn{3}{|c|}{ FISCAL YEAR } \\
\cline { 2 - 4 } & 1977 & 1978 & 1979 \\
\hline 1. Aquifer Characterization & & 2 & 31 \\
& & & \\
\hline $1=$ Report; 2 Initiate; $3=$ Complete & & \\
\hline
\end{tabular}


WBS Element: 2.1.2.2.3

Contract Title: JFK Airport Aquifer Storage Project: Phase II Engineering and Site Management

Contractor: Port Authority of New York and New Jersey

Principal Investigator: TBD*

Contract Amount: TBD

Contract Term: TBD

Objective: Design and construct on aquifer storage subsystem to demonstrate seasonal storage of cold water.

Project Description: Cold water generated during the winter (cooling tower, spray pond, or natural: snurce) is to be stored underground in an aquifer for summer recovery to chill water used in the existing air-conditioning system at the JFK Airport. The storage system will consist of a number of paired sets (injection/withdrawal) of large capacity water wells penetrating the aquifer. The initial phase of this project (Phase II of the overall program - see WBS 2.1.2.2.1) will construct one set of such wells and carry out tests over a sufficient number of discharge-recharge cycles (with and without thermal input) to establish performance characteristics and identify problems. Subsequent efforts will complete the storage subsystem (drill remaining required) and connect this element into the existing terminal building cooling system.

Prior Accomplishments: This is a continuing phase of the work described under WBS 2.1.2.2.1 and 2.1.2.2.2.

\footnotetext{
*To be developed.
} 
FY 1978 Program: Not funded.

Beyond FY 1978: Development of this project in the FY 1979 period and beyond hinges on: (1) the results of the feasibility analyses and initial aquifer characterization measurements, and (2) policy decisions by the Port Authority as to their level of involvement in and approval of the project at the JFK site. If initiated; consideration will be given also o storage of hot water generated in a garbageburning facility (being examined for location at JFK).

Schedule: TBD 
WBS Element: 2.1 .2 .2 .4

Contract Title: JFK Airport Aquifer Storage Project: Local Aquifer Characteristics

Contractor: U.S. Geological Survey

Principal Investigator: J. H. Kantrowitz

Contract Amount: $\$ 25,000$

Contract Term: Interagency Agreement (Initiated 1978 and reviewed annually)

Objective: Provide consultation and review services to the LTTES

program relative to the geological and hydrological characteristics of the Long Island, NY, region.

Project Description: USGS will interpret the geological and hydrological features of the Long Island, NY, area aquifer structures to the project principals (see WBS 2.1.2.2.1, 2.1.2.2.2, and 2.1.2.2.3), and w111 provide the LTTES program project manager with critical comment on the aquifer storage aspect of the JFK Airport cold generation, storage, and terminal building cooling project. USGS will also monitor any test drillings to assure proper execution and will perform the interpretative evaluation of the data obtained.

Prior Accomplishments: Effort initiated in FY 1978. 
FY 1978 Program: Review proposal to develop cold-water aquifer storage at JFK airport site in respect to implied aquifer performance.

Review drillers' specifications for drilling geological exploration holes at test site; log holes, analyze and describe samples, and provide a geological report of results of drilling operation.

Beyond FY 1978: Provide continued support as requested by LTTES program. Schedule:

\begin{tabular}{|c|c|c|c|}
\hline \multirow[b]{2}{*}{ USGS-NY } & \multicolumn{3}{|c|}{ FISCAL YEAR } \\
\hline & 1977 & 1978 & 1979 \\
\hline & & 2 & \\
\hline $\begin{array}{l}\text { 1. Consultative Services } \\
\text { 2. Aquifer Characterization }\end{array}$ & & $\Delta_{2}$ & $\begin{array}{c}31 \\
\square\end{array}$ \\
\hline $1=$ Report $; 2=$ Initiate 3 & & & \\
\hline
\end{tabular}


WBS Element: 2.1.3.1

Contract Title: Aquifer Storage-Analytic Modeling

Contractor: Lawrence Berkeley Laboratory

Principal Investigator: C. F. Tsang

Contract Amount: $\$ 160,000$

Contract Term: May 15, 1977 to September 30, 1978

Objective: Apply an existing computer model to predict the behavior (thermal-hydraulic and chemical) of aquifers storing hot and cold waters; develop injectlun/willidrawal strategico; determine preferred locations of observation wells for fleld tests and concept demonstrations.

Project Description: LBL will utilize an existing computer model (developed in support of geothermal studies) to study heat and mass flow in a 3-D, water-saturated, porous medium and to estimate the vertical deformation (subsidence/elevation) associated with water injection and withdrawal. Generic sensitivity studies will estimate recovery efficiencies, injection/withdrawal strategies, land surface vertical displacement, natural convectlon wllhin the stored fluid volume, effect of ground water flow on horlzontal displacement of the stored "bubble", etc. Similar calculations will guide instrument positioning in field tests; fleld results will be used to validatc and modify the model.

Prior Accomplishments: The code "CCC" was used to describe the behavior of an aquifer of postulated propertfes dally, semiannual, and annual storage of both hot and culd water. Calculationo were initiated for a two-well (doublet) system. 
FY 1978 Program: Analysis of the 2-well system will be completed and then extended to a 3-well arrangement; effects of regional ground water flows on recovery efficiencles will be examined.

Use CCC to analyze and interpret data from the Auburn experiment as this data becomes available.

Carry out workshop on the aquifer storage concept; provide LTTES program management with technical advice on aquifer characteristics.

Beyond FY 1978: Continue refinement of computer model utilizing data acquired in field tests of hot and cold water storage and provide advice on future course of these experiments. Carry out predictive studies for selected project sites. Expand the model capability to accommodate effects of chemical dissolution, precipitation, and resolution.

Schedule:

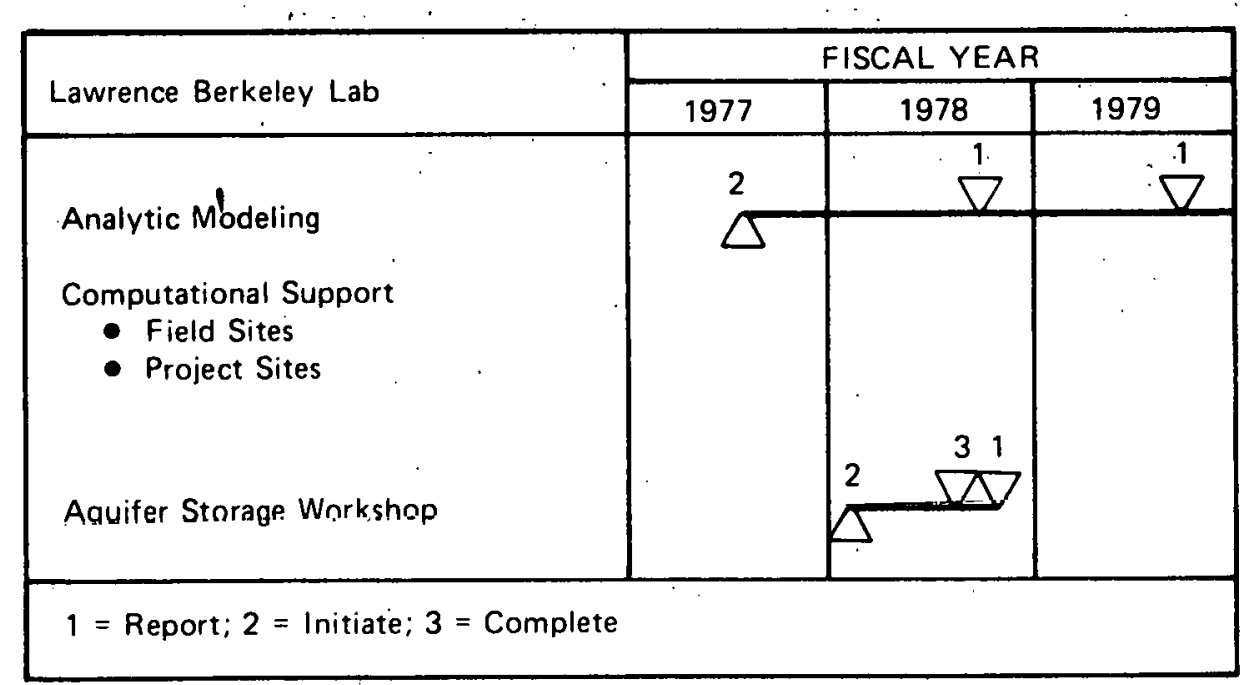


WBS Element: $2 \cdot 1 \cdot 4.1$

Contract Title: Aquifer Storage-Physical Modeling

Contractor: Tennessee Valley Authority (TVA), Division of Reservoir Properties, Engineering Laboratory

Principal Investigator: TBD*

Contract Amount: TBD

Contract Term: TBD

Objective: Construct and operate physical models of aquifers; coordinate with LBL analytic modeling (WBS 2.1.3.1).

Project Description: TVA will design and fabricate one or more physical models of aquifer structures to permit studies into the effects of 1.ensing, lithographic Inhomogenieties, stratification, and other natural anomalies that might affect aquifer performance as a storage medium. Corollary analytic modeling to describe and predict these effects will be closely coordinated with efforts at LBL (WBS 2.1.3.1). ORNL staff will particlpate in design and operation of these experiments.

Prior Accomplishments: None; new project in FY 1978.

*To be developed. 
FY 1978 Program: TVA will describe detalled workshop and cost esti- : mates.

Beyond FY 1978: Construct and begin physical model experiments.

Schedule: TBD 
5.2.2 Earth TES Projects (WBS 2.2)

Current efforts are limited to a study (experiment and analysis) at George Washington University on a concept for storing solar heat in wet sand beds; this project will be completed In FY 1978. Further activity is not now planned prior to FY 1980, when the concept will be reexamined in terms of residential solar heating/cooling needs of that time.

\subsubsection{Pond TES Projects (WBS 2.3)}

No activity is planned for FY 1978 in this area. 
Table 5.2.2. Projects supporting earth TES technology development

\begin{tabular}{lccc}
\hline WBS Element & Project & Contractor & Status \\
\hline Concept Studies: & characterization and feasibility & \\
2.2 .1 .1 & Solar heat storage & $\begin{array}{c}\text { George Washington } \\
\text { University }\end{array}$ & Active \\
& & & \\
\hline
\end{tabular}


WBS Element: 2.2.1.1

Contract Title: Long Duration Storage of Heat in the Earth

Contractor: George Washington University

Principal Investigator: S. W. Yuan

Contract Amount: $\$ 126,918$

Contract Term: July 1, 1975 to January 31, 1978

Objective: Determine the technical feasibility for storing solargenerated heat directly in the earth; establish preliminary economics.

Project Description: Solar heat collected during the summer months will be stored for winter use within the earth surrounding or beneath the using residence. The heat will be transferred to and recovered from the earth through an array of underground piping. GWU will carry out laboratory-scale tests on a pumped heat pipe concept for introducing the heat into the earth storage bed, will develop analytic models describing transient conduction within the storage medium, and will perform initial cost analyses based on a prelfminary engineering design.

Prior Accomplishments: Analysis using a model considering transient heat transfer in the earth storage bed established that this concept has potential for storing and recovering quantities of heat sufficient to meet seasonal heating requirements. A pumped heat pump for injecting heat into the storage medium was successfully developed and demonstrated at laboratory scale. 
FY 1978 Program: Systems analyses will be carried out to delineate the technical mertt and provide preliminary economics for three specific injection/storage/recovery systems; namely:

1. Using the earth surface as a solar collector with a system of piping to transfer the heat to a deeper earth storage region and an interlaced piping system to transport the recovered heat to the use station (residence),

2. Using "conventional" solar collectors to gather heat with a system of piping coupling the collector through the use station with the storage bed.

3. Using "conventional" solar collectors to gather heat, a pumped heat pipe to carry the heat into the storage bed, and a system of buried piping to recover the heat.

Beyond FY 1978: Follow-on activities have not been defined: Schedule:

\begin{tabular}{|c|c|c|c|}
\hline \multirow{2}{*}{ George Washington University } & \multicolumn{3}{|c|}{ FISCAL YEAR } \\
\hline & 1977 & 1978 & 1979 \\
\hline 1. Feasibility Studies & $\frac{3}{7}$ & $\stackrel{1}{\nabla}$ & \\
\hline 2. Systems Studies & $\Delta^{2}$ & $\begin{array}{cc}3 & 1 \\
\nabla & \nabla\end{array}$ & \\
\hline $1=$ Report $; 2=$ Initiate; 3 & & & \\
\hline
\end{tabular}




\subsection{Daily/Short-Term Storage Projects (WBS 3.0)}

Projects in this area consider two means for utilizing phase-change materials (PCM's) to achfeve dafly or short-term storage of heat; energy sources would be primarily solar and off-peak electricity.

PCM's can be incorporated directly into building structural elements such as bricks and concrete blocks or finish elements such as wall panels and floor and ceiling tiles. Alternatively, PCM's can be contained in modular units - akin to furnaces, heat pumps, window air conditioners, etc. - either in bulk form (i.e., within a containment tank) or in macroencapsulated form (i.e., within cans or plastic envelopes arranged, in turn, within a heat exchange duct). While projects in this category enjoy somewhat lower current priority than the efforts described in Sections 5.2.1 (aquifers) or 5.4.1 (industrial waste heat), interest is significant in view of the availability of cheap off-peak electrictly and the rospects for efficient solar heat collectors.

\subsubsection{PCM's in Building Materials TES Projects (WBS 3.1)}

Two concepts for incorporating PCM's directly into concrete blocks void infusion with surface sealing and aggregate substitution with polymer binding - are being pursued concurrently; as indicated in Table 5.3.1, work on both w11l be cuntinued in FY 1978. Plans will be dèveloped for the alternative of containment of macroencapsulated PCM (see WBS 3.2.1.3) within the hollow regions of concrete blocks. Attention will also be directed to geometries for wall panels and floor and ceiling tiles. 
Takle 5.3.1. Projects supporting daily/short-term TES technology development

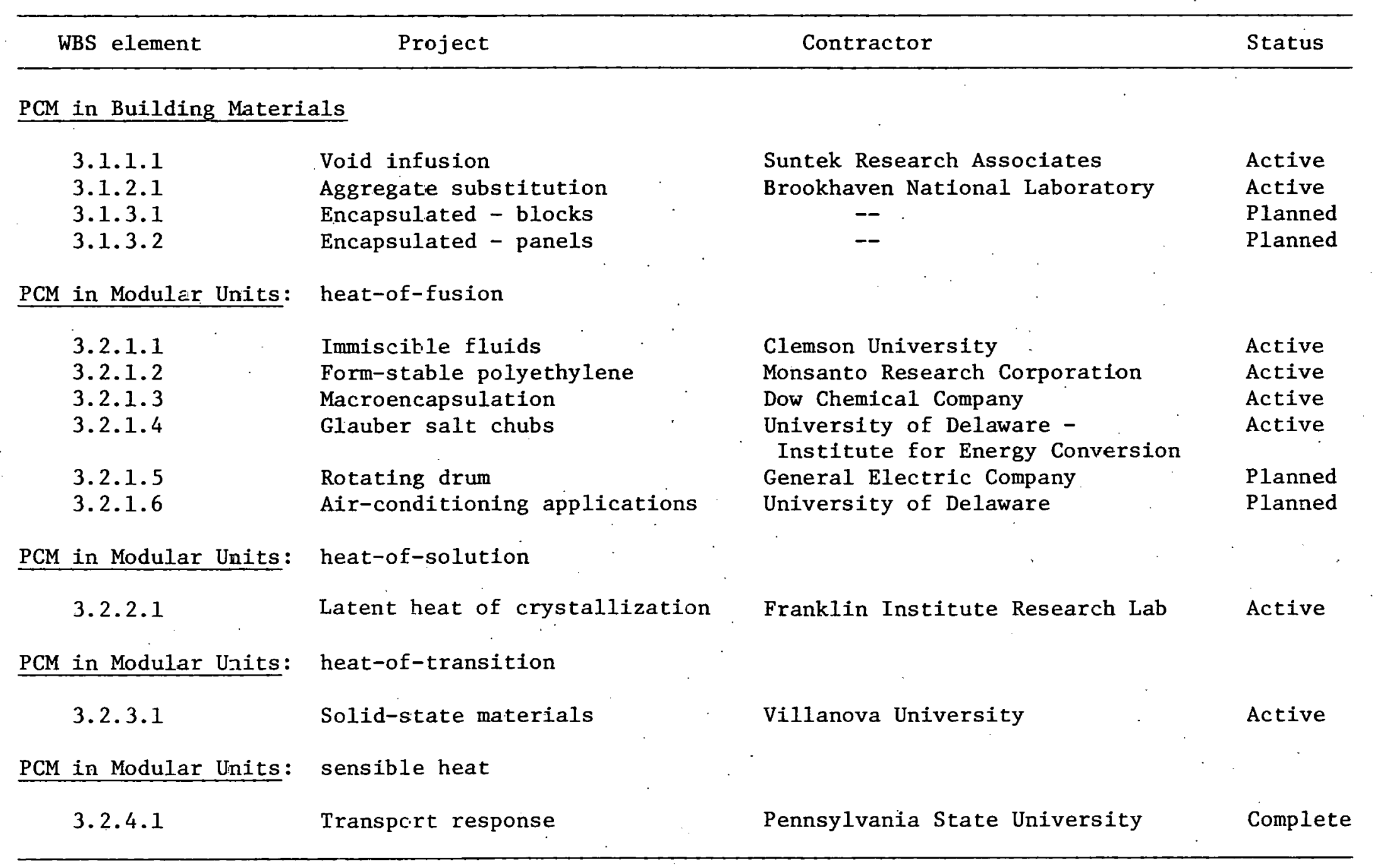


WBS Element: 3.1.1.1

ContractTitle: Concrete Building Materials Containing Phase-Change Materials for Thermal Storage

Contractor: Suntek Research Associates

Principal Investigator: Day Chahroudi

Contract Amount: $\$ 259,788$

Contract Term: August 15, 1976 to June 30, 1978

Objective: Develop techniques for containing phase-change materials within the voids of light-weight concrete building blocks.

Project Description: Th1s is a multiphase effort to develop (1) techniques for incorporating appropriate phase-change materials into the void sturcture of concrete blocks, (2) techniques for manufacturing this product at acceptable costs, and (3) techniques for introducing the product to the bullding construction industry. In Phase 1, Suntek will develop means for infusing PCM's into the void volume of sample blocks and for surface sealing to prevent PCM loss, carry out tests to establish stability under repeated thermal cycling, and generate preliminary fabrication cost data.

Prior Accomplishments: Scoping tests Involving investigation of various combinations of concrete formulation, PCM, nucleator, and sealant led to further consideration of three blocks:

1. a structural block of pumice concrete filled with $\mathrm{CaCl}_{2} \cdot 6 \mathrm{H}_{2} \mathrm{O}$ (mp $\sim 26^{\circ} \mathrm{C}$ ) and a nucleating agent and sealed with urethane coal tar for passive solar application,

2. a nonseructural block of foamed cement filled with $\mathrm{CaCl}_{2} \cdot 4 \mathrm{H}_{2} \mathrm{O}$ (mp $\sim 45^{\circ} \mathrm{C}$ ) and a nucleator and sealed with a polyester resin for active solar application, and

3. a nonstructural block of foamed sement filled with $\mathrm{CaCl}_{2} \cdot 6 \mathrm{ll}_{2} \mathrm{O}$ diluted with $\mathrm{NaCl}$ (mp of $19-25^{\circ} \mathrm{C}$ ) and sealed with a polyester resin for distributed storage.

In performance studies, conconcentrating on the first of these initial samples were subjected to several hundred freeze/melt cycles without apparent deterioration. However, blocks stored isothermally 
over longer periods of time ( $\sim 4$ to 6 months) exhibited cracking of the surface sealant and subsequent loss of block integrity.

FY 1978 Program: Carry out studies necessary to resolve the problem of block deterioration; this will include identification of mechanisms causing sealant cracking and PCM-concrete interactions. Evaluate prospects for a viable product.

Beyond FY 1978: Continued efforts will depend on the success of the FY 1978 investigation.

Schedule:

\begin{tabular}{|c|c|c|c|}
\hline \multirow{2}{*}{ Suntek Research } & \multicolumn{3}{|c|}{ FISCAL YEAR } \\
\hline & 1977 & 1978 & 1979 \\
\hline \multirow{4}{*}{$\begin{array}{l}\text { 1. Block Development } \\
\text { 2. Failure Evaluation }\end{array}$} & & $\sqrt[3]{7} 17$ & \\
\hline & & & \\
\hline & & 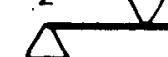 & \\
\hline & . & & \\
\hline \multicolumn{4}{|c|}{$1=$ Report $; 2=$ Initiate $; 3=$ Complete $; 4=$ Continuation Decision } \\
\hline
\end{tabular}


WBS Element: 3.1.2.1

Contract Title: Polymer Cement Materials Changing Phase-Change Materlals for Thermal Storage

Contractor: Brookhaven National Laboratory

Principal Investigator: M. J. Sansone

Contract Amount: $\$ 152,000$

Contract Term: August 1977 through September 1978

Objective: Develop a polymer concrete structural containing phasechange materials.

Project Description: Polymer concretes - a cement material in which polymers are added binders - are proposed as a vehicle for containing PCM's in concrete building blocks and tiles. This study will develop the parameters for forming such materials through examination of means for incorporating the PCM into the $\mathrm{mix}$, compatibility of the PCM with the other mix constituents, durability under isothermal conditions, mechanical characteristics, and preliminary economic evaluation.

Prior Accomplishments: Program initiated in August 1977. 
FY 1978 Program: Tasks to be accomplished in FY 1978 are as follows: 1. Identify and select appropriate PCM's.

2. Develop methods for Incorporating and containing the PCM's in the polymer concrete.

3. Perform mechanical and thermophysical property measurements on selected samples.

4. Carry out economic evaluations.

5. Investigate and identify commercial and industrial interfaces.

Beyond FY 1978: Spectfic efforts in FY 1979 and beyond will depend on successes achieved and problems identified in FY 1978; a dectsion regarding continuation to production technique development and concept demonstration will be made by the end of the third quarter of FY 1979.

Schedule:

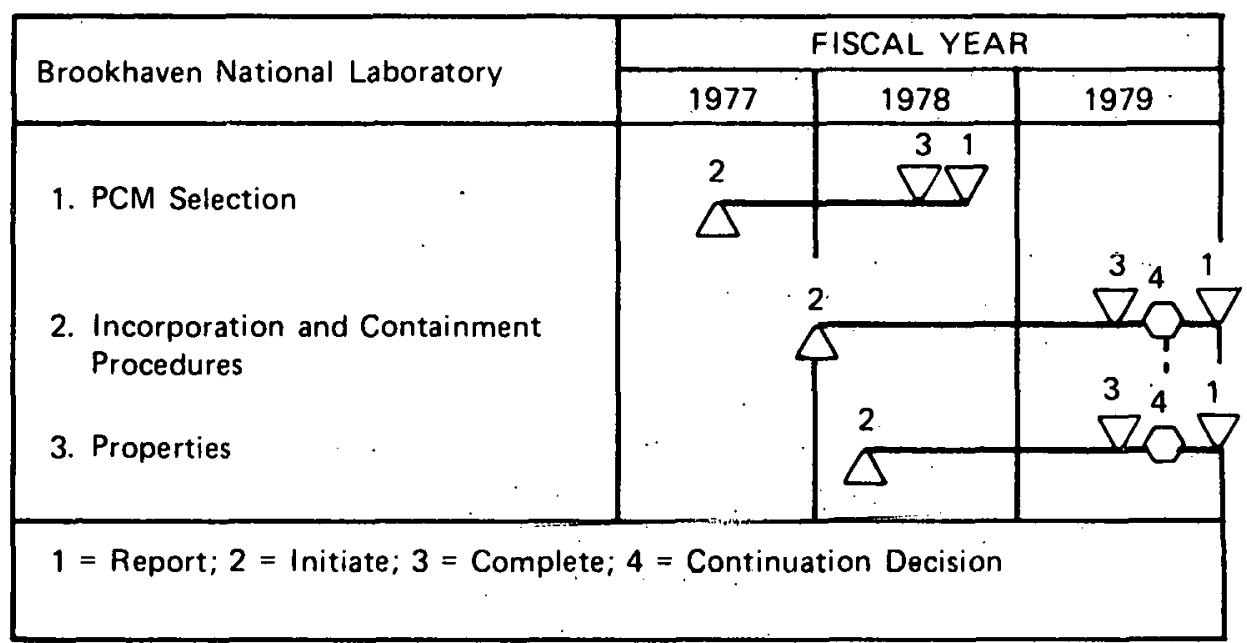




\section{THIS PAGE WAS INTENTIONALLY LEFT BLANK}




\subsubsection{PCM's in Modular Units TES Projects (WBS 3.2)}

Because of the attractiveness of isothermal heat storage by material phase-change and the apparent simplicity of tanks filled with PCM's, this area has attracted much "invention." of the many possible concepts proposed, the LTTES program currently supports works examining the potential for utilizing the heat of fusion, the heat of solution, and the solidstate heat of transition of a variety of materials. Further, two geometries are distinguished: (1) the PCM in bulk form as in a tank with heat exchange to immersed tubing, and (2) the PCM in macroencapsulated form as in "beer cans" arranged within a duct with heat exchange to a fluid flowing through the duct. The several studies underway or planned for FY 1978 are listed in Table 5.3.1 and described individually on the pages immediately following.

It should be noted that most of this activity developed from unsolicited proposals funded by the National Science Foundation or DOESOLAR and subsequently transferred to LTTES program management. As such, these efforts do not fully span the field of interesting concepts. Of the several thrusts within the LTTES program, this area will probably remain the most responsive to unsolicited ideas showing innovative solutions and promising economics. 
WBS Element: 3.2.1.1

Contract Title: Immiscible Fluid - Heat Fusion Storage System

Contractor: Clemson University

Principal. Investigator: D. D. Edie

Contract Amount: $\$ 139,000$

Contract Term: June 1, 1976 to November 30, 1978

Objective: Evaluate the feasibility of utilizing direct contact heat. transfer in a phase-change (heat of fusion) system to overcome problems of heat transfer lag and phase separation

Project Description: This study will examine the utilization of an immiscible second liquid phase as the thermal transport medium in a hydrated salt PCM storage system. The advantages of this approach are significant: (I) direct contact heat exchange affording both improved heat transfer efficiencies and rates and improved economics through elimination of the heat exchange surface, and (2) turbulent mixing between the immiscible phases minimizing problems associated with hydrated salts of surface nucleation and phase separation.

Prior Accomplishments: A review of the literature identified a number of aqueous salt systems with suitable properties; a similar search for heat transfer fluids with desirable properties was less successful in that no fluids met all requirements. Crystal growth rates were determined for selected salts. A bench-scale experiment with $\mathrm{Na}_{2} \mathrm{HPO}_{4} \cdot 12 \mathrm{H}_{2} \mathrm{O}$ and Varsol confirmed the viability of the basic concept of immsclble heat transfer with a crystallizing hydrated salt. 
FY 1978 Program: Studies will continue in all areas: systems identification, crystal growth rates, and system performance. Emphasis will be on the search for an acceptable heat transfer fluid and on the determination of the interphase heat transfer coefficients (particularly effects of system geometry and fluid flow rates). A pilot-scale study for a selected salt-immiscible fluid combination will study performance degradation under extended thermal. cycling arising from gradual phase separation and salt carry-over into other portions of the loop.

Beyond FY 1978: The study of operational characteristics at pilot scale will be completed. Applications will be identified, and preliminary economics developed.

\section{Schedule:}

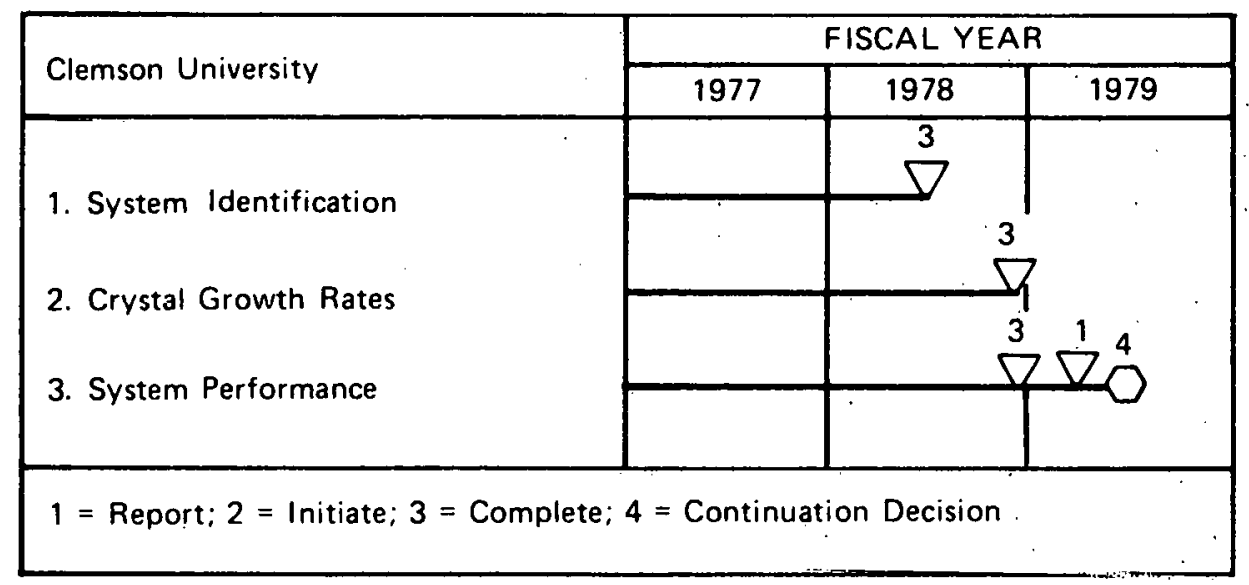


WBS Element: 3.2.1.2

Contract Title: Form-Stable Crystalline Polymer Pellets for Thermal Energy Storage

Contractor: Monsanto Research Corporation

Principal Investigator: G. L. Ball

Contract Amount: $\$ 211,237$

Contract Term: July 1, 1976 to February 15, 1978

Objective: Develop a form-stable crystalline polyethylene as a thermal storage material and determine preliminary ennnomics.

Project Description: Crystalline polyethylene (PE) has been identified as a material of sufficiently interesting properties (melting temperature of $\sim 130^{\circ} \mathrm{C}$ and heat of fusion of $2.50 \mathrm{cal} / \mathrm{g}$ ) to be considered seriously for thermal energy storage with application in both building heating and cooling (absorption cycle). The potential of this TES medium is further enhanced by the Monsanto proposal to cross-1ink (polymerize) this material just sufficiently that it retains shape on melting but not enough to severely degrade the heat of fusion. This This study examines the characteristics of cross-1inked polyethylene formed by different processes, determines its stability in response to temperature cycling, and develops preliminary economics for material production and system implementation.

Prior Accomplishments: A silane grafted and cross-linked PE was found to. retain over $95 \%$ of the heat of fusion of the crystalline material. Melt/freeze cycling of several samples ( $100 \mathrm{~g}$ for $400 \mathrm{cycles}$, and $2550 \mathrm{~kg}$ for 170 cycles) with an ethylene glycol heat carrier resulted in no performance degradation. Initial form-stable PE costs of "\$0.42/1b were not optimistic but could be reduced by approximately one-third by starting with a less pure polyethylene. 
FY 1978 Program: Studies in this period will emphasize the economics of form-stable polyethylene as a TES medium; thus:

1. Evaluate crystalline polyethylene intermediates (less pure material formed along the route to commerctal molding compounds) as the starting material for form-stable PE.

2. Determine synthesis routes to crystalline polyethylene that use other than natural gas or petroleum as the source material.

3. Carry out cost comparisons between a TES system based on formstable polyethylene and ones based on other storage concepts.

In addition; Monsanto will continue melt/freeze cycling of the 550-kg sample and will evaluate air as the heat transport fluid in a formstable PE bed.

Beyond FY 1978: Future efforts toward developing this concept will rest on the cost competitiveness determined in the FY 1978 studies. Schedule:

\begin{tabular}{|c|c|c|c|}
\hline \multirow{2}{*}{ Monsanto Research } & \multicolumn{3}{|c|}{ FISCAL YEAR } \\
\hline & 1977 & 1978 & 1979 \\
\hline \multirow{2}{*}{ 1. Form-Stable PE Development } & $\stackrel{3}{7}$ & $\nabla^{11}$ & \\
\hline & & 31 & \\
\hline \multirow{2}{*}{ 2. Thermal Cycle Testing } & & $\checkmark v$ & \\
\hline \multirow{2}{*}{\multicolumn{4}{|c|}{ 3. Materiäl/System Economics }} \\
\hline & & & \\
\hline $1=$ & & $n \mathrm{D}$ & \\
\hline
\end{tabular}


WBS Element: 3.2 .1 .3

Contract Title: Macroencapsulation of Phase-Change Storage Materials

Contractor: Dow Chemical Company

Principal Investigator: G. A. Lane.

Contract Amount: $\$ 175,000$

Contract Term: September 7, 1976 to September 7, 1978

Objective: Select and evaluate combinations of phase-change materials and encapsulant materials appropriate to TES in several application temperature ranges in respect to technical and economic feasibility.

Project Description: This study will select and examine combinations of PCM's with various encapsulating materials to determine the best combination for each of several applications (temperature range). The applications considered are hydronic heating $\left(70^{\circ} \mathrm{C}\right.$ to $\left.90^{\circ} \mathrm{C}\right)$, potable water heating $\left(60^{\circ} \mathrm{C}\right.$ to $\left.70^{\circ} \mathrm{C}\right)$, forced-air heating $\left(40^{\circ} \mathrm{C}\right.$ to $\left.60^{\circ} \mathrm{C}\right)$, and heat pump systems $\left(20^{\circ} \mathrm{C}\right.$ to $\left.40^{\circ} \mathrm{C}\right)$. "Best-of-the show" combinations will be tested under temperature cycling conditions.

Prior Accomplishments: 'Best candidate PCM's were selected for each of the four application areas in combination with three basic container shapes (cylinders, tetrahedra, and pillows) formed of commercially available materials (cans, bottles, and films). A simple computer, simulation of a hypothetical heat of fusion TES heat exchanger was developed to specify container thermal requirements. Polyethylene/ aluminum/polyester commercial films, steel cans, and high density polyethylene or polyethylene-saran laminate bottles were identified as appropriate containers. Compatibility of the selected PCM's with these containers was determined. 
FY 1978 Program: A final selection will be made as to the best combination of PCM for each application temperature range with encapsulant. material and shape. These will then be tested under temperature cycling conditions in an apparatus using air as the heat transport fluid. Economic comparisons will be completed.

Beyond FY 1978: Studies beyond those now being performed are undefined: Schedule:

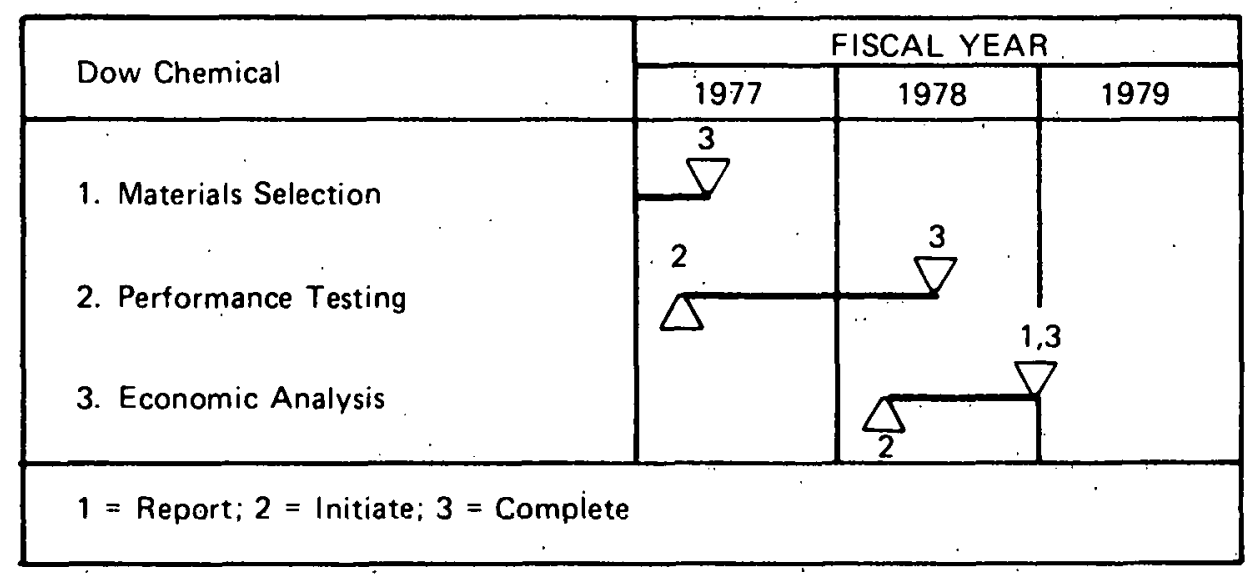


WBS Element: 3.2.1.4

Contract Title: Life and Stability Testing of a "Cool" Storage Unit Changed with Phase-Change Materials

Contractor: Institute of Energy Conversion (University of Delaware)

Principal Investigator: G. R. Frysinger

Contract Amount: $\$ 146,255$

Contract Term: September 1, 1978 to October 31, 1979

Objective: Demonstrate that the PCM packaging concept proposed has the reliability, life expectancy, and stability (both physical and chemical) to satisfy the requirements of the market place.

Project Description: IEC, working with duPont, has developed a film packaging concept for containing their Glauber's salt mixture that is claimed to be technically and economically appropriate to the TES application. This study will subject standard "chubs" to both diurnal and accelerated (simulating seasonal) thermal cycling to verify chub integrity (contain moisture) and obtain data on life and stability of the packaged material. Diurnal cycles will consist of 10-hr freezing followed by 14-hr thawing over 100 cycles (equals approximate 100 days of a cooling season); accelerated cycles will consist of a 4- to 6-hr freeze-thaw period over about one year. Failures encountered during the life and stability testing program will be analyzed; the exposed packaging film will be examined at the test conclusion to detect incipient failures.

Prior Accomplishments: Development of a Glauber's salt mixture said to overcome phase separation problems and identification of an appropriate containment material and configuration. 
FY 1978 Program: Program to begin late in FY 1978 or at beginning of FY 1979.

Beyond FY 1978: Assemble chubs and perform materials qualification tests, package integrity tests, and thermal cycle tests at $55^{\circ} \mathrm{F}$ (cooling application) for the proposed TES package.

\section{Schedule:}

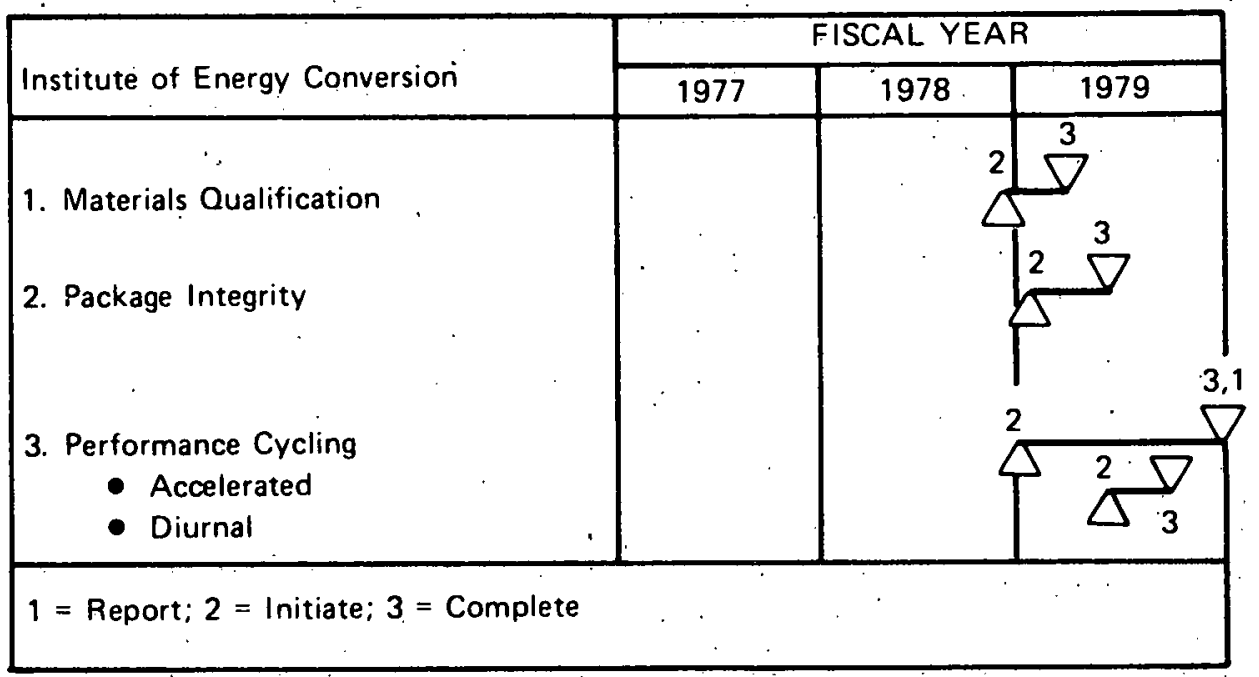


WBS Element: 3.2.1.5

Contract Title: Development of Intermediate Temperature Thermal Storage Units Using Phase-Change Materials

Contractor: University of Delaware (Mechanical Engineering Department)

Principal Investigator: J. R. Moszynski

Contract Amount: TBD*

Contract Term: TBD

Objective: Develop phase-change TES systems in the temperature range appropriate to utilizing solar energy for absorption air conditioning.

Project Description: This project - funded under a DOE-SOLAR award and managed by ORNL-LTTES - will identify and evaluate PCM's melting in the temperature range of $90^{\circ} \mathrm{F}$ to $180^{\circ} \mathrm{F}$ and containment materials compatible with these PCM's. Physical properties are to be determined as necessary to the design and performance testing of a system model. A full-scale system will be designed on the basis of this information and judged as to economic viability.

Prior Accomplishments: None; however, significant experience exists in the University's Institute-for Energy Conversion.

*To be determined. 
FY 1978 Program: To be negotiated during FY 1978 for funding by end of fiscal year or early in FY 1979.

Beyond FY 1978: The program will consist of the following activities:

1. Feasibility study - complete search for appropriate PCM and/or chemical reaction storage materials; complete search for materials properties; identify contalnment problems; carry out preliminary performance and cost analyses; investigate low-cost containment of large vapor volumes, and define application conditions (storage capacity) appropriate to use of water vapor.

2. Engineering analysis and design - determine missing thermodynamic.: and transport properties of selected material (probably ferrous sulphate); verify containment compatibility; carry out thermal cycling tests; establish heat exchange configurations; design. full-scale storage system and project costs and performance; design scaled model.

3. Construction and testing - construct and instrument scaled model; test in accord with approved standards; analyze and report results.

\section{Schedule:}

\begin{tabular}{|l|r|r|r|}
\hline \multirow{2}{*}{ University of Delaware } & \multicolumn{3}{|c|}{ FISCAL YEAR } \\
\cline { 2 - 4 } 1. System Selection & 1977 & 1978 & 1979 \\
2. Analysis and Design & & & \\
3. Construction and Testing & & \\
\hline 1 $=$ Report; 2 = Initiate; 3 = Complete; 4 = Continuation Decision \\
\hline
\end{tabular}


WBS Element: 3.2.1.6

Contract Title: Prototype Design and Testing of the Rolling Cylinder Thermal Storage System

Contractor:: General Electric Company - Corporate Research and Development

Principal Investigator: C. S. Herrick

Contract Amount: TBD*

Contract Term: TBD

Objective: Develop the rotating drum concept for utilizing hydrated salts as thermal energy storage media.

Project Description: The rotating drum concept is proposed as a means for avoiding such problems in using hydrated salts för TES as solids buildup on the heat exchange surface, phase separation, and supercooling. This is accomplished by containing the aqueous PCM in a horizontal cylinder that is supported and slowly rotated by a set of rollers. The flow thus created in the fluid affects sufficient mixing to eliminate the above noted problems. This effort is a DOE-SOLAR award to be managed by ORNL-LTTES.

Prior Accomplishments: GE has carried out, with corporate funding, exploratory bench-scale experiments that have shown:

. continued fu11-recovery of the latent heat of phasc change for Glauber's salt $\left(\mathrm{Na}_{2} \mathrm{SO}_{4} \cdot 1 \mathrm{UH}_{2} \mathrm{O}\right)$ after 200 mell/freeze cyclcc -reliable nucleation . no solids buildup on the heat transfer surface

*To be developed. 
FY 1978 Program: To be negotlated during FY 1978 for funding by end of fiscal year or early in FY 1979.

Beyond FY 1978: Phase I of this effort will consider:

1. Thermal analysis - identify and analyze thermal behavior within the PCM, between the PCM and the cylinder wa11, and between the wall and the external heat carrier and delineate impact on economics.

2. Thermal testing - carry out cests appropriate to verifying the thermal analysis and identifying physical problems.

3. Corrosion evaluation - review behavior and carry out tests as needed.

4. Design prototype - conduct preliminary conceptual design, evaluate economics, and design equipment to obtain quantitative performance data.

5. Prototype construction - procure equipment and construct prototype; carry out shakedown tests with water or other appropriate material.

Schedule:

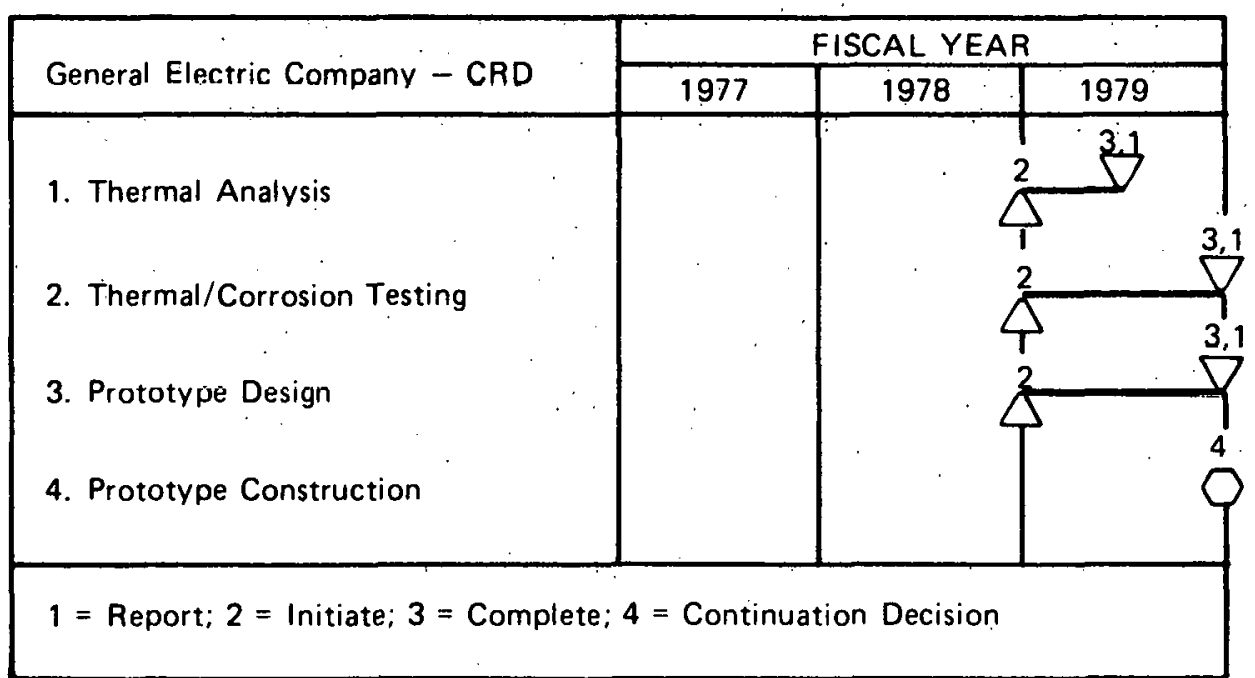


WBS Element: 3.2.2.1

Contract Title: Thermal Energy Storage by Means of Heat of Solution

Contractor: Franklin Institute Research Laboratories

Principal Investigator: K. W. Kauffman

Contract Amount: $\$ 107,061$

Contract Term: June 22, 1976 to December 31, 1977

Objective: Evaluate the feasibility of thermal energy storage by means of the latent heat of crystallization of solutes from saturated aqueous solutiuns.

Project Description: This study considers a means for TES in the range $0^{\circ} \mathrm{C}$ to $120^{\circ} \mathrm{C}$ using saturated aqueous solutions of salts that dissolve endothermically and have large coefficients of solubility with temperature. Thus, the latent heat of crystallization is continuously released on cooling and absorbed on heating, resulting in enhanced heat capacities relative to pure water. Economic advantage should accrue by virtue of the pumpability of the TES medium. Phase I will select salts for both heating and cooling applications, design a demonstration luop, and gather data for. construction of an engineering prototype; Phase II will build the prototype, carry out tests, and evaluate and report performance data.

Prior Accomplishments: Solutes were selected for several applications: sodium carbonate for cooling, trisodium phosphate for heating, and bortc acid for hot-side air conditioning. Heat exchanger surface fouling (salt deposition) resulted in discontinuation of tests. Problems were encountered with emulsification in an immiscible fluid heat exchange system proposed as an alternative. 
FY 1978 Program: Complete data evaluation and publish final report on Phase I efforts.

Beyond FY 1978: Condition will depend on FY 1978 results.

Schedule:

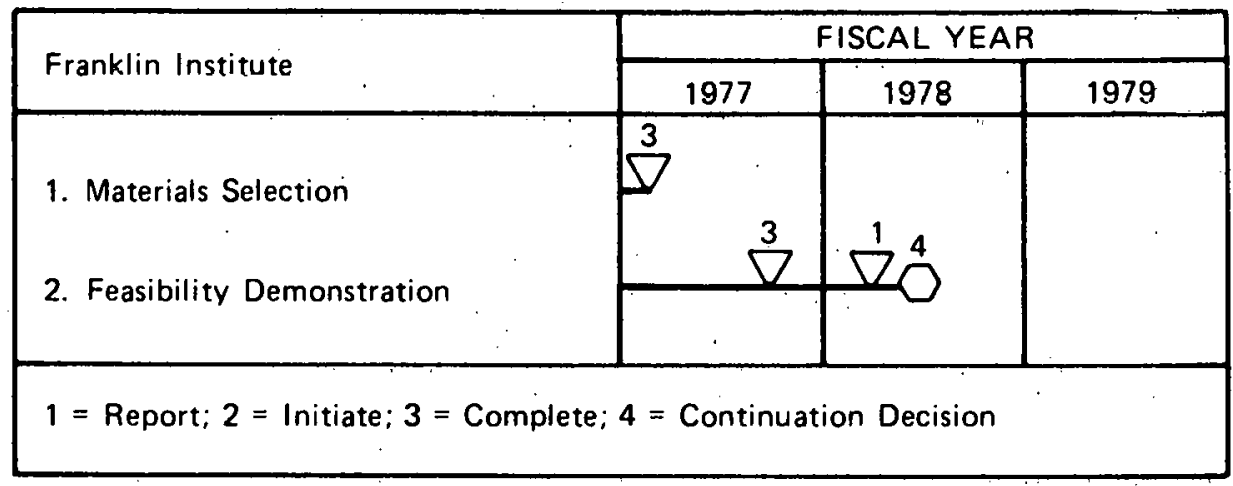


WBS Element: $3 \cdot 2 \cdot 3.1$

Contract Title: Use of Solid-State Phase Transitions for Thermal Energy Storage

Contractor: Villanova University

Principal Investigator: A. J. Leffler

Contract Amount: $\$ 26,205$

Contract Term: June 1, 1977 to August 31, 1978

Objective: Identify materials showing solid-solid phase transitions of sufficient magnitude to be of interest for TES.

Project Description: 'Some solids undergo reversible phase transitions of sufficient magnitude to be of potential use as TES media. While the properties of such solids have been reported in the general literature, there has been no effort to list these materials in respect to their latent heats of transition, availability and cost, chemical and physical stability, solubility in thermal transport fluids, etc. This study will carry out this cataloguing and combine the information into an initial assessment of TES potential.

Prior Accomplishments: Fifteen classes of materiale wcre searclied for appropriate solid-state energy transitions. This search also revealed several theoretical developments that are useful in judging the possibility in given materials for phase transitions of desirable magnitude. 
FY 1978 Program: Samples will be obtained of some of the more promising candidate materials; these will be purified and examined by differential scanning calorimetry to determine the existence and magnitude of solid-state transitions. Where transitions of desired magnitude are observed, related compounds will be procured and studied also.

Beyond FY 1978: Efforts in FY 1979 and beyond will depend on results obtained in FY 1978.

Schedule:

\begin{tabular}{|c|c|c|c|}
\hline \multirow{2}{*}{ Villanova University } & \multicolumn{3}{|c|}{ FISCAL YEAR } \\
\hline & 1977 & 1978 & 1979 \\
\hline 1. Identification Studies & 2 & & \\
\hline
\end{tabular}


WBS Element: 3.2.4.1

Contract Title: Prediction of the Performance of Soldd Sensible Heat Thermal Storage Units

Contractor: Pennsylvania State University

Principal Investigator: F. W. Schmidt

Contract Amount: $\$ 114,000$

Contract Term: July 1, 1975 to December 31, 1977

Objective: Develop a computer model describing the transient response of a solid sensible-heat storage unit in both single-fluid and twoflu1d configurations; develop a methodology for optimizing such units in respect to maximum heat utilization or maximum storage capability.

Project Description: Sensible heat storage is currently the most common method for storing thermal energy. In this category, two basic systems can be identified: (1) wherein the thermal storage medium also serves as the energy transport fluid [e.g., hot water in tanks]; (2) wherein the storage medium is stationary and the energy transport fluid flows over or through the storage material [e.g., hot water and rocks]. This study develops for the latter geometry with discrete fluid passages and continuous storage material elements a transient response model, and validates predictions through experimental measurements.

Prior Accomplishments: Computer models for both one- and two-fluid solid sensible-heat storage units of rectangular and hollow cylindrical storage material have been developed and applied to the optimization. of the design of units initially at uniform temperature. The transient response of a TES unit formed of Feolite (enriched iron ores) to step changes in inlet fluid temperature and flow rates was decermined experimentally; results compared well with analytic predictions. 
FY 1978 Program: Complete documentation of the finite difference programs; complete final project report.

Beyond FY 1978: No further activity under LTTES program aegis is planned.

Schedule:

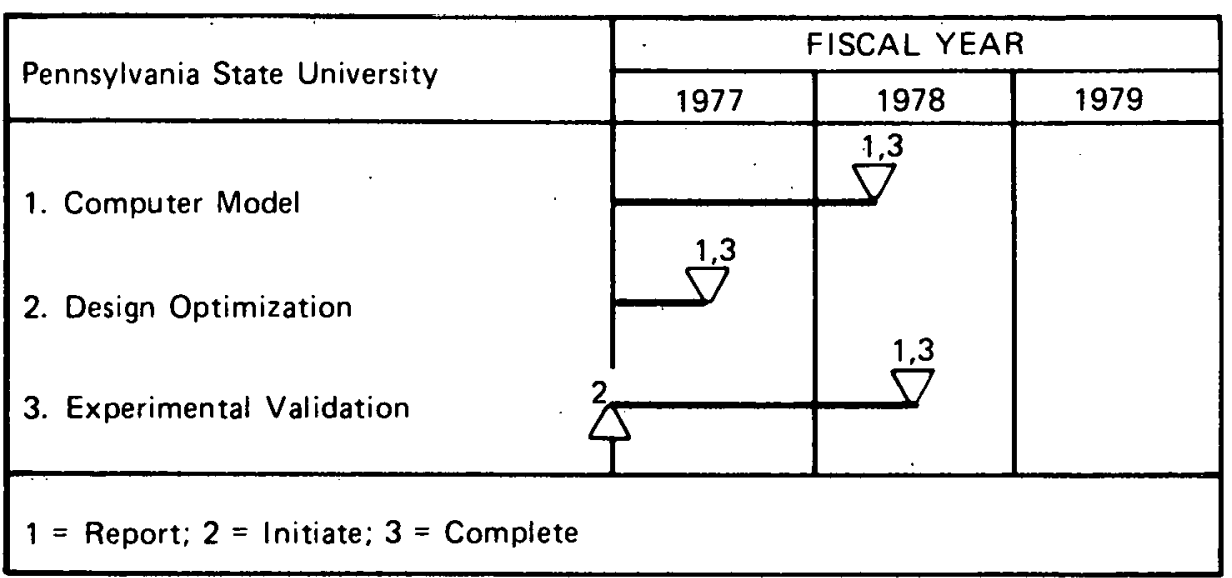




\subsection{Waste Energy Recovery and Reuse Projects (WBS 4.0)}

Projects in this category consider TES as a means for recovering and utilizing thermal energy currently being discarded (rejected) in industrial, commercial, agricultural, and utility operations. Included, for . current convenience, within the compass of "waste energy" is projected utility cogenerated heat (i.e., heat from utility stations designed to produce both thermal and electrical power). In contrast to other TES development areas described, concern here is not with the development of specific TES technology but with the recovery and utilization of waste heat through any appropriate storage technology whether this be considered existing or advanced. The area of industrial waste heat recovery has been accorded particular emphasis.

\subsubsection{Industrial Waste Heat TES Projects (WBS 4.1)}

Industrial production uses about $40 \%$ of the total energy consumed in the United States with the major share of this energy being derived from fossil fuels. Substantial savings in consumption of these nonrenewable energy sources are conceived possible through recovery and storage of waste/ process heat for later use in the production process or for off-site community/commercial utilization.

At least twenty industrial categories have been identified as areas wherein thermal energy storage appears to be both economically and technologically feasible and a necessary component of the energy recovery and reuse system. Within this general domain, two specific industries were identified for Initial funding under the DOE-STOR PRDA to explore technical problems and delineate preliminary economics; namely, primary aluminum manufacture, and food processing. These projects are identified in Table 5.4.1 and described in further detail as WBS Ëlements 4.1.1.1 and 4.1.2.1.

These above two projects should be viewed as pilot projects selected for study under the specific constraints of the PRDA. In the longer range, it is planned to examine in more detail prospects throughout the industrial sphere and, where appropriate, to fund in FY 1979 and beyond other feas 1bility studies. In turn, such studies will lead into prototype demonstrations of waste heat recovery and reuse systems. 
Table 5.4.1. Projects supporting waste heat recovery and reuse through TES technology development

\begin{tabular}{cccr}
\hline WBS Element & Project & Contractor & Status \\
\hline Concept Studies: & characterization and feasibility & & \\
4.1 .1 .1 & Aiuminum industry & Rocket Research Corporation & Active \\
4.1 .2 .1 & Food processing industry & $\begin{array}{l}\text { Westinghouse Electric } \\
\text { Corporation }\end{array}$ & Active \\
4.3 .1 .1 & Crop drying & Lockheed-Huntsville Center & Active \\
\hline
\end{tabular}


WBS Element: 4.1.1.1

Contract Title: Aluminum Industry Reject Heat Capture, Storage, and Utilization

Contractor: Rocket Research Corporation

Principal Investigator: L. B. Katter

Contract Amount: $\$ 89,428$

Contract Term: August 30, 1977 to September 30, 1978

Objective: Determine the technical feasibility and economic incentive for capturing reject heat (as hot water) from the Intalco Aluminum Company primary aluminum plant in Ferndale, WA, storing this heat appropriately, and subsequently using this energy for district heating in Bell1ngham, WA.

Project Description: Feasibility will be examined for recovering heat currently exhausted from the Intalco plant as hot gases and utilizing this energy for residential and commercial heating in nearby communities. The proposed scheme would capture the heat through water heat exchangers located in the exhaust gas ducts, transport the hot water through pipelines to storage near the use point, and distribute the hot water through a district heating system to the users. The storage component compensates for discrepancies between the source availability and use demand protiles.. Associated with Rocket Research in this endeavor are Intalco Aluminum and the Bonneville Power Administration.

Prior Accomplishments: New program funded in FY 1978 under the DOE-STOR "industrial" PRDA. 
FY 1978 Program: The following tasks will be essayed:

1. Survey U.S. primary aluminum industry to establish the potential for conservation through waste energy recovery,

2. Select a heat recovery and storage system,

3. Collect data at Intalco plant on hot gas fiows and temperatures,

4. Delineate interface requirements between aluminum plant source and heat recovery and storage systems,

5. Conduct sizing, performance, and cost analyses,

6. Prepare Intial system design and obtain preliminary economics, and 7. Develop an implementation plan.

Beyond FY 1978: Evaluate aquifers for storage role; further activity will rest on the potential indicated by the feasibility study.

\section{Schedule:}

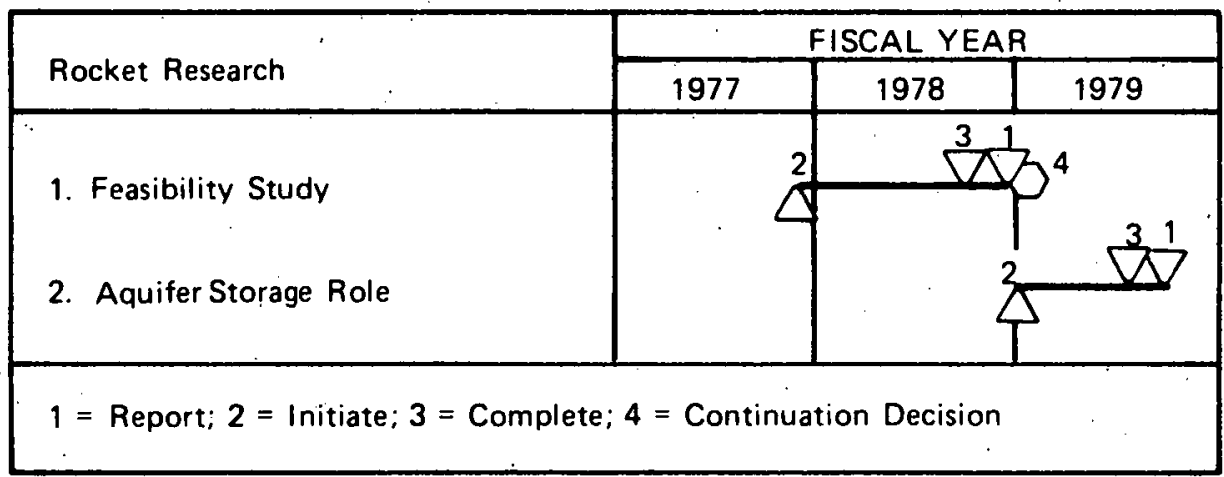


WBS Element: 4.1.2.1

Contract Title: Food Industry Reject Heat Capture, Storage, and Utilization

Contractor: Westinghouse Electric Corporation

Principal Investigator: W. L. Lundberg

Contract Amount: $\$ 96,195$

Contract Term: August 30, 1977 to September 30, 1978

Objective: Determine the technical feasibility and economic incentive for capture reject heat (as hot water) at the H. J. Heinz Company food processing plant in Pittsburgh, PA, storing this heat appropriately, and revising the hot water for later in-plant operations.

Project Description: Feasibility will be examined for recovering hot water currently wasted to the drains during food processing shifts at the Heinz plant and utilizing this heat in subsequent lower temperature operations or in third shift clean up. This study will establish the magnitude of the several hot water sources, propose a storage scheme, and develop preliminary system (capture, store, use) economics. Heinz Company personnel are actively associated with Westinghouse staff in this endeavor.

Prior Accomplishments: New program funded in FY 1978 under the DOE-STOR "industrial" PRDA. 
FY 1978 Program: The following tasks will be carried out:

1. Survey plant process streams to obtain heat balance and reject heat stream temperatures,

2. Estimate potential for energy conservation if this concept were implemented nationally,

3. Prepare conceptual system design and develop preliminary econiomics, and

4. Develop a commercialization plan.

Beyond FY 1978: Further activity will rest on the potential indicated by the feasibility study.

\section{Schedule:}

\begin{tabular}{|l|c|c|c|}
\hline \multirow{2}{*}{ Westinghouse Electric Corporation } & \multicolumn{3}{|c|}{ FISCAL YEAR } \\
\cline { 2 - 4 } 1. Feasibility Study & 1977 & 1978 & 1979 \\
\hline & & 3 & 3 \\
& & & 3 \\
\hline
\end{tabular}

$1=$ Report; $2=$ Initiate; $3=$ Complete; $4=$ Continuation Decision 
WBS Element: 4.3.1.1

Contract Title: Development of a Regenerated Desiccant System for Industrial and Agricultural Drying

Contractor: Lockheed Missile and Space Company - Huntsville Research and Engineering Center

Principal Investigator: D. V. Merrifield

Contract Amount: $\$ 189,608$

Contract Term: July 26, 1976 to December 31, 1977

Objective: Develop and demonstrate technical and economic feasibility of a regenerated desiccant system for agricultural and industrial drying applications.

Project Description: The large quantities of natural and bottled gases now consumed in farm and manufacturing drying operations provide incentive for developing new energy-conserving concepts. This study considers a means whereby the latent heat of vaporization of the water removed is recovered for preheating the dryer air. Moist, cool air from the dryer is circulated through a desiccant-containing column to remove the water. In turn, the diluted desiccant is reconcentrated; and the evaporated water, condensed to preheat the dry air exiting the desiccant column. This project examines the thermodynamics of this process, tests the scheme at lahoratory scale, and develops preliminary economics.

Prior Accomplishments: Data obtained through operation of a bench-scale model, when coupled with systems analysis, have shown that this scheme can reduce the energy consumption by a half over conventional dryers for a fossil fuel heat source. Though capital custs are higher, life-cycle calculations indicate cost competitiveness. 
FY 1978 Program: Efforts will emphasize reducing the installed cost of

a system while maintaining the high energy conservation potential;

thus, the following tasks will be undertaken:

1. Develop, install, and test improved regeneration techniques and/or configurations using the bench-scale model,

2. Design and determine the performance of a system using solar energy for the heat source,

3. Carry out mathematical modeling and component trade-off studies to define an optimum system, and

4. Apply results to specific drying applications so as to establish the conservation potential.

Beyond FY 1978: Transfer technology for demonstration and commercialization to appropriate DOE divisions, other federal agencies, or private organizations.

Schedule:

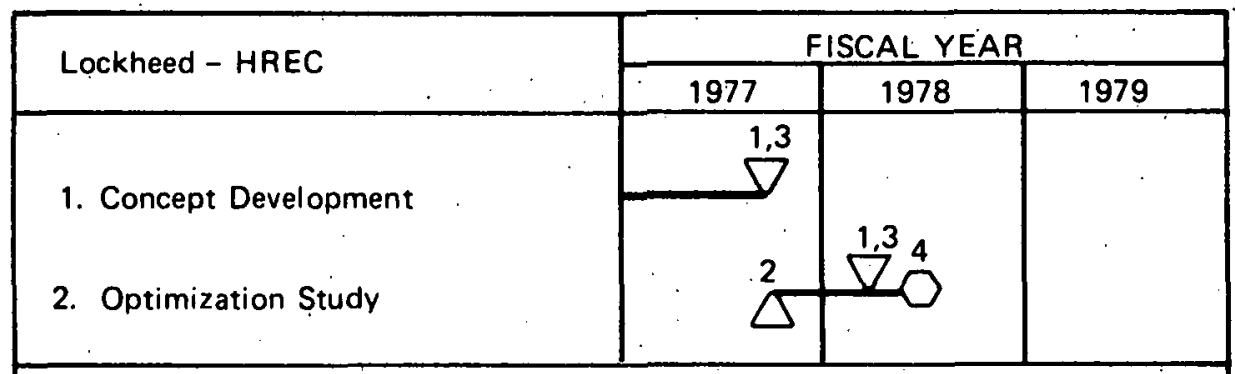

$1=$ Report; 2 = Initiate; $3=$ Complete; 4 = Continuation Decision 


\subsubsection{Agricultural Waste Heat Projects (WBS 4.3)}

Agricultural uses of energy involve principally fueling of equipment, heating and/or cooling of animal shelters, pumping of water, and processing of crops. This latter area of crop and grain drying alone consumes about one quad per year generated from the burning of natural gas and propane. Energy recovery schemes, with or without a solar heat source, could significantly reduce this usage.

The only project currently funded in this area involves a regenerated desiccant crop-drying scheme; th1s is 1isted in Table 5.4.1 and described as WBS Element 4.3.1.1. On the completion of this project early in FY 1978, no further activity is scheduled in this area.

\subsubsection{Commercial Waste Heat TES Projects (WBS 4.2)}

No activity is planned for FY 1978 in this area.

\subsubsection{Utility Cogenerated Heat TES Projects (WBS 4.4)}

Limited activity in this area is described in Section 5.2.1 relative to the Minneapolis/St. Paul District Heating Project. . 


\subsection{Support R\&T and Systems Studies Projects (WB 5.0)}

A limited but significant effort on the more basic aspects of TES concepts and on the role and economics of TES is necessary to the productive development of such systems. In the main, these activities are carried out In-house ( $1 . e$. , by ORNL staff) or by subcontracts in direct support of ORNL studies. Work in each of these specific areas (concept evaluation, materials characterization, and component performance) are considered separately below.

\subsubsection{Concept Evaluation (WBS 5.1)}

Development of a TES concept requires, in addition to the solution of technical (physical) problems and demonstration of performance, that the role of the particular concept in the energy utilization matrix be defined in respect to need, economic, environmental, institutional, and legal parameters. This area - relegated perhaps arbitrarily to support activity is therefore significant in the decision to move a concept to demonstration.

In FY 1978, activity concentrates on these several pertinent aspects of aquifer season storage systems (see Table 5.5.1 and WBS Elements 5.1.1.1, 5.1.1.2, 5.1.1.3, and 5.1.2.2). One study in this category (WBS 5.1.3.1) on residential furnace TES is a completion of a limited activity initiated in FY 1977.

\subsubsection{Materials Characterization (WBS 5.2)}

An understanding of the behavior of the substances involved in thermal storage systems (the storage agent as well as any containment materials) is necessary to development of a viable system. Intrinsic performance (e.g., nucleation with PCM's) and containment interactions (e.g., corrosion and heat transfer) are vital factors in developing both the technical feastbility and the economic performance (lifetime, containment costs, etc.).

Studies in FY 1978 concentrate on PCM behavior (see Table 5.5.1, WBS Elements 5.2.1.1 through 5.2.1.6 and 5.2.2.1). Emphasis is on behavior in modular units, though thermal and corrosion characteristics of PCM's in a concrete matrix are considered. Work on the geochemistry of aquifer 
systems has been considered necessary to seasonal storage in aquifers but is not currently funded.

\subsubsection{Component Performance (WBS 5.3)}

TES systems w1ll interface with energy sources and energy sinks (demands) through a variety of mechanical components, some of which are standard while others may currently either be nonexistent or operating in nonstandard modes. Activity in this area will define needs, establish avallabilities, develop devices, and test components.

FY 1978 activity is limited to the completion of a study estabilshing the availability, cost, and performance of gas-to-gas heat exchangers relative to waste heat recovery (Table 5.5.1, WBS Element 5.3.1.1). 
Table 5.5.1. Systems studies and research in support of TES technology development

WBS Element Project Contractor $\quad$ Status

\section{Concepts: characterization and feasibility}

5.1.1.1 National aquifer TES opportunities

5.1 .1 .2

5.1 .1 .3

5.1 .2 .2

5.1 .3 .1

Residential furnace TES
TBD by RFP

Tennessee Valley Authority

Oak Ridge National Laboratory

Oak Ridge National Laboratory

TRW-Energy Systems

Materials: fundamentals and behavior
5.2 .1 .1

5.2 .1 .2

5.2 .1 .3

5.2 .1 .4

5.2 .1 .5

5.2 .1 .6

5.2 .2 .1
PCM nucleation

PCM properties and behavior

Hydrated salt crystal structure

Math modeling of PCM processes

Physical modeling of .PCM processes

Thermal performance

Concrete PCM behavior
Desert Research Institute

Oak Ridge National Laboratory

Oak Ridge National Laboratory

Oak Ridge National Laboratory

Oak Ridge National Laboratory

Oak Ridge National Laboratory

Oak Ridge National Laboratory
Planned

Planned

Planned

Planned

Active

Active

Active

Active

Active

Planned

Planned
Planned

Components: availability and performance

5.3.1.1

Heat exchangers

TRW-Energy Systems

Active 
WBS Element: 5.1.1.1

Contract Title: Low-Temperature Thermal Energy Utilization Through Aquifer Storage-Avallability and Suitability of Sources, Storage Sites, and Applications

Contractor: To be developed through the RFP process

Principal Investigator: Not yet identifled

Contract Amount: $\$ 200,000$ (maximum)

Contract Term: October 1, 1978 through March 31, 1979 (anticipated)

Objective: Identify and describe opportunities for the acquisition and ut1lization of wasted or untapped thermal energy (hot or cold) for seasonal applications through aquifer storage.

Project Description: This study will delineate the national potential for acquiring and utilizing through aquifer storage such energy sources as industrial waste heat, winter-chill, etc., to satisfy seasonal residential/commercial energy demands. This is to be accomplished through survey of sources and storage sites and identification of appropriate applications, integration of the data obtained in a format exposing opportunities, and development and implementation of a methodology for ranking these opportunities. These results are to be used to judge the potential impact of aquifer storage on national energy conservation and to identify "most promising" opportunities for in-depth technical and economic evaluations.

Prior Accomplishments: None; new program. 
FY 1978 Program: Develop RFP work statement; initiate procurement. Beyond FY 1978: During FY 1979, the contractor will carry out the following tasks:

1. Identify and characterize sources of waste thermal energy sufficiently large and concentrated as to merit consideration for season use (heating or cooling) and develop a methodology for assessing the suitability of such sources.

2. Where appropriate sources exist; survey existing hydrologic data to determine the availability of accessible aquifers.

3. Where both source and storage capability exist, identify and characterize application opportuntities (existing or potential).

4. Develop and implement a methodology for integrating the source; storage site, and application data in a format facilitating the identification of opportunities.

5. Develop a methodology for ranking the opportunities identified on the basis of relative technical advantages.

\section{Schedule:}

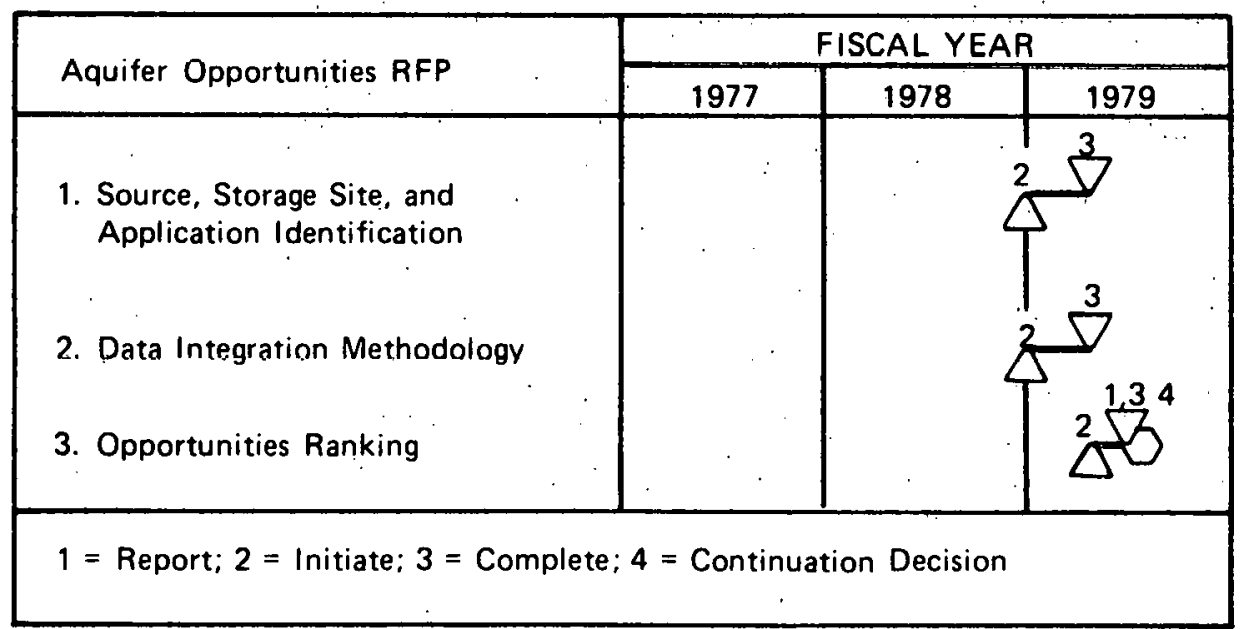


WBS Element: 5.1.1.2

Contract Title: Aquifer Storage Opportunities in Tennessee Valley Authority (TVA) Region

Contractor: Tennessee Valley Authority

Principal Investigator: TBD*

Contract Amount: TBD

Contract Term: TBD

Objective: Survey TVA service area to identify combinations of sources of waste or cogenerated heat, probable storage aquifers, and potential stored heat uses.

Project Description: TVA will carry out a detalled examination of thermal energy storage opportunities in 1 ts service area and will identify specifically those where aquifer storage seems feasible and profitable. This is to take into account TVA plans or prospects for cogenerated heat, describe waste heat sources and magnitudes available from industries in the TVA region, propose viable utilization schemes, and investigate aquifer availability. Subsequent efforts would establish aquifer suitability and provide systems details on which to base demonstration project decisions.

Prior Accomplishments: New project planned in FY 1978.

$\star$ To be developed. 
FY 1978 Program: Submit description of work scope and cost estimate; initiate survey.

Beyond FY 1978: Complete survey of heat sources, aquifer avallability, and potential applications within TVA service area. Develop plans for aquifer characterizations and carry out systems studies to identify best locations for demonstrations; initiate one or more appropriate demonstrations.

Schedule: TBD 
WBS Element: 5.1.1.3

Contract Title: Aquifer Storage Environmental Assessment

Contractor: Oak Ridge National Laboratory - Energy Division

Principal Investigator: E. K. Triegel

Contract Amount: $\$ 25,000$

Contract Term: FY 1978

Objective: Assess the environment impact of storing low-temperature heat in aquifers.

Project Description: Aquifers have been proposed as the vehicle for seasonal storage of hot and cold waters. The study will develop a generic environmental impact assessment (EIA) covering the LTTES program on aquifers TES in accordance with the requirements for environmental review contained in 10CFR1021. This w11l include a statement of the proposed Federal actions, a description of the existing affected environment, an assessment of potential environmental impacts, a determination of institutional problems, and a listing of reasonable alternatives to the proposed actions. Subsequent work may focus on specific projects.

Prior Accomplishments: None; new program in FY 1978. 
FY 1978 Program: Define the level of environmental statement that will be required for the aquifer program.

Beyond FY 1978: Complete the generic EIA; highlight problem areas in specific applications.

Schedule:

\begin{tabular}{|l|r|r|r|}
\hline \multirow{2}{*}{ ORNL - Environmental Assessment } & \multicolumn{3}{|c|}{ FISCAL YEAR } \\
\cline { 2 - 4 } 1. Generic Environmental Assessment & 1977 & 1978 & 1979 \\
2. Speçific Sites & & 2 & \\
\hline $1=$ Report; 2 = Initiate; 3 = Complete & & & \\
\hline
\end{tabular}


WBS Element: $5 \cdot 1 \cdot 2.2$

Contract Title: Economic Evaluations of Low-Temperature TES Aquifer Storage Projects

Contractor: Oak Ridge National Laboratory - Engineering Technology Division

Principal Investigator: E. C. Fox

Contract Amount:

Contract Term: Initiated

Objective: Support LTTES program staff through economic evaluations of aquifer energy storage projects.

Project Description: The cost effectiveness, potential fuel saving, and rate of return on capital investment will be determined for the several proposed aquifer energy storage systems being examined under the LTTES program. These studies will develop an independent evaluation methodology. The results will be used by the LTTES program, in conjunction with similar estimates prepared by project subcontractors, to establish the cost advantage of seasonal storage through aquifers.

Prior Accomplishments: New program in FY. 1978. 
FY 1978 Program: Initiate a preliminary economic evaluation of the JFK airport cold-water aquifer storage project.

Beyond FY 1978: Continue support of LTTES efforts on other aquifer storage projects as these develop.

Schedule:

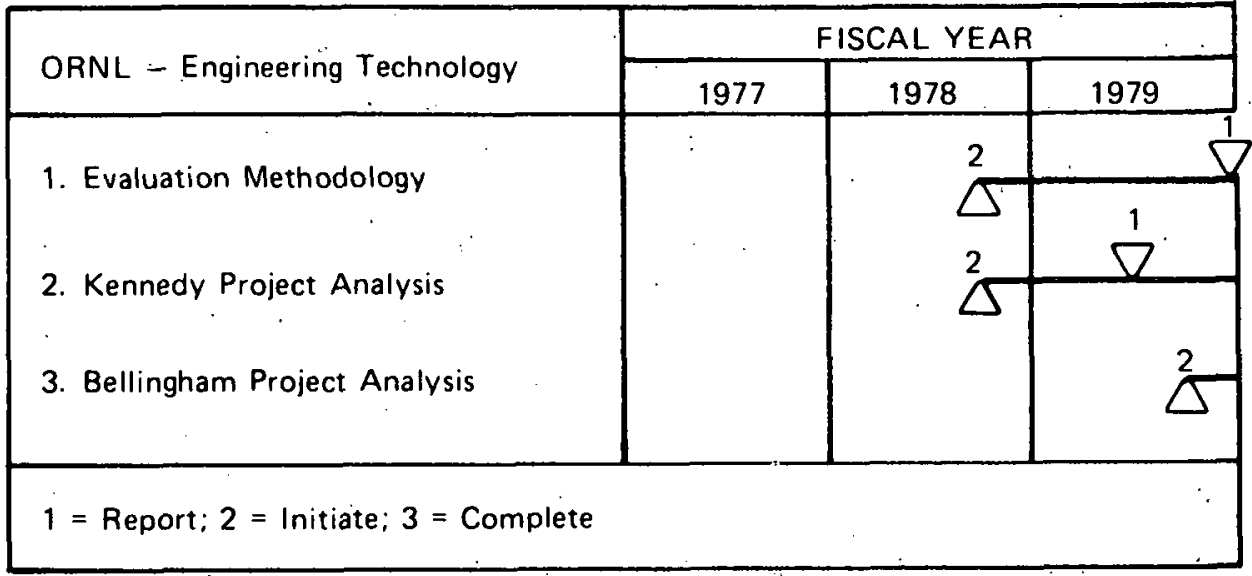


WBS Element: 5.1.3.1

Contract Title: Fossil Energy Home Heating Furnace Efficiency

Improvement Using Thermal Energy Storage

Contractor: TRW-Energy Systems Group

Principal Investigator: R. Gorman

Contract Amount: $\$ 7200$

Contract Term: April 1977 through October 1978

Objective: Determine the feasibility of Integrating thermal energy storage into an existing fossil-fired home heating system to increase system effectiveness and efficiency.

Project Description: Hot-air heating from fossil-fired furnaces is common in the U.S. Because of the economic trade-off between heat exchanger size and the cost of energy saved, current practice exhausts a significant amount of energy as hot combustion gases to the furnace flue. This study will develop a conceptual design for a system to recover this waste heat through TES, determine system performance for representative heating systems, and perform preliminary cost estimation.

Prior Accomplishments: Based on a pebble-bed TES design, analysis showed that the seasonal average performance of a typical warm air furnace could be increased from $55 \%$ to about $96 \%$. On furnace startup, combustion gases pass through the storage bed to capture both the sensible heat of the gases and the latent heat of vaporization of the water vapor. Following, purging of residual combustion products, household air can be circulated through the bed to recover the stored heat. The improved efficiency is associated primarily with the recovery of the latent heat of vaporization of water. 
FY 1978 Program: Complete and publish final report; consider experiment to test concept and develop optimum performance parameters.

Beyond FY 1978: No activity planned.

Schedule:

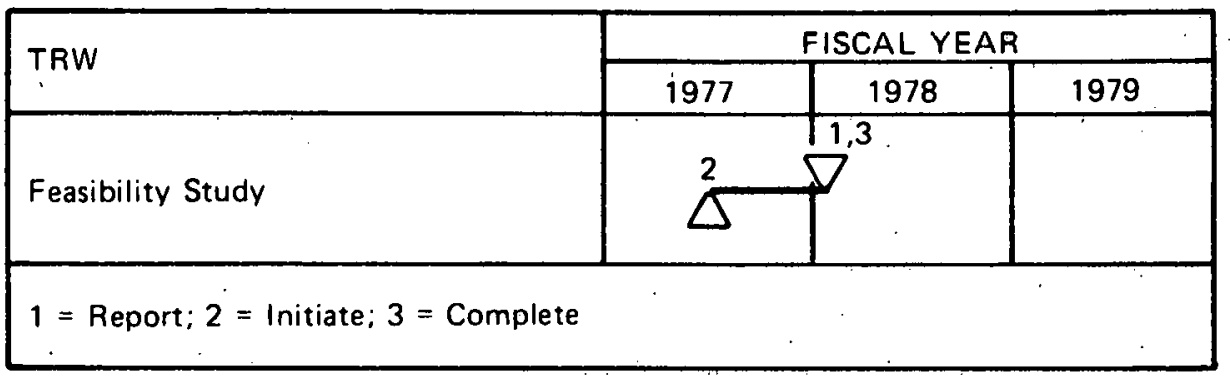


WBS Element: 5.2.1.1

Contract Title: Studies of a Salt Hydrate Heat Storage System Contractor: Desert Research Institute (UnIversity of Nevada)

Principal Investigator: J. Hallett

Contract Amount: $\$ 176,000$

Contract Term: July 1, 1975 to August 31, 1978

Objective: Develop the physical criteria for crystal growth and secondary crystal production for salt hydrates; design and operate a pilot system based on these criteria utilizing conc1nuous crystallizatlun and sedimentation to give an essentially unencumbered heat transfer surface.

Project Description: Production by agitation of small secondary crystals in the bulk of a salt hydrate solution with subsequent growth and fallout is proposed as a means for achieving a constant heat flux in a heat of fusion TES system. To this end, this study investigates the microphysical characteristics of crystallization (nucleation, crystal growth velocity and habit, and crystal fall velocity) in a series of benchscale experiments with three hydrated salts having transition temperatures of $32.5,48$, and $58^{\circ} \mathrm{C}$ appropriate to solar systems using flatplate collectors. The performance of each of these salts will also be examined in tests lnvolving both solid heat exchange surfaces and immiscible heat exchange fluids.

Prior Accomplishments: Reproducible supercooling was observed with small samples of all three salts; crystallization velocities were proportional to the square of the supercooling. Falling crystals grow at a higher rate than do stationary crystals; and, for supercoolings $>6^{\circ} \mathrm{C}$, copious secondary crystals are produced in the wake of the falling crystal. 
FY 1978 Program: Fundamental studies w1ll be carried out to determine the effects of fluid flow (velocity and turbulence level) on crystal growth habit, crystallization velocity, and production of secondary crystals. Bounds will be determine for flow rate, local supercooling, and turbulence level for a system that utilizes a large fraction of the salt latent heat and does not permit sedimentation of the anhydride. Beyond FY 1978: Continuing work will depend on the results obtained in FY 1978.

Schedule:

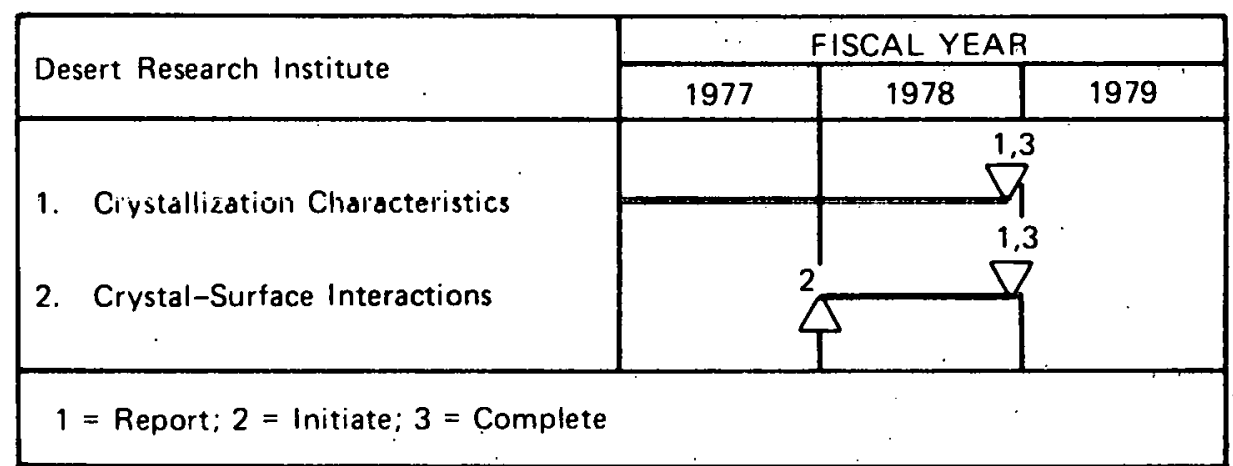


WBS Element: 5.2.1.2

Contract Title: Thermophysical Properties and Behavioral Characteristics of Phase-Change Materials

Contractor: Oak Ridge Natłonal Laboratory - Chemistry Division (1)

Princlpal Investigator: S. Cantor

Contract Amount: $\$ 100,000$ (FY 1977); $\$ 90,000$ (FY 1978)

Contract Term: Initiated October 1, 1976; extended annually

Objective: Investigate the physical and thermal properities of phase-change materials having potential for heat storage in absorption air-conditioning systems $\left(90^{\circ} \mathrm{C}\right.$ to $250^{\circ} \mathrm{C}$ temperature range)

Project Description: Compounds and mixtures melting in the temperature range $90^{\circ} \mathrm{C}$ to $250^{\circ} \mathrm{C}$ will be surveyed as to suitability for isothermal heat storage; initial criterla will be magnitude of the latent heat of fusion, thermal stability material avallability and cost, corrosion characteristics and toxicity. The properties of successful candidates will be listed in a compllation showing not only published data but also the results of limited current measurements filling in data gaps. Laboratory instruments, including the differential scanning calorimeter (DSC), w11l be assembled to provide rapid in-house capability for evaluating the chemical and thermal behavior of PCM's.

Prior Accomplishments: Screening of organic compounds in terms of bulk price, thermal stability, and safety yielded seven compounds of attrac-. tive cost (less than $\$ 1.10 / \mathrm{kg}$ ), of reasonable chemical stability, and minimum toxicity. Of these seven, four (urea, phtalamide, adipic acid, and phthalic anhydride) were examined by DSC. Urea was found to have the most favorable heat of fuston per unit cost but exhibited a decrease in both melting temperature and heat of fusion when thermally cycled and showed supercoollng. Two well-characterlzed PCM's were studied with the DSC to test its applicability for rapid evaluation of thermal decomposition and supercooling; the results confirmed (and extended) data on thermal performance characteristics obtalned by other means. 
FY 1978 Program: Complete compilation of PCM's suitable for absorption air-conditioning application. Continue DSC measurements on such PCM!s as $\mathrm{Na}_{2} \mathrm{SO}_{4} \cdot 10 \mathrm{H}_{2} \mathrm{O}$, polyethylene, urea, and other organic materials.

Beyond FY 1978: Continue general support of LTTES activity in developing PCM heat storage systems.

Schedule:

\begin{tabular}{|c|c|c|c|}
\hline \multirow{2}{*}{ ORNL - Chemistry (1) } & \multicolumn{3}{|c|}{ FISCAL YेEAR } \\
\hline & 1977 & 1978 & 1979 \\
\hline \multicolumn{4}{|l|}{ 1. PCM Characteristics } \\
\hline \multicolumn{4}{|l|}{ 2. Compilation $\left(90-250^{\circ} \mathrm{C}\right)$} \\
\hline 3. Measurement Techniques & & & \\
\hline $1=$ Report $; 2=$ Initiate $3=$ & & & \\
\hline
\end{tabular}


WBS Element: 5.2 .1 .3

Contract Title: Crystal Structures of Salt Hydrates for Thermal Energy Storage

Contractor: Oak Ridge National Laboratory - Chemistry Division (2)

Principal Investigator: W. R. Busing

Contract Amount: $\$ 80,000$ (FY 1977); $\$ 15,000$ (FY 1978)

Contract Term: Inttiated October 1, 1976; extended annually

Objective: Determine the crystal structures of hydrated salts and their nucleators at the atomic level; use this information to develop models in terms of atom-atom potential functions; develop criteria for predicting the efficacy of a salt as a nucleator for other hydrated salts.

Project Description: Neutron diffraction w1ll be used to determine the crystal structures of salt hydrates and their known nucleators. These experimental measurements will yield the coordinates and thermal motion parameters of a1l atoms including hydrogen. Atom-atom potential function models will be used to identify posstble nucleators for hydrated salts where empirical knowledge is lacking.

Prior Accomplishments: - The structures of Glauber's salt $\left(\mathrm{Na}_{2} \mathrm{SO}_{4} \cdot 10 \mathrm{H}_{2} \mathrm{O}\right)$. and its known nucleating agent, borax $\left(\mathrm{Na}_{2} \mathrm{~B}_{4} \mathrm{O}_{7} \cdot 10 \mathrm{H}_{2} \mathrm{O}\right)$ were determined by single-crystal neutron diffraction measurements; similarity in cell parameters and in the cation chains are probably important to understanding the nucleating characteristics. Similar studies on sodium thiosulfate pentahydrate $\left(\mathrm{Na}_{2} \mathrm{~S}_{2} \mathrm{O}_{3} \cdot 5 \mathrm{H}_{2} \mathrm{O}\right)$ were also completed. 
FY 1978 Program: Crystal structure studies will be discontinued at the end of the first quarter.

Beyond FY 1978: No work is planned.

Schedule:

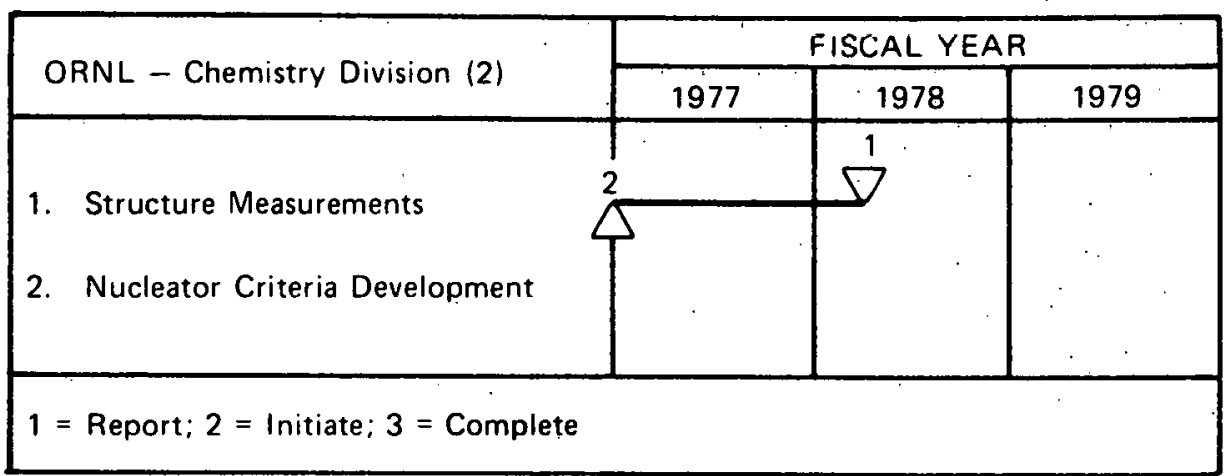


WBS Element: 5.2.1.4

Contract Title: Mathematical Modeling of Moving Boundary Problems with Phase-Change Materials

Contractor: Oak Ridge National Laboratory - Computer Sciences Division

Principal Investigator: A. D. Solomon

Contract Amount: Initiated October 1, 1976; extended annually

Contract Term: $\$ 50,000$ (FY 1977); $\$ 50,000$ (FY 1978)

Objectlve: Develop a computer model of the moving boundary phase-change mechanism in the context of a latent heat TES proçess; analytical support of the LTTES program.

Project Description: A computer model is to be developed describing the melt-freeze boundary movement in a PCM actively storing or discharging heat. The initial model will be based on a one-dimensional, timedependent solution of the moving boundary conduction equation in slab, cylindrical, and spherical geometries. The model will then be coupled to various heat sources and sinks and exercised to describe the thermal performance of a TES system. Subsequent extensions of the model will attempt to incorporate more reality, such as the inclusion of density varlations.

Prior Accomplishments: The analytic basis for the model was developed, and writing of the computer program was initiated. The melt time of a PCM cylinder, the effect of a container wall, the influence of density changes, conductivity enhancement, and the periodic boundary temperature for a PCM slab were studied analytically. 
FY 1978 Program: Activities during FY 1978 will include the following:

1. Comparison of the computer model and the analytical results with available experimental data.

2. Coupling of the computer model with a variety of heat sinks and sources.

3. Sensitivity and parametric analyses for selected sṭtuations.

Beyond FY 1978: Documentation and distribution of the computer model

will be completed. Extension of the model to account for density

variations and free convection will be attempted.

\section{Schedule:}

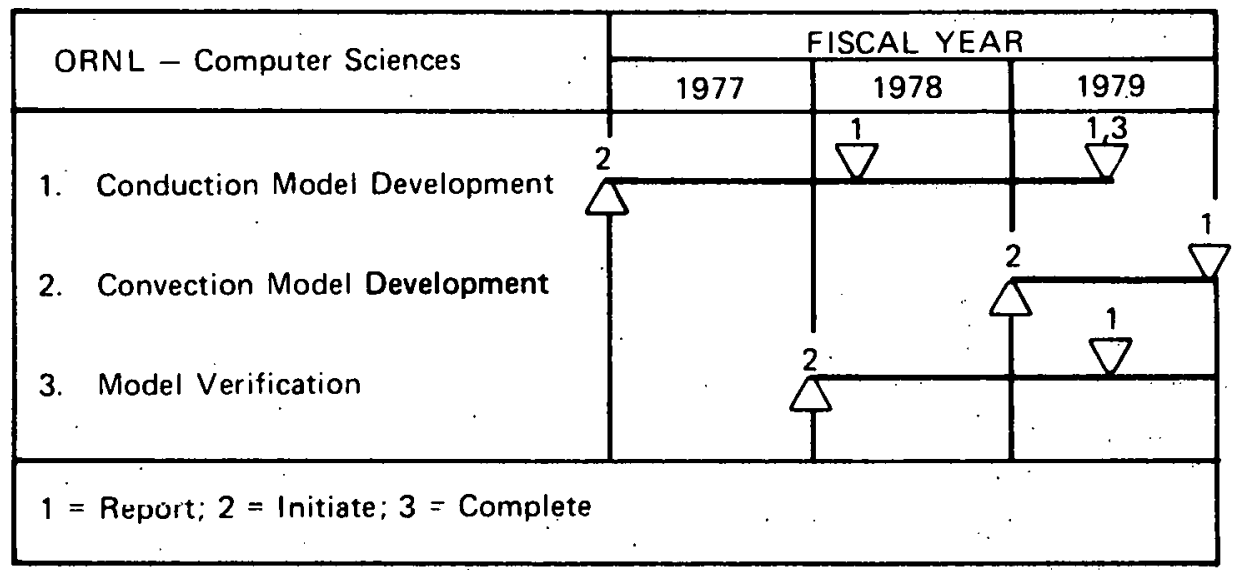


WBS Element: 5.2 .1 .5

Contract Title: Thermal Transport in Systems Involving PCM's for TES

Contractor: Oak Ridge National Laboratory - Engineering Technology Diviston

Principal Investigator: R. M. Deal

Contract Amount: $\$ 20,000$

Contract Term: Initiated April 1, 1978; extended annually

Objective: Study experimentally thermal transport phenomena at the liquidsolid (melt-freeze) boundary in a PCM actively storing (or releasing) the latent heat of phase change; determine the effects of natural convection, temperature stratification, and conductivity enhancing additives on system behavior; acquire data for use in verifying the analytical models being developed (WBS 5.2.1.4)

Program Description: The successful development of TES systems utilizing the latent heat of PCM's is inhibited by the variable thermal resistance associated with solid phase buildup on the heat exchange surfaces. Thermal transport behavior associated with this condition will be studied in a small (bench-scale) loop utilizing a circulating water stream of variable temperature to effect thermal cycling of a PCM in a channel of selected geometry. Photography and temperature measurements will he combined to obtain phenomenological descriptions. The effects of thermal mechanisms and geometry will. be determined. These experiments will. interface with the effort on computer modeling (WBS 5.2.1.4),

Prior Accomplishments: New program in FY 1978. 
FY 1978 Program: Activities in this period will include:

1. Design and fabricate a thermal cycling loop and a test section.

2. Initiate tests for use in validating the conduction computer model.

Beyond FY 1978: Complete conduction simulation experiments; initiate experiments to determine effects of natural convection, temperature stratification, and conductivity enhancement on melt-freeze boundary movement velocity and overall heat transfer; carry out tests in multi$\mathrm{rod} / \mathrm{multitube}$ geometries.

\section{Schedule:}

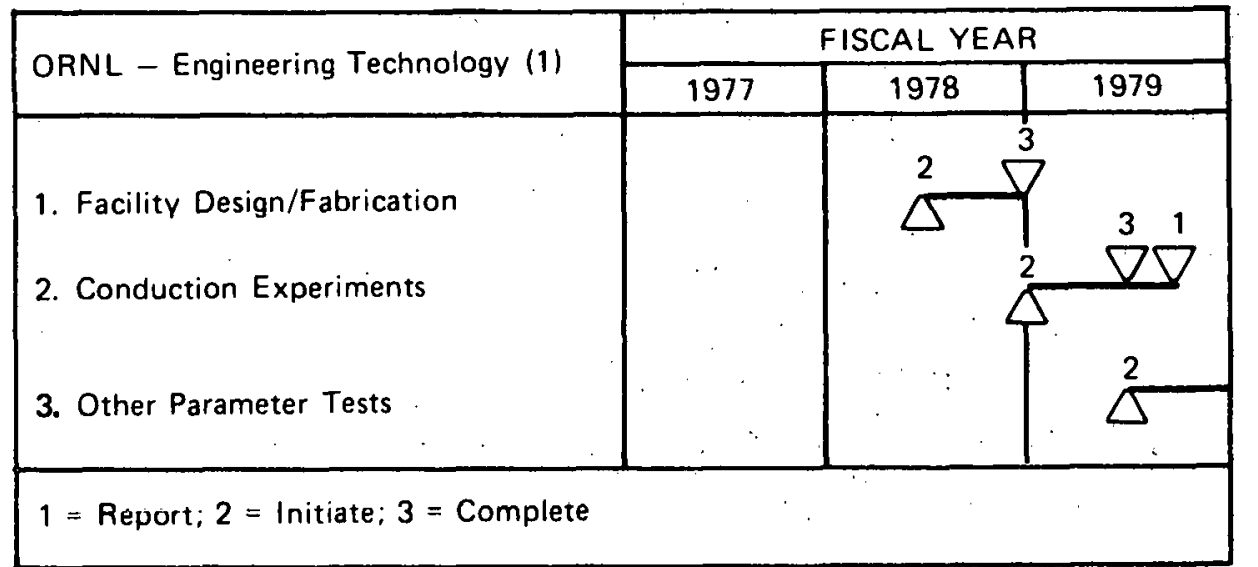


WBS Element: 5.2.1.6

Contract Title: Thermal Performance of TES Units

Contractor: Oak Ridge National Laboratory - Engineering Technology Division

Principal Investigator: R. J. Ked1

Contract Amount:

Contract Term:

Objective: Determine the response of prototypical TES units based on latent heat storage to thermal cycles simulating natural energy inputs and demands.

Project Description: LTTES efforts on developing PCM thermal storage concepts have thus far addressed the technical feasibility and preliminary economics. A number of such projects have now reached the stage where prototypical units have been or can be constructed; testing of such units for realistic but simulated thermal inputs and demands is indicated. To this purpose, two recirculating loops will be assembled: in one, the thermal transport fluld will be water; in the other, air. These loops will be able to test units having thermal capacities of 50,000 to $500,000 \mathrm{Btu}$. The results obtalned will guide further development of these concepts.

Prior Accomplishments: None; new project in FY 1978. 
FY 1978 Program: Activity in this period will be limited to the design of the liquid transport loop and the initiation of procurement on long-lead components.

Beyond FY 1978: Complete assembly of the 11quid transport 1oop; perform check-out tests with a hot-water (sensible heat) storage device; initiate tests with advanced-concept units provided by other elements of the LTTES program.

Design and fabricate a second test facility using air as the thermal transport fluid; check-out with a solid, sensible-heat (rock bed) unit, and initiate tests on supplied prototypes.

Schedule:

\begin{tabular}{|c|c|c|c|}
\hline \multirow{2}{*}{ ORNL - Engineering Technology (2) } & \multicolumn{3}{|c|}{ FISCAL YEAR } \\
\hline & 1977 & 1978 & 1979 \\
\hline $\begin{array}{l}\text { 1. Liquid Loop-Assembly and } \\
\text { Checkout } \\
\quad \text { - Prototype Tests } \\
\text { 2. Air Loop-Assembly and Checkout } \\
\text { - Prototype Tests }\end{array}$ & & $\Delta^{2}$ & $\frac{3}{\Delta}$ \\
\hline $1=$ Report $; 2=$ Initiate; $3=$ Complete & & & \\
\hline
\end{tabular}


WBS Element: 5.2.2.1

Contract Title: Behavior of Concrete in Presence of PCM's

Contractor: Oak Ridge National Laboratory .

Principal Investigator: D. J. Naus

Contract Amount: $\$ 10,000$

Contract Term: Initiated July 1, 1978; extended annually

Objectfve: Elucidate the behavior of concretes in the presence of PCM's.

Project Description: LTTES is investigating several concepts for incorporating PCM's into concreces. Of signilicant concern to this cffort is the potential interaction between the concrete and any given PCM in respect to both physical expansion due to phase change and chemical reaction between the PCM and the concrete. This task will provide inhouse support to LTTES management in evaluating such effects as discovered in the several experimental efforts; limited in-house experiments will be considered where deemed appropriate to developing understanding. Prior Accomplishment: None 
FY 1978 Program: Activity in FY 1978 will be limited to discovering the cause of swelling and concrete breakdown in the $\mathrm{CaCl}_{2}$-infused concrete blocks being developed (WBS Element

Beyond FY 1978: Activities will be limited to technical consultative support.

Schedule: Intermittent activity as requested by LTTES program management. 
WBS Element: 5.3.1.1

Contract Title: Evaluation of Heat Recovery Methods

Contractor: TRW-Energy Systems Group

Principal Investigator - D. Goldenberg

Contract Amount: $\$ 15,000$

Contract Term: April 1977 through October 1977

Objective: Catalogue cost/performance relationships for commercially available gas-to-gas heat exchangers and air-cleaning devices.

Project Description: Energy recovery from low-temperature gas waste heat streams for reuse through storage is one element of the LTTES program. This cffort will provide initial information on the custs and performance of commercially available heat exchangers and gas-stream cleaning equipment of potential application in heat recovery. The data obtained through survey of manufacturers will be collated and catalogues in a form useful to the LTTES effort.

Prior Accomplishments: Data on heat exchange equipment were obtained from 32 U.S. equipment manufacturers of plate and fin, shell and tube, heat pipe, or heat wheel exchangers and electrostatic, centrifugal, or filter air cleaners. A methodology was developed for evaluating the thermodynamic and economic feasibility of various schemes for recovering, storing, and utilizing waste heat. The study concluded that (1) suit-. able heat exchange and air-cleaning devices are available as off-theshelf items, (2) heat transport costs are peculfar to each installation and vary widely, (3) plate and fin heat exchangers are most economical, and (4) waste heat recovery is economically feasible but identification of specific applications requires a total system's analysis including cost optimization. 
FY 1978 Program: Complete and publish final report.

Beyond FY 197.8: No further effort planned.

Schedule:

\begin{tabular}{|l|c|c|c|}
\hline \multirow{2}{*}{ TRW } & \multicolumn{3}{|c|}{ FISCAL YEAR } \\
\cline { 2 - 4 } & 1977 & 1978 & 1979 \\
\hline Data Compilation and Evaluation & 2 & & \\
\hline 1 = Report; 2 = Initiate; 3 = Complete & \multicolumn{3}{|c|}{} \\
\hline
\end{tabular}




\section{THIS PAGE WAS INTENTIONALLY LEFT BLANK}




\subsection{PROGRAM BUDGETS}

The fiscal resource requirements are summarized in Tables 6.1.1 through 6.1.3; these tables give, respectively, the consolidated budget, a detailed breakdown by thrust, and a breakdown by funding source.

Table 6.1.1. LTTES program consolidated budgets ${ }^{a}$ (FY 1978)

\begin{tabular}{|c|c|c|c|}
\hline Program thrust & $\frac{F Y 1978}{\left(\$ \frac{B A}{\text { in } t r}\right.}$ & $\frac{\text { budget }}{\frac{\mathrm{BO}}{\text { usands) }}}$ & $\begin{array}{c}\text { WBS } \\
\text { Element }\end{array}$ \\
\hline Seasonal storage & 902 & 537 & 2.0 \\
\hline Daily/short-term storage & 370 & 460 & 3.0 \\
\hline Waste energy recovery and reuse & 195 & 205 & 4.0 \\
\hline Support R\&T/systems studies & 230 & 285 & 5.0 \\
\hline Management & $355^{b}$ & $380^{\mathrm{b}}$ & 1.0 \\
\hline & 2052 & 1867 & \\
\hline
\end{tabular}

${ }^{a}$ Includes funds from all sources.

${ }^{b}$ Includes costs of $100 \mathrm{BA} / 125$. BO for TRW subcontract. 
Table 6.1.2. LTTES program FY 1978 budget detalls by thrusts

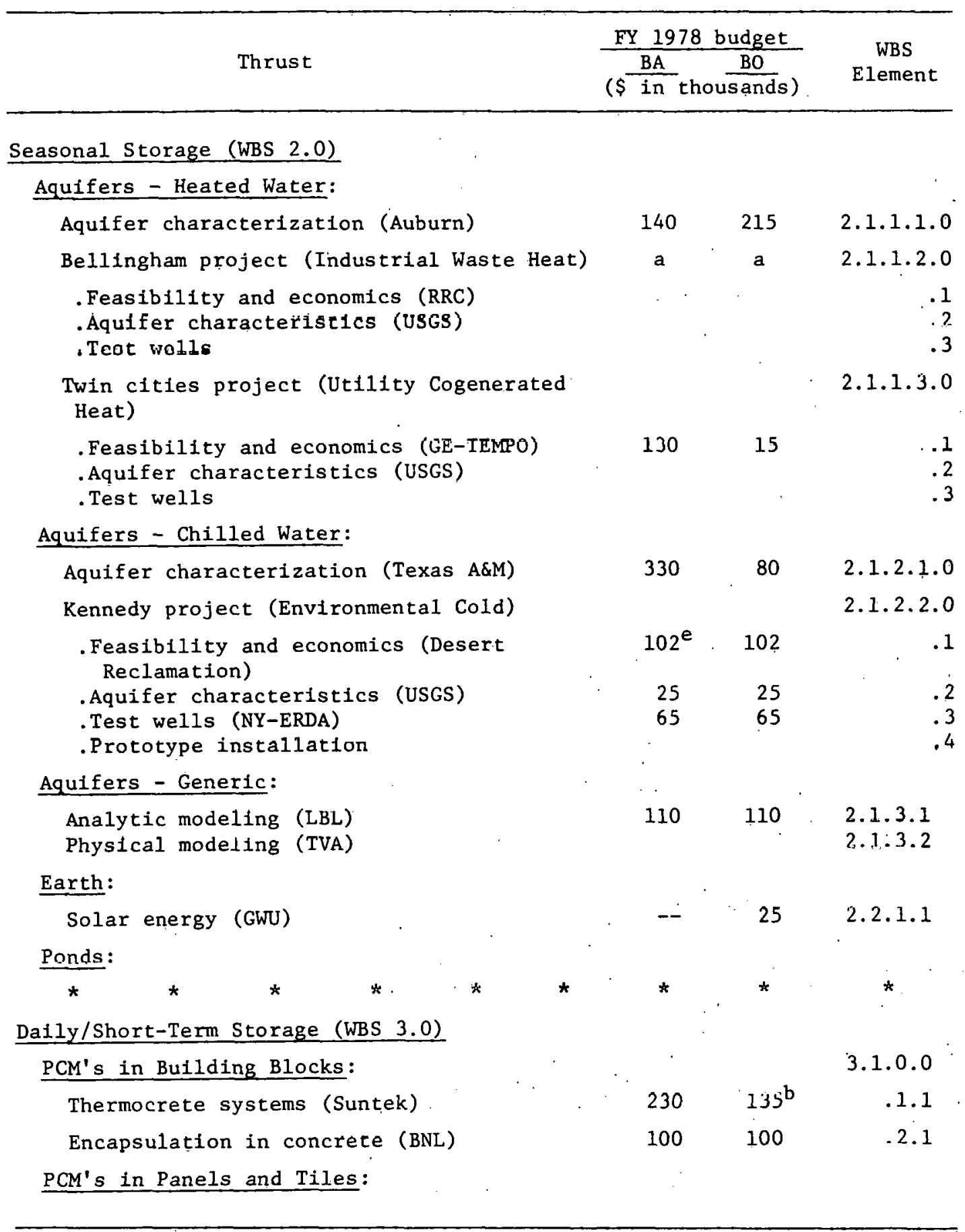

\footnotetext{
${ }^{a}$ Feasibility funded under waste energy (WBS 4.0).

${ }^{b}$ Includes $\$ 10 \mathrm{~K}$ funded by DOE-STOR.

CFunded by DOE-STOR.

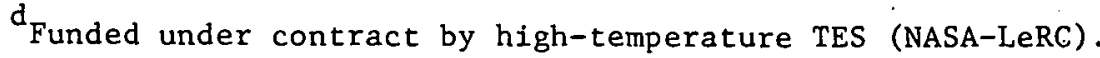


Table 6.1.2 (continued)

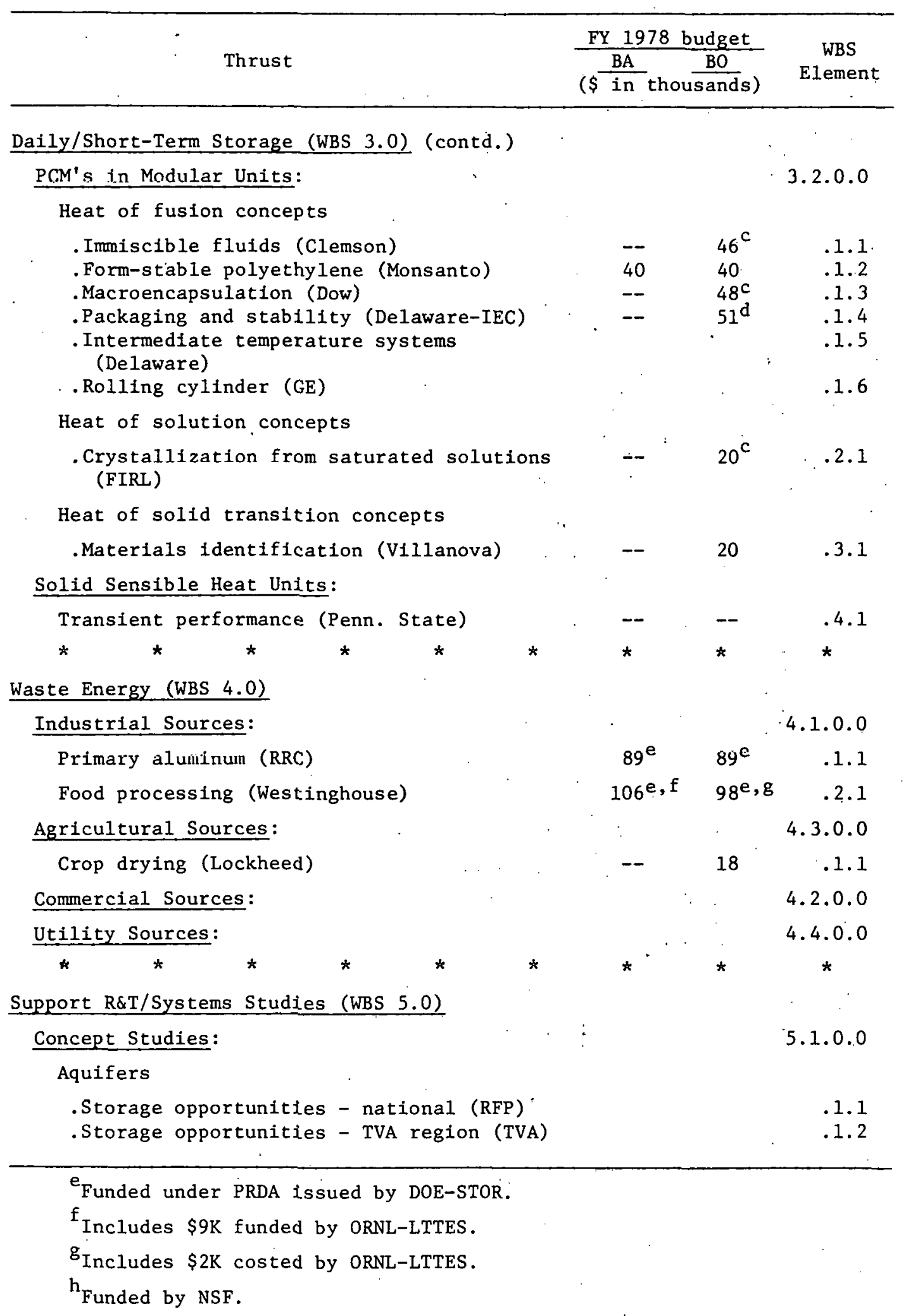


Table 6.1.2 (continued)

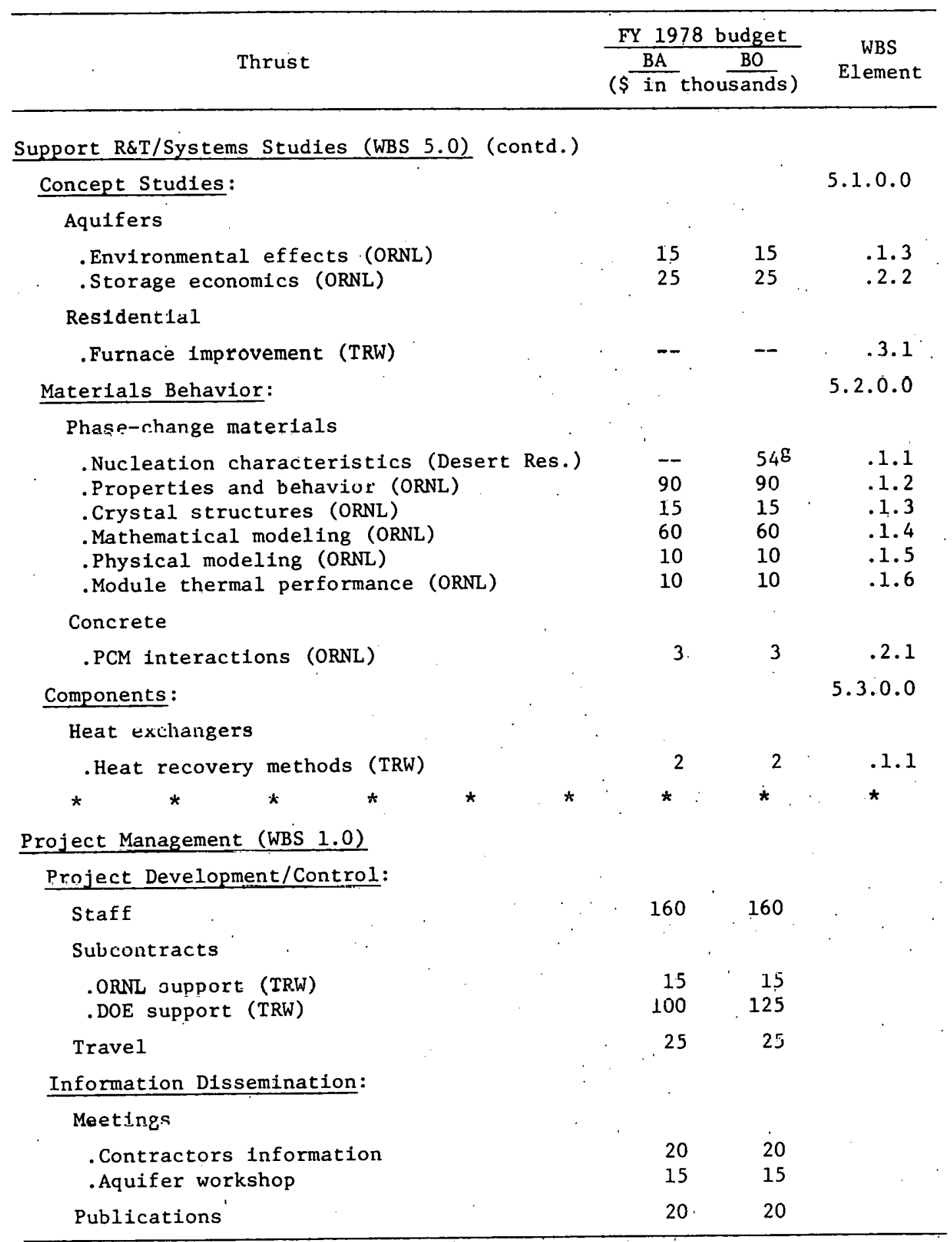


Table 6.1.3. LTTES program FY 1978 budgets by funding source

\begin{tabular}{|c|c|c|c|c|c|c|c|}
\hline \multirow{3}{*}{ Contractor } & \multirow{3}{*}{$\begin{array}{l}\text { WBS } \\
\text { Element }\end{array}$} & \multicolumn{6}{|c|}{ Funding source } \\
\hline & & \multicolumn{2}{|c|}{ LTTES } & \multicolumn{2}{|c|}{ DOE-STOR } & \multicolumn{2}{|c|}{ NSF } \\
\hline & & $\mathrm{BA}$ & $\mathrm{BO}$ & $\mathrm{BA}$ & $\mathrm{BO}$ & $\mathrm{BA}$ & $\mathrm{BO}$ \\
\hline \multicolumn{8}{|l|}{ Seasonal Storage } \\
\hline $\begin{array}{l}\text { Auburn } \\
\text { GE-TEMPO } \\
\text { Texas A\&M } \\
\text { Desert Reclamation } \\
\text { USGS } \\
\text { NY-ERDA } \\
\text { LBL } \\
\text { GWU }\end{array}$ & 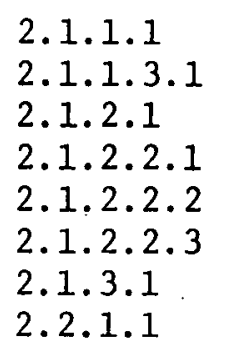 & $\begin{array}{r}140 \\
130 \\
330 \\
\\
25 \\
65 \\
110 \\
--\end{array}$ & $\begin{array}{r}215 \\
15 \\
80 \\
\\
25 \\
65 \\
110 \\
25\end{array}$ & 102 & 102 & & . \\
\hline \multicolumn{8}{|c|}{ Daily/Short-Term Storage } \\
\hline $\begin{array}{l}\text { Suntek } \\
\text { BNL } \\
\text { Clemson } \\
\text { Monsanto } \\
\text { Dow } \\
\text { Delaware-IEC } \\
\text { FIRL } \\
\text { Villanova }\end{array}$ & $\begin{array}{l}3.1 .1 .1 \\
3.1 .2 .1 \\
3.2 .1 .1 \\
3.2 .1 .2 \\
3.2 .1 .3 \\
3.2 .1 .4 \\
3.2 .2 .1 \\
3.2 .3 .1\end{array}$ & $\begin{array}{c}230 \\
100 \\
40\end{array}$ & $\begin{array}{l}125 \\
100 \\
40\end{array}$ & $\begin{array}{l}-- \\
-- \\
-- \\
-- \\
--\end{array}$ & $\begin{array}{l}10 \\
45 \\
50 \\
50 \\
20 \\
\end{array}$ & & · \\
\hline \multicolumn{8}{|l|}{ Waste Energy } \\
\hline $\begin{array}{l}\text { RRC } \\
\text { Westinghouse }\end{array}$ & $\begin{array}{l}4.1 \cdot 1 \cdot 1 \\
4 \cdot 1 \cdot 2 \cdot 1 \\
4 \cdot 3 \cdot 1 \cdot 1\end{array}$ & 10 & $\begin{array}{r}2 \\
18\end{array}$ & $\begin{array}{l}89 \\
96\end{array}$ & $\begin{array}{l}89 \\
96\end{array}$ & & \\
\hline \multicolumn{8}{|l|}{ Support R\&T } \\
\hline $\begin{array}{l}\text { ORNL } \\
\text { URNL } \\
\text { Desert Res. } \\
\text { ORNL } \\
\text { ORNL } \\
\text { ORNL } \\
\text { ORNL } \\
\text { ORNL } \\
\text { ORNL } \\
\text { TRW }\end{array}$ & $\begin{array}{l}5.1 .1 .3 \\
5.1 .2 .2 \\
5.2 \cdot 1.1 \\
5.2 .1 .2 \\
5.2 .1 .3 \\
5.2 .1 .4 \\
5.2 .1 .5 \\
5.2 .1 .6 \\
5.2 .2 .1 \\
5.3 .1 .1\end{array}$ & $\begin{array}{r}15 \\
25 \\
90 \\
15 \\
60 \\
10 \\
10 \\
3 \\
2\end{array}$ & $\begin{array}{r}15 \\
25 \\
90 \\
15 \\
60 \\
10 \\
10 \\
3 \\
2\end{array}$ & . & $\cdot$ & $\therefore$ & 55 \\
\hline \multicolumn{8}{|l|}{ Management } \\
\hline \multirow[t]{2}{*}{$\begin{array}{l}\text { ORNL } \\
\text { TRW }\end{array}$} & 1.0 & $\begin{array}{l}255 \\
100 \\
\end{array}$ & $\begin{array}{r}255 \\
125 \\
\end{array}$ & & & & \\
\hline & & 1765 & 1450 & 287 & 462 & -- & 55 \\
\hline
\end{tabular}




\section{THIS PAGE}

\section{WAS INTENTIONALLY LEFT BLANK}




\subsection{MANAGEMENT PLAN}

\subsection{Introduction}

Responsibility for the LTTES program is delegated to the Oak Ridge National Laboratory (ORNL) by the Department of Energy-Division of Energy Storage Systems (DOE-STOR). Under the general coordination of the DOESTOR TES Program Manager, the LTTES Program Manager at ORNL has the authority to execute, manage, and plan all LTTES activities subject to the restrictions that:

1) approval is required for Program Plans,

2) approval is required for Annual Operating Plans, and

3) concurrence is required for in-house and subcontract procurements.

The LTTES Program Manager will develop and implement plans, review and evaluate technical efforts, monitor and control costs, schedules, and other resources, disseminate to the technical and general public results of investigations, and report to both ORNL and DOE-STOR managers all matters of programmatic significance (technical and administrative).

ORNL control of the LTTES program will be exercised through the management structure depicted in Table 7.1.1. In carrying out program functions, the LTTES Program Manager will report through the Head of the Heat Transfer-Fluid Dynamics Section and the Director of the Engineering Technology. Division to the Associate Laboratory Director for Nuclear and Engineering Technologies. Close coordination is maintained with the Associate Laboratory Director for Advanced Energy Systems, who has been assigned ORNL responsibility for all energy conservation programs. Reporting to the LTTES Program Manager are staff responsible for implementing and controlling technical efforts in the several principal thrust areas. Procurement actions will be supported by the Union Carbide Corporation-Nuclear Division (UCC-ND) Contracts office, with review and concurrence by the DOE-Oak Ridge Operations office (ORO). 
Table 7.1.1. ORNL-LTTES program organizational structure

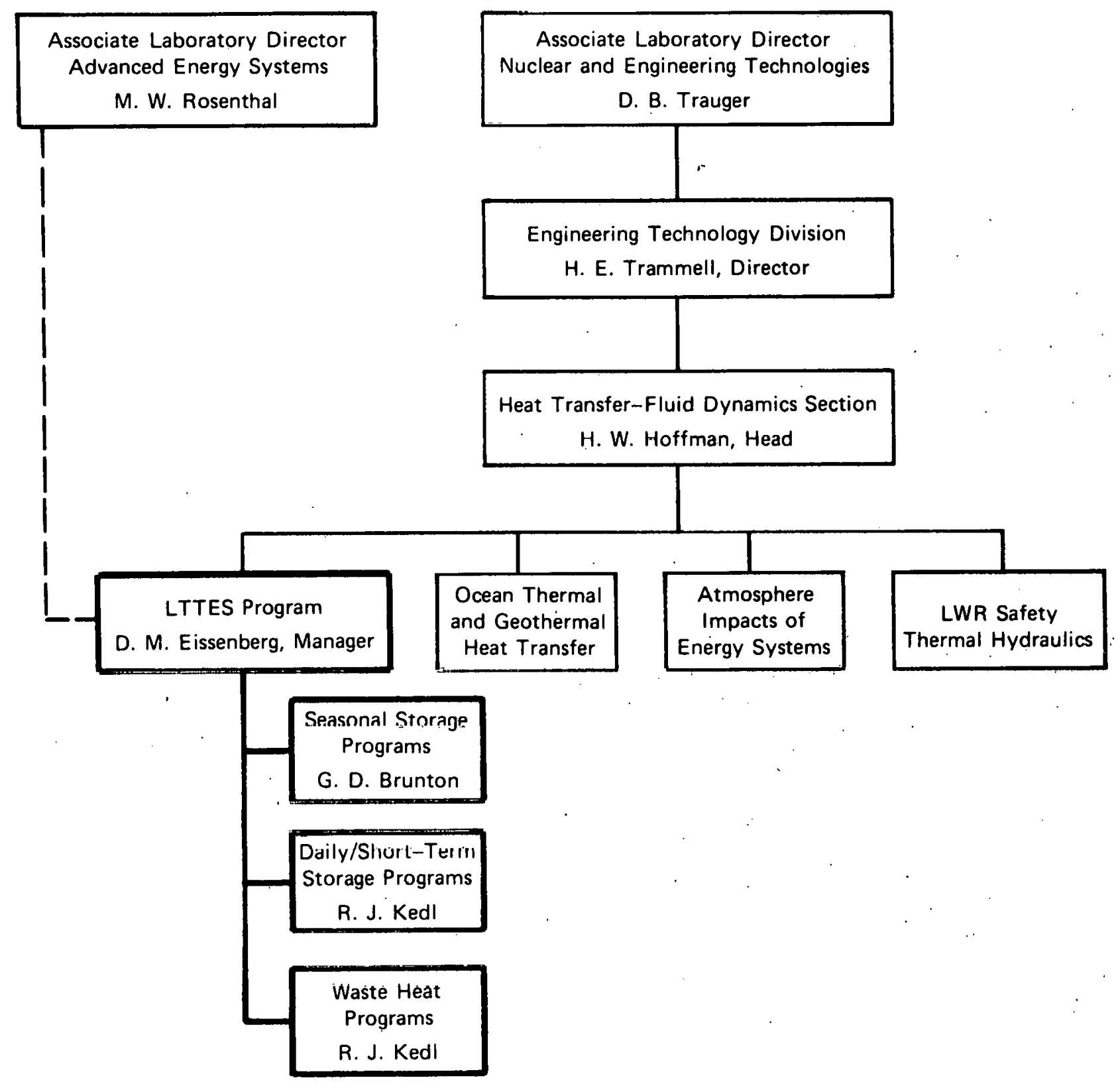




\subsection{Subcontractor Procurements}

All contractual arrangements will be made in accord with existing UCC-ND policy, regulations, and procedures, except where specific statutory requirements of DOE prevail.

Negotiated procurements will be conducted under competitive procedures to the extent practicable. Noncompetitive procurements will require formal and complete justification for selection. The ORNL/UCC-ND procurement system provides definite guidelines for contract preparation, the extent and clarity of request-for-proposal (RFP) instructions, and source evaluation and selection processes.

The LTTES Program Manager will be responsible for initiating all procurements, assuring appropriate procedures are followed, and obtaining necessary concurrences from the DOE-STOR TES Program Manager. All unsolicited proposals submitted to DOE-STOR but falling within the LTTES program purview will be referred to the LTTES Program Manager for action.

\subsection{Planning, Controlling, and Reporting}

Annual Operating Plans (supporting 189 budget requests) and updated long-range Program Plans will be submitted regularly to DOE-STOR by ORNL. These plans, on approval by DOE-STOR, will provide the basic control for both subcontractor and in-house technical efforts. The LTTES Program Manager will be responsible for achieving the technical goals within the fiscal guidelines described by these Program Plans; these responsibilities wili be carried out subject to the following general understandings:

1. DOE-STOR will provide sufficient funding, within their limitations, to execute all approved technical and management activities.

2. DOE-STOR will designate sufficient funding within the total funding to support a viable in-house technical program directed to LTTES objectives; this funding should be over and above that required for program management.

3. All technical studies (subcontract and in-house) will be subject to concurrence by the DOE-STOR TES Program Manager.

4. ORNL will assign appropriate staff to manage the LTTES effort and will perlodically review and evaluate the performance of this staff. 
5. DOE-STOR will review the LTTES program status and the performance of the ORNL management team regularly.

6. Uncommitted funds may be recalled by the DOE-STOR TES Program Manager as dictated by overall program changes.

The preparation and submission of work plans, technical progress narratives, financial reports, topical reports, and final reports on all subcontract activities will be in accordance with ORNi contract management control procedures. Distribution of contract status reports will be limited to ORNL and, on request, to the DOE-STOR TES Program Manager; contractor topical and final reports will recelve public distribution in accord with ORNL procedures subject to the concurrence of DOE-STOR.

The L'l'l'E's Program Manager w1ll subillt slalus iejurts to DOE-STOR that cover both in-house and subcontract technical results and program schedule and fiscal activity; this reporting will be normally constrained to monthly and annual frequencies but may be varied through mutual agreement. 
ORNL/TM-6605

\section{Internal Distribution}

1. R. S. Carlsmith

2-21. D. M. Eissenberg

22. H. L. Falkenberry

23-24. H. W. Hoffman

25. M. W. Rosenthal

26. H. E. Tramme1l
27. D. B. Trauger

28-29. Central Research Library

30. Document Reference Section

31-33. Laboratory Records Department

34. Laboratory Records (RC)

35. ORNL Patent Office

\section{Externa1 Distribution}

36. John A. Gahimer, Chief for Chemical and Thermal Storage Branch, Division of Energy Storage Systems, Department of Snergy, Washington, DC 20545

37. R. Holliday, Manager for Seasonal Storage Projects, Diviston of Energy Storage Systems, Department of Energy, Washington, DC 20545

38. W. Masica, NASA-Lewis Research Center, Cleveland, OH 44101

39. G. C. Pezdirtz, Director for Division of Energy Storage Systems, Department of Energy, Washington, DC 20545

40-54. C. J. Swet, Manager for Thermal Energy Storage Programs, Division of Energy Storage Systems, Department of Energy, Washington, DC 20545

55. J. D. Swisher, Assistant Director for Physical Storage Systems, Division of Energy Storage Systems, Department of Energy, Washington, DC 20545

56. W. Wilson, Sandia Laboratories, Livermore, CA 94550

57. Assistant Manager for Energy Research and Development, DOE-ORO

58. Director, Energy Programs and Support Division, DOE-ORO

59-85. Technical Information Center, DOE, Oak Ridge 